Illinois State University

ISU ReD: Research and eData

Theses and Dissertations

7-28-2014

\title{
Limitation, Subversion, and Agency: Gendered Spaces in the Works of Margaret Mahy, Cynthia Voigt, and Diana Wynne Jones
}

Elizabeth Ann Pearce

Illinois State University, bethannpearce@gmail.com

Follow this and additional works at: https://ir.library.illinoisstate.edu/etd

Part of the English Language and Literature Commons, and the Feminist, Gender, and Sexuality

Studies Commons

\section{Recommended Citation}

Pearce, Elizabeth Ann, "Limitation, Subversion, and Agency: Gendered Spaces in the Works of Margaret Mahy, Cynthia Voigt, and Diana Wynne Jones" (2014). Theses and Dissertations. 246.

https://ir.library.illinoisstate.edu/etd/246

This Dissertation is brought to you for free and open access by ISU ReD: Research and eData. It has been accepted for inclusion in Theses and Dissertations by an authorized administrator of ISU ReD: Research and eData. For more information, please contact ISUReD@ilstu.edu. 


\title{
LIMITATION, SUBVERSION, AND AGENCY: GENDERED SPACES IN THE WORKS OF MARGARET MAHY, CYNTHIA VOIGT,
} AND DIANA WYNNE JONES

\author{
Elizabeth A. Pearce
}

226 Pages

December 2014

In this dissertation, I argue that adolescent literature featuring female protagonists often illustrates complicated relationships between gender and space. My contention is that because of their gender, these protagonists are uniquely constrained to the home, which creates a literary pattern that has serious ideological implications. While I argue that the dominant discourse of these novels implies that girls should adhere to specific cultural norms, some of these works, however, provide room for subversion and agency, including new ways of looking at patriarchal constructions.

In Chapter One I explain that the home is not always a space of entrapment or limitation, but that this dominant discourse is problematic even as some authors allow room for subversion and agency. In Chapter Two I argue that there is a problematic connection in some of Margaret Mahy's adolescent novels between the Maori people and the female adolescent body. I contend that this connection sets up a system of false binaries between Other/Not Othered, colonizer/colonized, and male/female; these binaries elide many considerations between these extremes, such as race, class, age, and 
various levels of agency. In Chapter Three I argue that unlike Mahy's novels, Cynthia Voigt's novels allow for a subversions of the binaries between the female adolescent body and specific spaces. I assert that abjected fluids are connected to the home and domestic labor. In Chapter Four I use the theories of ethics of care to argue that two of Diana Wynne Jones' novels provide much room for agency and do not limit the female adolescent protagonists to certain spaces. In Chapter Five I advocate for including more direct discussions of gender and space in the classroom, arguing that this type of discussion will lead to a deeper understanding of discourse, feminism, and power. 
LIMITATION, SUBVERSION, AND AGENCY: GENDERED SPACES IN THE WORKS OF MARGARET MAHY, CYNTHIA VOIGT, AND DIANA WYNNE JONES

ELIZABETH A. PEARCE

A Dissertation Submitted in Partial Fulfillment of the Requirements for the Degree of

DOCTOR OF PHILOSOPHY

Department of English

ILLINOIS STATE UNIVERSITY 
(C) 2014 Elizabeth A. Pearce 
LIMITATION, SUBVERSION, AND AGENCY: GENDERED SPACES IN THE WORKS OF MARGARET MAHY, CYNTHIA VOIGT, AND DIANA WYNNE JONES

ELIZABETH A. PEARCE

COMMITTEE MEMBERS:

Roberta S. Trites, Chair

Karen Coats

Mary J. Moran 


\section{ACKNOWLEDGMENTS}

I am so grateful for the support of many friends, colleagues, and mentors throughout this project. First, I would like to thank my committee, Dr. Roberta S. Trites, Dr. Karen Coats, and Dr. Mary Jeanette Moran, for their time, thoughtful comments, and help throughout this project. I truly could not have done this without them and I cannot thank them enough for all of their guidance and support. I would like to extend a special thanks to Roberta who has been a friend and mentor throughout my doctorate experience and for knowing exactly when to let me muddle through it on my own and when to push me. I also owe a great debt to my Texas State mentors, Dr. Marilynn Olson and Dr. Teya Rosenberg, for setting me out on this quest and for their mentorship far above and beyond expectations. I would not be here without them.

I would also like to thank my family, Jane Pearce, Michael Pearce, Mary Frances Baker, and Josh Baker, for their support throughout this process and for letting me move away from Texas to go to graduate school (and for providing me with lots of Tex-Mex food when I visit). Special thanks to my Texas friends and our traditional Trudy's gettogethers which have ensured my survival throughout this process, including Rachel McCarty Gomez, Sarah Junkin Hernandez, and Erin Webb. To Valerie Creveling, the hardest working and most giving person I have ever met: thank you for the emails, phone calls, book shopping trips, encouragement, and understanding. You are my rock, and I'm so glad you get me. 
Huge thanks to my graduate school friends for the laughter, tears, sharing, support, Facebook messages, stickers, cat-sitting, drinks, food, and most of all for the yelling. Beth Zold, Melissa Smith, Emily Woster, Julie Pond, Meg Gregory, and Oren Whightsel, you all are amazing scholars and I aspire to be more like you every day. Special thanks also to Ollie, Apollo, and Helo for sitting right next to me as I wrote almost every single word and for always giving me a reason to take a break.

E. A. P. 


\section{CONTENTS}

Page

ACKNOWLEDGMENTS

CONTENTS

INTRODUCTION

CHAPTER

I. THEORETICAL BACKGROUNDS OF FEMINIST, SPATIAL, ADOLESCENT, AND SUBJECTIVITY THEORY

Introduction

Feminist Theory

Spatial Theory

Adolescent/Subjectivity Theory

Conclusion

II. “AND THIS ISLAND IS MINE": POSTCOLONIALISM AND GENDERED SPACE IN MARGARET MAHY'S

Introduction

The Space of Postcolonialism and Gender

Postcolonialism and Adolescent Literature

Postcolonialism, Adolescent Literature, and Gender:

Spaces of Oppression and Resistance in Margaret Mahy's

Fiction

The Changeover

The Catalogue of the Universe

The Tricksters

86

The Other Side of Silence

93

Kaitangata Twitch

100

Conclusion 
III. “MY MAP! I DON'T EVEN KNOW WHERE WE ARE. HOW COULD I FORGET THE MAP?": DOMESTIC LABOR, ABJECTION, AND SUBVERSION IN CYNTHIA VOIGT'S ADOLESCENT LITERATURE

Introduction

Domestic Labor

Abjection, Abject Fluids, and Adolescence

In Practice: Domestic Labor and Abject Fluids in Cynthia Voigt's Series

The Kingdom Series

Jackaroo

On Fortune's Wheel

The Wings of a Falcon

Elske

The Tillerman Cycle

Homecoming

Dicey's Song

Conclusion

IV. “CONCENTRIC CIRCLES OF CARING": DIANA WYNNE JONES' HOWL SERIES AND CARING AS AGENCY

Introduction

Feminist Ethics of Care

Annis Pratt and the Female Archetype Pattern

Ethics of Care in Diana Wynne Jones: Circles of Agency and Care

Conclusion

V. PEDAGOGY, SPACE, AND GENDER IN THE LITERATURE CLASSROOM

Introduction

Research Questions

Pedagogical Influences

Description of the Class, Assignments, and Students 
Goals

213

Course Design

214

Assignments

214

Future Research and Conclusions

REFERENCES 


\section{INTRODUCTION}

I've been thinking about the relationship between gender and space in theoretical terms since I was a master's student at Texas State University-San Marcos, but that wasn't necessarily the beginning of my interest in space. I've always been interested in home, other people's spaces, and how spaces could reflect the people who lived in them. I remember being around ten or eleven years old and being able to pick out my first new comforter for my bed and talking my parents into buying the matching sheets and bedskirt. While is a materialistic memory, it is significant in that it was one of my first introductions to the idea that $I$ had control over at least some of the space around me. No longer did I have an old, worn out teddy bear blanket; instead I could show myself (and anyone who entered my room) that I had grown up and was able to pick out mature purple and green flowers for my bed. At the time, I was not aware of the interconnections that exist among agency, space, and growth. Now, as I look around my current living room in an old house with bright yellow walls, tons of windows, and lots of books and blankets, I realize I am still obsessed with connecting my space with my idea of my identity.

When I started reading and studying adolescent literature critically, I began to care about understanding more about the same kind of agency I sought as an adolescent, long before I really understood what agency was. In my master's program at Texas State, 
I read Diana Wynne Jones' Fire and Hemlock; I was amazed by the complicated intertextual narrative and the way that Jones plays with spaces in that novel, both literal and figurative. Reading and writing about that book served as the first foundation for what would eventually become this project, many years later. When I discovered a whole world of criticism in feminist geography, I felt like I'd found a home. (See? I can't stop with the space metaphors!) I was finally able to uncover the cultural discourse I'd been so taken with as an adolescent and explain why I, and so many of the adolescent protagonists I'd read about, are interesting in controlling the spaces surrounding them.

This project was inspired by these experiences, but has grown and changed along the way. Chapter One begins with the introduction of my main argument: that adolescent female protagonists are often constrained to the home by cultural constructions of space and gender. I explain that the home is not always a space of entrapment or limitation, but that this dominant discourse is problematic even as some authors allow room for subversion and agency. I continue with a theoretical review of feminist theory, especially highlighting the work of Judith Butler, who challenges the very concepts of woman and gender. I also present some of the theoretical focuses I will be using in later chapters, especially the work of Julia Kristeva on abjection and feminist ethics of care. In the next section I look at different spatial theorists, including Gaston Bachelard and Yi-Fu Tuan, then move on to current feminist geographers. I particularly look at the theories set out by Doreen Massey about the way spaces are gendered by culture and Linda McDowell's contention that power also plays an important part in the overlapping relationship between space and gender. I then move on to exploring adolescent and subjectivity theories, including the work of Karen Coats, Robyn McCallum, Perry Nodelman, Maria 
Nikolajeva, and Roberta Seelinger Trites. In this section I argue that space and gender issues become problematic in adolescent literature because of the prevalence of the Bildungsroman pattern and the liminal status of adolescents in patriarchal culture.

Chapter Two deals with overlapping areas of postcolonial theory and gendered spaces. In this chapter I argue that there is a problematic connection in some of Margaret Mahy's adolescent novels between the Maori people and the female adolescent body. I contend that this connection sets up a system of false binaries between Other/Not Othered, colonizer/colonized, and male/female; these binaries elide many considerations between these extremes, such as race, class, age, and various levels of agency. I begin with an overview of postcolonial criticism, especially focusing on defining the Other, the subaltern, the Unheimlich, and challenging Bhabha's third space. I also include postcolonial criticism in children's literature, highlighting the need for more work to be done on postcolonial criticism, adolescent literature, and gender issues. I use several of Margaret Mahy's novels to exemplify my argument, including The Changeover, Catalog of the Universe, The Tricksters, The Other Side of Silence, and Kaitangata Twitch. I conclude by reinforcing my argument that while adolescent female protagonists may be culturally tied to certain spaces and seek out agency, they are in very different circumstances from the Maori land and people, and have access to different aspects of privilege.

In Chapter Three I argue that unlike Mahy's novels, Cynthia Voigt's novels allow for a subversions of the binaries between the female adolescent body and specific spaces. I assert that abjected fluids are connected to the home and domestic labor. Using two of Cynthia Voigt's series, The Kingdom and the Tillerman Cycle, I discuss the ways in 
which this connection is problematic - because it limits the female adolescent protagonists to a certain kind of labor and space — but also how it allows room for agency — by showing the protagonists subverting the domestic labor they perform to make their own choices in the world. I review some of theories behind domestic labor becoming a gendered activity tied to a gendered space, then move on to noting Julia Kristeva's and Karen Coats' theories of abject fluids and abjection. I then analyze all four of Voigt's novels in The Kingdom series and also focus specifically on Dicey Tillerman as an adolescent in the Tillerman Cycle. Within these novels I find many examples of abjected fluid tied to domestic labor, which the female adolescent protagonists use to subvert the patriarchal systems they live under. I conclude by emphasizing that Voigt's novels straddle the line between featuring adolescent protagonists problematically associated with a certain space (as with Mahy) and able to achieve agency by caring for others and the self (as with Jones).

In Chapter Four I use the theories of ethics of care to argue that two of Diana Wynne Jones' novels provide much room for agency and do not limit the female adolescent protagonists to certain spaces. I specifically set out a model of balanced care for others and the self, which helps to break down binaries between male/female and the spaces associated with each gender. I emphasize the field of ethics of care, including the work of Carol Gilligan, Nel Noddings, Virginia Held, and Michelle Boulous Walker. I also call attention to the problematic Bildungsroman pattern from Annis Pratt's female archetype pattern, arguing that a female adolescent hero's search for agency doesn't have to involve leaving the home or retreating to another space traditionally associated with women: nature. I demonstrate this argument with specific examples from Jones' Howl's 
Moving Castle and House of Many Ways, while also noting that perhaps one of the reasons these female characters are able to achieve so much agency is because the novels are fantasy. I conclude by emphasizing the importance of thinking about the kind of agency which can be achieved through ethics of care as a continuum, or circle, balanced carefully between caring for the self and caring for others.

In Chapter Five I advocate for including more direct discussions of gender and space in the classroom, arguing that this type of discussion will lead to a deeper understanding of discourse, feminism, and power. I outline the three research questions I used in my internship to test this theory, then focus on providing answers to these questions. I use the pedagogical theories especially of Amy Lee and bell hooks to challenge the space of the classroom as a safe space, and to describe how I encourage the students to think about the way discourse and cultural constructs affect their lives. I end with some examples of student writing during the semester, especially journaled responses to material discussed during class. I then provide a conclusion and overview of the total project. Throughout, I emphasize the element of choice in all situations connected with space; breaking down problematic binaries between difference conceptions of gender and space allows me to argue that an adolescent protagonist can be powerful in some ways and limited in others. However, I contend that the space of the home does not have to be a space of entrapment but instead can allow room for the adolescent female protagonists' choices and their ability to make their own decisions about the spaces they inhabit. 


\section{CHAPTER I}

\section{THEORETICAL BACKGROUNDS OF FEMINIST, SPATIAL, ADOLESCENT, AND SUBJECTIVITY THEORY}

Introduction

In this dissertation, I argue that adolescent literature featuring female protagonists often illustrates complicated relationships between gender and space. My contention is that because of their gender, these protagonists are uniquely constrained to the home, which creates a literary pattern that has serious ideological implications. While I argue that the dominant discourse of these novels implies that girls should adhere to specific cultural norms, some of these works, however, provide room for subversion and agency, including new ways of looking at patriarchal constructions. To demonstrate these issues at work, I use the novels of three female authors from three different countries to demonstrate how gendered spaces work across different genres and geographies. Margaret Mahy of New Zealand, Cynthia Voigt of the United States, and Diana Wynne Jones of England are all novelists concerned with gender issues, and their specific novels feature female adolescent protagonists struggling with society's expectations for their lives, their bodies, and their voices. The earliest of these novels (Mahy's The Changeover) was published in 1982; the most recent (Jones' House of Many Ways) was published in 2008, so these authors' works span a chronology of more than twenty-five 
years. I will devote a chapter to each of these authors; in these chapters, I trace problematic depictions of agency in Mahy's work, subversive depictions of agency in Voigt's, and a clearer inclusion of female agency in Jones' novels. That Jones' work is the most recent may well reflect evolving trends about agency in adolescent literature.

In support of my thesis, this first chapter will synthesize many different kinds of theory from different academic disciplines, including literary criticism, feminist theory, and human geography. One unifying feature of all of these disciplines, and the focus of this dissertation, is the use of space in literature. To demonstrate the connections between these diverse theories, I have split them into three related groups: theories about feminism, theories about space, and theories about literature for children and adolescents. Each section is organized roughly chronologically, as each theorist refers to and complicates his/her predecessor. The blending of these theories will constitute the framework by which I consider how gender, space, and agency interact in the lives of the protagonists of the novels under study.

Feminist Theory

Nineteenth-century constructions of gender still inform ideas about traditional gender roles in Anglo-American cultures. The "angel of the house" archetype and the separate spheres of influence experienced by the Victorians play a large part in some of the gender constructions with which many scholars still grapple. Virginia Woolf's $A$ Room of One's Own, first published in 1929 and based on a series of lectures given in 1928 , is one of the touchstones of feminism. Woolf sets out to "speak about women and fiction" but quickly shifts her focus to a statement that would has resonated through the 
years (3). She writes, "a woman must have money and a room of her own if she is to write fiction; and that, as you will see, leaves the great problem of the true nature of woman and the true nature of fiction unresolved" (4). Woolf is specifically addressing the plight of women writers here, but her statement can be applied to many women seeking to have control over their own lives. The crucial point for my argument is that Woolf demands "a room of her own," implying that the rest of the house does not belong to her. Instead, she is seeking a space away from the routines of domestic duty in which to write. Later in the text she goes into more detail by pointing out, "[i]n the first place, to have a room of her own, let alone a quiet room or a sound-proof room, was out of the question, unless her parents were exceptionally rich or very noble, even up to the beginning of the nineteenth century" (52). This is another important aspect of Woolf's argument, that a woman requires some measure of independent means in which to have a vocation or more towards any kind of career aspirations. Woolf understands that the means to isolate oneself while also not being responsible for the domestic life of the house are privileges, but she is clear independence and a physical space in which to create is important for all women. Although not writing during the Victorian era, Woolf is still influenced by Victorian ideologies about gender; her struggle to assert that women should be able to have a space of their own challenges those Victorian notions of gendered spaces. Susan Gubar, herself part of a partnership investigating the affects of gender ideologies in literature, has written an introduction to A Room of One's Own. Gubar praises Woolf”s text, noting “[n]o piece of expository prose could be more luminous or, to use on of Virginia Woolf's favorite adjectives, more incandescent than $A$ Room of One's Own" (xxxv). 
Inspired by Woolf's writings, Sandra M. Gilbert and Susan Gubar's The

Madwoman in the Attic provides a pivotal argument about the way feminist criticism has become connected to issues of space that is still relevant in twenty-first century literature even though it was written in 1979 about several nineteenth century texts. For example, in their critique of Charlotte Bronte's Jane Eyre, Gilbert and Gubar note:

[Jane's] story, providing a pattern for countless others, is ... a story of enclosure and escape, a distinctively female Bildungsroman in which the problem encountered by the protagonist as she struggles from the imprisonment of her childhood toward an almost unthinkable goal of mature freedom are symptomatic of difficulties Everywoman in a patriarchal society must meet and overcome.... Most important, her confrontation, not with Rochester but with Rochester's mad wife Bertha, is the book's central confrontation, an encounter... with her own imprisoned "hunger, rebellion, and rage." (338-39)

Although Gilbert and Gubar are describing Jane's experience of entrapment, they also connect Jane's experience as a protagonist to the experiences of "countless others" in novels (338). That entrapment, not always literal, is usually symbolized in literature by the use of a domestic sphere, whether a home, attic, garden, or other space related to domesticity.

Lissa Paul draws from Gilbert and Gubar to build on these ideas of entrapment when she focuses on the difference between entrapment for women and entrapment for children. In her article "Enigma Variations: What Feminist Theory Knows About Children's Literature” (1987), Paul writes, “the common ground between women's 
literature and children's literature [is] a theme that lies in a shared content (the enclosed, interior scenes of the action); and in a shared language (of otherness)" (187). She also notes that the "forms of physical, economic and linguistic entrapment that feminist critics have been revealing in women's literature match the images of entrapment in children's literature" (187). Refining Gilbert and Gubar's argument, Paul points out one major difference between a female and child protagonist: children can grow up to escape. Thus, while "[w]omen in literature are disproportionately shown as physically trapped in rooms, attics, in their father's houses, or in their husbands...the protagonist in children's literature transcend, and, for the most part win, even when the endings of stories are not conventionally happy" (188). In other words, while children are able to grow into power and the freedom to escape the domestic sphere, women remain tied to that domestic space without hope of freedom. This leads to a significant question: if children can grow up to escape their entrapment, what happens to the female child? The role of the female adolescent protagonist is particularly problematic in this framework; if she is supposed to escape into adulthood, how does she then become entrapped as an adult woman? In $O f$ Woman Born (1952), the early feminist Simone de Beauvoir provides one summation of this time in a young girl's life: it is a time of waiting, "more or less disguised. She is awaiting Man” (345). She elaborates, “...the girl, since childhood and whether she intends to stay within or go beyond the bounds of femininity, has looked to the male for fulfillment and escape; he wears the shining face of Perseus or St. George; he is the liberator; he is rich and powerful, he holds the keys to happiness, he is Prince Charming" (345). In this heteronormative structure, the adolescent female is waiting to be entrapped by the bounds of femininity, or in spatial discourse, the domestic sphere. In adolescent 
literature this is often problematized when the female character attempts to leave the home during adolescence. As I will demonstrate in later chapters, the troubling patriarchal pattern de Beauvoir identifies has been challenged and adapted in literature for adolescents throughout the second half of the twentieth century and into the twentyfirst, but the pattern remains troubling in that female adolescents so frequently struggle with their relationship to the home in YA novels.

Complicating these issues still further are the ideas of contemporary gender theorists like Judith Butler. In her influential work on gender and sexuality Gender Trouble (1990), Butler point outs, “[t]he very subject of women is no longer understood in stable or abiding terms" (2). Butler then goes on to separate the body from the cultural construction of gender, establishing what she describes as a theory of performativity. She writes, "the effect of gender is performatively produced and compelled by the regulatory practices of gender coherence... gender proves to be performative - this is, constituting the identity it is purported to be" (34). Butler's performative view of gender allows for the distancing of gender as a construct from the biological body: in emphasizing gender as performed, Butler makes clear that gender is a cultural construct, not a biologically predetermined certainty. What makes performativity especially crucial to my project is how frequently gender in YA literature is constructed within two additional constructs: space and adolescence. By separating the body from the social construction of gender, Butler opens to the door for us to examine how gender is constructed through space and associations with the home. For example, later in Gender Trouble, Butler quotes social anthropologist Mary Douglas, who looks at the boundaries of the body: “...ideas about separating, purifying, demarcating and punishing transgressions have as their main 
function to impose system on an inherently untidy experience. It is only by exaggerating the difference between within and without, above and below, male and female, with and against, that a semblance of order is created" (178). Butler's use of Douglas demonstrates that performance theory acknowledges physical bodies have physical boundaries. Julia Kristeva provides an even more helpful description of the body's boundaries in her work on abjection in Powers of Horror: An Essay on Abjection (1982) as a an exclusion (6). She writes:

the "unconscious" contents remain here excluded but in a strange fashion: not radically enough to allow for a secure differentiation between subject and object, and yet clearly enough for a defensive position to be established—one that implies a refusal but also a sublimating elaboration. As if the fundamental opposition were between I and Other, or in more archaic fashion, between Inside and Outside. (7)

I will explore Kristeva's ideas about abjection more thoroughly in Chapter Three, but her perspective here on the body demonstrates the importance of Douglas' statements about the work of creating a system of order for the body out of the body itself. Kristeva's work highlights the body rejecting and expelling that which is not acceptable to subject; Douglas emphasizes that that which is rejected is that which does not fit into traditional patriarchal binaries. My point here is that abjection—-the process of expelling that which does not fit into the "clean and proper body" of society—helps to reinforce the binaries of male/female, inside/outside, powerful/powerless, which is reflected in the spaces inhabited by female adolescent protagonists (101). 
That semblance of order, fascinating to an anthropologist, is another one of the cultural binaries that Butler tries to dispel. Many of the differences Douglas lists, such as the binaries created to reinforce differences between the genders, focus on the physical body as an object with discrete boundaries. Moreover, spaces separated into the binaries of home and not/home are as much social constructions as any gender binary. Adolescents inhabit a liminal space on a spectrum between childhood and adulthood, and they therefore sometimes struggle to come to terms with the social constructions of what an adolescent or adult should look like during the process of growing up. Without always acknowledging that adulthood is as much of a social construct as adolescence, adult authors of adolescent literature often seek to establish stable identities for their adolescent characters by the end of the novel. For fictional boys, this stable identity is often a matter of achieving independence and leaving the home; for girls it frequently means ending adolescent rebellions and accepting gendered norms, including confinement to domestic spaces. By returning the female character to a safe home space, authors frequently construct adolescence as a time during which girls (and boys) must learn to accept social norms. As Butler notes, "[i]f the inner truth of gender is a fabrication and if a true gender is a fantasy instituted and inscribed on the surface of bodies, then it seems that genders can be neither true nor false, but are only produced as the truth effects of a discourse of primary and stable identity" (186). The same could be said for stages of life, such as childhood, adolescence, and adulthood.

In a 2005 essay, Butler further questions the "assumption that the term women denotes a common identity" ("Subjects" 146). She writes: 
Rather than a stable signifier that commands the assent of those whom it purports to describe and represent, women, even in the plural, has become a troublesome term, a site of contest, a cause for anxiety. ... If one "is" a woman, that is surely not all one is; the term fails to be exhaustive, not because a pregendered "person" transcends the specific paraphernalia of its gender, but because gender is not always constituted coherently or consistently in different historical contexts, and because gender intersects with racial, class, ethnic, sexual, and regional modalities of discursively constituted identities. As a result, it becomes impossible to separate out "gender" from the political and cultural intersections in which it is invariably produced and maintained. (146)

While I will address the difference between subjectivity and identity later in this chapter, it is important to note that Butler is connecting the social constructions of gender to identity here, to which I would also like to add layers in which adolescence and space are also conceptualized as constructs and in terms of gender.

Also addressing the complications between separating the concept of gender from culture, Michelle Boulous Walker's Philosophy and the Maternal Body (1998) 'ask[s] questions about the silencing of women" (1). Walker specifically uses the spatial metaphor of inside and out to explore gender through a psychoanalytic lens, a concept I will address further in my discussion of abject fluids in Chapter Three. However, her spatial metaphor is an interesting concept when thinking about the difficulties of discussing gender when many theorists are challenging the term gender to begin with. In 
her conclusion, Walker works to break down her argument about the space of women's writing. She writes:

I suspect that the complex spatial metaphor that emerged at the beginning of this book helps us to imagine where this writing lies. It is neither simply inside nor outside the symbolic domain. The ambiguity that is symbolized in writing between mother and daughter, the undecidable difference between the two, mirrors the disruption of our sense of space in such a way as to re-figure relations between inside and out. (176)

The important part of Walker's argument here for my purposes is that she is also working to break down the binary between gendered spaces as being separate into only two categories. She reemphasizes throughout that inside and outside are the spatial metaphors commonly associated with women but that they are ultimately too simplistic categorizations to encompass what women are experiencing. Ultimately, Walker refers to Luce Irigaray who "manages to displace the spatial logic of Lacan's symbolic. While she is often criticized for saying that women are excluded from the symbolic, it is really more the case that she sees women excluded from Lacan's symbolic" (179). This, Walker explains, means that "[w]omen are thus outsiders in the symbolic as it is conceived by Lacan and others. They are not naturally predisposed to this exteriority. They are socially positioned as outsiders within a discursive system that constructs its own politically motivated spatial and logical arrangements between in and out" (179). That women are bound into specific spaces is, as Walker and Butler note, a social construction not an innate characteristic. The overall point for my argument in this project is that women have traditionally been set into specific spaces by culture's 
emphasis on binaries and setting women apart from men. By breaking down the concept of gender itself, the challenges facing women and the spaces associated with them, begins to break down as well.

Understanding that gender is an ongoing process of social construction during adolescence requires us to think about many other forms of social construction. For example, a female adolescent's relationship to space is often entwined with the process of constructing gender norms. In her text Gender, Identity and Place: Understanding Feminist Geographies (1999) Linda McDowell cites Butler's performativity theory, and then applies the separation of sex (biology) and gender (cultural construct, something we perform) to the work of spatial theory:

Assumptions about the correct place for embodied women are drawn on to justify and to challenge systems of patriarchal domination in which women are excluded from particular spatial arenas and restricted to others. In this sense to "know their place" has a literal as well as a metaphorical meaning for women, and sexed embodiment is deeply intertwined with geographical location. Social relations and spatial processes are mutually reinforcing...in the construction of gender regimes with particular patterns of the segregation of the sexes and gendered hierarchies of power. (56) In YA literature, as a female adolescent protagonist is faced with making decisions about the kind of adult she wants to be, patriarchal power constructions usually limit her to specific choices. These choices are often limited to the home and the domestic realm, or an escape to nature; as I will discuss below, ecofeminism has identified the social conventions by which the natural world and women become connected, so in fictional 
texts, nature is often a place the female adolescent runs to. However, too frequently, she can be only one kind of female: the opposite, and subordinate, of male, which connects to Butler's anxiety about the concept and construct woman. Butler's challenges to the definition of the word woman demonstrates that the construction of gender is necessarily limited; I argue that this limitation is reflected in literature in the spaces females are associated with and the limited choices they have to exist in only certain kinds of spaces. While some authors are looking to widen the world of their adolescent female protagonists, many others reinforce gendered limitations by associating these characters with only a few types of spaces. However, by challenging these self-perpetuating constructions, a female protagonist can make the choice to not follow female gender constructions, but to remain in the home. Or she can decide to become an adult by leaving home, but continue to embrace some aspects of her femininity. The work of spatial theory thus helps us interrogate characters' choices in many ways: where do adolescent girl characters reside? where do they work? where do they choose to exist by novel's end? who interacts with them in various settings? and how do these interactions occur? In short, how is gender implicated differently in different spaces?

Yet another theory that overlaps with concepts of gender and space includes feminist ethics of care, which specially attempts to reframe the traditional labor of caring for others. By focusing on the type of labor women have traditionally performed as a kind of agency, ethics of care works to break down gendered binaries in similar ways to feminist spatial theorists and allows me to explore the type of labor adolescent female protagonists are responsible for in the work of Mahy, Voigt, and Jones. In 1982 Carol Gilligan's book In a Different Voice: Psychological Theory and Women's Development 
set out what was then a different way of looking at "the experience of males and females and the relations between the sexes" (2). Gilligan identifies a masculine tendency to make ethical decisions in terms of hierarchical thinking and a feminine tendency to think of ethical decisions in terms of contingencies; she likens the masculine model-which is not limited only to men — to a ladder and the feminine ethics of care- which is not limited only to women - to a web (62-63). It is to be noted that both men and women can display a feminine ethics of care; Gilligan's argument is about styles of moral-decision making, not biological imperatives. Rosemarie Jong's text Feminine and Feminist Ethics of Care (1993) provides a general view of "feminist and feminine approaches to ethics" (ix). She also cites another perspective on feminist thinking, philosopher Betty A. Sichel, who defines a feminine ethics of care as, "the advocacy of an ethic of care that includes nurturance, care, compassion, and networks of communications" (qtd. in Jong 4). Jong works to establish a basis of understanding for the different voices in ethics of care, including summaries of noted theorists like Carol Gilligan and Nel Noddings. Jong very carefully points out the strengths and weaknesses of each point of view. Feminine ethics of care allows me to analyze the crucial link in adolescent literature between domestic labor and domestic spaces. Gilligan herself, in the 1993 Letter to Readers before the text of $A$ Different Voice, acknowledges the dichotomy inherent in the public/private split, and she elaborates on how female adolescents struggle to have a voice in the public world (xxii). I explore much more about ethics of care in Chapter Four. Ultimately, interrogating why and how characters in Voigt's, Mahy's, and Jones' novels are obligated to care for others helps me analyze the connections between home, domesticity, and the cultural constraints many of their adolescent characters struggle with. 


\section{Spatial Theory}

There are many ways of looking at how spaces are constructed in society and literature; some theorists focus on what spaces, especially domestic spaces, such as the home, mean to humanity. One of the earliest space theorists, Gaston Bachelard, was a French philosopher interested in ideas of space. In The Poetics of Space (1958), Bachelard's introduction argues for "taking the house as a tool for analysis of the human soul.... Our soul is an abode. And by remembering 'houses' and 'rooms,' we learn to 'abide' within ourselves" (xxxvi-xxxvii). Both Bachelard and later space theorist Yi-Fu Tuan conflate the home with a woman's body in their foundational texts about space. This sets up a problematic binary which both scholars reinforce throughout their work. Bachelard states:

...the house...maintains him though the storms of the heavens and through those of life. It is body and soul. It is the human being's first world. Before he is "cast into the world," as claimed by certain hasty metaphysics, man is laid in the cradle of the house.... Life begins well, it begins enclosed, protected, all warm in the bosom of the house. (6-7) Here Bachelard is using an embodied metaphor; a house is like a woman's body because both can support life. Approximately twenty years later, spatial theorist Yi-Fu Tuan (1977) makes a similar association between women's bodies and the home. When differentiating between place as "security" and space as "freedom," Tuan explains: [i]f we define place broadly as a focus on value, of nurture and support, then the mother is the child's primary place.... Later she is recognized by the child as his essential shelter and dependable source of physical and 
psychological comfort. A man leaves his home or hometown to explore the world; a toddler leaves his mother's side to explore the world. Places stay put. Their image is one of stability and permanence. (29) In Tuan's terms place, or the home, is also a metaphor for a mother's body. Similar to Bachelard, Tuan also connects the mother's body with the (male) child's birth. The process of developing away from the mother's body as the home is an implicit part of the metaphor; when the child grows up he must leave the home which assumes that maturity demands separation. ${ }^{1}$ Just as the powerful gendered space ideologies of the Victorian era continue to dominate society, both Tuan and Bachelard continue to bind women to the home and, as I will argue throughout this project, their binary implies that the home can only be a space of limitation and permanence for women, instead of describing the home as one of many opportunities and choices open to everyone. As Tuan notes, "[p]lace is a pause in movement...the pause makes it possible for a locality to become a center of felt value" (138). Tuan implies that woman's body, because it physically houses life, is the home and is frozen in place as a result. Tuan further notes, “[p]ermanence is an important element in the idea of place" (138). Although Tuan's notions of the female body and home are needlessly rigid, I would argue that the fixity of these ideas of space often accrue to adolescent fiction. I thus argue that according to this rigid binary, the female in YA novels sometimes cannot escape the home because she is the home.

Geography theorists influenced by Bachelard and Tuan have taken up issues of

${ }^{1}$ This is a gendered concept covered in depth by Carol Gilligan In A Different Voice; I will go into further detail about this in Chapter Four. 
space and connected them to issues of gender, and thus a newer sub-field has emerged called feminist geographies that is significant for the analysis of adolescent literature because of the increasing emphasis on gender issues in these texts. Leading the movement are Linda McDowell, Doreen Massey, and Daphne Spain. While feminist geographies look at real world examples of how gender and space interact, much of their work is rooted in a variety of feminist theories and is applicable to all kinds of literature. For example, published in 1992, Daphne Spain's Gendered Spaces claims that the "primary form of gender segregation created by capitalism is the separation of home from workplace...[t]he masculine production of labor was thus removed spatially from the feminine reproduction of labor" (107). Spain uses examples from both indigenous peoples around the world and the United States, starting with the nineteenth century.

Doreen Massey (1994) takes a different look at Tuan's space and place definitions; she makes explicit Tuan's assumption that the "lines of debate over the conceptualization of space and place are also tied up with gender, with the radical polarization into two genders which is typically hegemonic in western societies today, and with the bundles of characteristics typically assigned to each" (Space 6). Massey also begins to unwind the interdependent relationship between identity, geography, and gender. In contrast to many other interpretations, Massey points out that the home is an image of false security, and that "such understanding of the identity of places require[s] them to be enclosures, they have boundaries and - therefore and most importantly - to establish their identity through negative counterposition with the Other beyond the boundaries" (169). In other words, establishing boundaries is much more of a process of expelling that which is Other than it is a process of creating a safe place; moreover, being 
able to see the home as a safe space is tied in with other elements of privilege. The ability to create a safe place is something not available to everyone, and the act of Othering is often a sign of privilege, whether racial, cultural, or economic. It is during this process of exclusion, Massey claims, that "spaces and places are not only themselves gendered but, in their being so, they both reflect and affect the ways in which gender is constructed and understood. The limitation of women's mobility, in terms both of identity and space, has been in some cultural contexts a crucial means of subordination" (179). That both gender and space are constructed ideas built on social contexts is a crucial connection; the fact that women are limited both by spatial and gender constructions is an idea being explored in numerous ways by feminist geographers. This struggle, which as Massey notes, "has been in the West related to the culturally specific distinction between public and private," appears over and over again in adolescent literature (179). My work in this project draws primarily from works by feminist geographers and their interrogations into how specific spaces are constructed in society. As I will discuss in later chapters, female adolescent characters are frequently identified with nature and the natural world as an alternative to the home, but I find this connection between gender and space similarly problematic. I thus turn to feminist ecocriticism to further bolster my argument. Much “[E]cological feminism, or 'ecofeminism,", is defined by Karen J. Warren as "the position that there are important connections between how one treats women, people of color, and the underclass on one hand and how one treats the nonhuman natural environment on the other" (xi). Gretchen T. Legler extends the definition of ecofeminism, noting that "[o]ne of the primary projects of ecofeminist literary critics is analysis of the cultural construction of nature, which also includes an 
analysis of language, desire, knowledge, and power" (227). My dissertation primarily deals with the conceptualization of place and the home in terms of gender, not social class, because the association between nature and women can be seen clearly in many of the adolescent texts I will be examining. Often when the female protagonist escapes from the home, she flees into nature, regardless of whether she is working class, like many of Voigt's characters, or middle-class, like many of Mahy's. I will more fully explore this phenomenon by which gender and space are connected in Chapter Four relying on Annis Pratt's ideas expressed in her Archetypal Patterns in Women's Fiction. The crucial part of Pratt's pattern is the female hero's escape to the "green world" away from the home as part of "the inward plunge away from patriarchal experience" (139). The green world becomes a place of adventure and growth for the female hero in a bildungsroman novel, because she cannot hope to grow while remaining in the middleclass home, under patriarchal rule. As ecofeminist Stacy Alaimo notes though, "[d]efining woman as that which is mired in nature thrusts woman outside the domain of human subjectivity, rationality, and agency" (2). The association between women and nature has been a conflict even within feminist criticism because while some "feminists have countered the claim that women's inferiority is 'natural' by insisting that women are socially constructed," others have "identified the pervasive association of women with nature as itself a root cause of misogyny and have advocated a feminist flight from this troublesome terrain" (3). The struggle between avoiding all association between women and nature versus trying to redefine "nature as an undomesticated ground" is the center of Alaimo's work, and is important to the world of female adolescent protagonists who often escape the home into nature. Linda McDowell, a feminist geographer, points out 
that the association between women and nature also makes it "hard for women to escape their entrapment in their bodies" (44) implying that connecting women to nature is as limiting as connecting women to the home. My focus will remain, however, on looking at how and why these spaces are gendered in order to break down traditional gender binaries, a goal which has much more in common with the field of feminist geography. My argument is that female adolescent characters are sometimes limited to certain spaces by patriarchal constructions of gendered norms; limiting a character to one kind of space without choice or agency reinforces those gendered norms. I share McDowell's concern that some forms of ecofeminism are establishing another binary which limits female characters, rather than allowing them to choose from multiple spaces, including those traditionally associated with women and those traditionally associated with men.

In practice, ecofeminism takes a different perspective than my argument about adolescent subjectivity, gender, and space. As Legler explains:

[e]cofeminists suggest that reimagining what nature is and what kinds of relationships can exist between humans and the nonhuman world is part of the elimination of institutionalized oppression on the basis of gender, race, class, and sexual preference and part of what may aid in changing abusive environmental practices. Combining these two fields of knowledgeecological literary criticism and ecofeminist criticism—allows us to ask important questions about literary texts. (228)

The second part of that quotation is the most important in differentiating feminist geography from ecofeminism: the effort to take a stand against "abusive environmental practices" and looking at ecology is a separate field from studying how spaces work and 
affect people. The two fields do have much in common in the ways that they examine how a space is associated with gender, but ecofeminism explores such questions as, "[h]ow can developing an ecocritical literary theory help solve environmental problems?" (228). This question represents a hard line between the goals of ecofeminism and feminist geographies, and changes much about the theoretical practices of both fields; the dual focus of ecofeminism becomes about limiting or eradicating the oppression of women and the environment. While those are worthy and admirable goals, defending the environment from further abuse is tangential to my argument about the problematic identification of female adolescents with the home. My goal is to trace the problematic depiction of agency in relation to gendered spaces. I agree that the natural world is another space often associated with women, but activism is outside of the scope of this project.

Linda McDowell also builds on the work done by Massey and other feminist geography scholars. McDowell's text Gender, Identity and Place: Understanding Feminist Geographies provides the cornerstone of the work I will be doing in the rest of this dissertation. McDowell cites Massey when explaining:

[g]eographers now argue that places are contested, fluid and uncertain. It is socio-spatial practices that define places and these practices result in overlapping and intersecting places with multiple and changing boundaries, constituted and maintained by social relations of power and exclusion...[p]laces are made through power relations which construct the rules which define boundaries. (4) 
Just as gender has come to be understood as culturally constructed, so too can spaces. This connects to the Victorian ideal of separate spheres, because the inside of the home is also arranged by power. Feminist geography explores all kinds of spaces, including bodies, homes, communities, cities, work and workplaces, public vs. private spaces, and national spaces. My specific focus in this project is primarily on domestic spaces, particularly that of the home, and on bodies, including the boundaries between the constructed female adolescent body and the fictional world she inhabits.

While the Victorians certainly did not invent the connection between women and the home, their concern with sex and sexuality changed the way homes are built. Michel Foucault's History of Sexuality is devoted to the history of ideologies about sex (especially from the changes during the nineteenth century on). The text is significant to my research because so many of the domestic spaces we inhabit are constructed around sex and sexuality, central concerns for much adolescent literature. Foucault notes that a: ...network of pleasure and powers [is] linked together at multiple points and according to transformable relationships. The separation of grownups and children, the polarity established between the parents' bed room and that of the children... all this made the family, even when brought down to its smallest dimensions, a complicated network, saturated with multiple, fragmentary, and mobile sexualities. $(46)^{2}$

\footnotetext{
${ }^{2}$ Foucault argues that the "medicalization of the sexually peculiar" became a
} "form of power [which] demanded constant, attentive, and curious presences for its exercise" (44). This focus on sexuality by the medical community "produced a twofold 
This point in carried to the logical extreme in Foucault's work (he writes about spaces that include dormitories, classrooms, etc.), but the significance of the spaces in the home remains my primary concentration. Many children's literature critics have argued that home is sometimes used as a symbol in literature for children, a place often exempt from all mentions of sexuality. ${ }^{3}$ Sex and the separation from sex are built into the very walls of children's literature, but adolescents' experience with spaces and sexuality are fundamental to adolescent literature. ${ }^{4}$ As Foucault notes, "whereas to begin with the child's sexuality had been problematized within the relationship established between

effect: an impetus was given to power through its very exercise; an emotion rewarded the overseeing control and carried it further; the intensity of the confession renewed the questioner's curiosity; the pleasure discovered fed back to the power that encircled it" (44-45). This leads to his claim that the medical community "function[s] as mechanisms with a double impetus: please and power"- which is the network of pleasure and power cited above (45). This network, incited by a focus on the sexually peculiar, is what leads to changes in the space of the home to reinforce new societal norms of sexuality.

${ }^{3}$ For example, in "Hansel and Gretel," the siblings are led into the woods by a stepmother eager to banish them from the sexual sphere she shares with the children's father, or in Charlotte's Web, a world of procreating animals exists in which sexuality and mating are never once acknowledged.

${ }^{4}$ As Roberta Seelinger Trites argues in Disturbing the Universe (2000), "for many characters in YA novels, experiencing sexuality marks a rite of passage that helps them define themselves as having left childhood behind" (84). Since the time of her 
doctor and parents (in the form of advice, or recommendations to keep the child under observation, or warnings of future dangers), ultimately it was in the relationship of the psychiatrist to the child that the sexuality of adults themselves were called into question" (99). By removing sex and sexuality from childhood, adults of the Victorian era were calling into focus their own anxieties, and so they built walls to separate children from any sight or mention of sex. Victorian attitudes about sexuality, gender, and separate spaces have continued to affect social constructions today, although the dominant discourse continues to evolve throughout the twenty-first century. Socially constructed gender plays an important part in the association between space and sexuality as well; female bodies have been intimately connected to the home in ways that male bodies are historically not, so female protagonists' relationship with sexuality, the home, and the process of growing up is very different from most male protagonists. According to Annis Pratt's analysis of the female journey-quest, most female adolescent protagonists are left with unappealing choices: they can stay associated with the home and all of the limitations and restrictions contained with the domestic realm, or they can go into nature and become associated solely with fertility and sexuality. As I will discuss in future chapters, this binary is problematic not just because it sets up the trajectory of the female adolescent's future as limited to only two choices, but also because agency has been removed from both sides of the binary. Pratt's identification of these two spaces demonstrates how certain gender constructions limit fictional characters to specific places

writing, however, sex in YA novels has become more commonplace and does not always, in fact, mark a rite of passage. 
based on gender. Although scholars from Gilbert and Gubar to Doreen Massey have worked to identify and free these spaces from the constricted binaries they've traditionally been connected with and to envision new pathways for female agency in old spaces, I believe that more attention needs to be paid to female adolescence and the way it sometimes reifies these binaries in YA literature.

Among feminist geographers, McDowell is another scholar working to reclaim space and gender from these restrictive binaries. She notes that while "feminist scholars have convincingly demonstrated the flawed nature of binary assumptions, the belief in binary gender divisions has remained a key element of contemporary social practices" (11). She continues exploring this gender binary, which is "deeply implicated in the social production of space, in assumptions about the 'natural' and built environments and in the sets of regulations which influence who should occupy which spaces and who should be excluded" (11). Feminist scholars have worked for years to break down the "natural" boundaries between genders, so McDowell and other feminist geographers are extending that work in the spaces-homes, nature, the private/public sphere split-which have been constructed in the ideology of gendered binaries. In a clear statement about the goal of feminist geographers (especially contrasted with ecofeminism), McDowell writes, "[t]he specific aim of a feminist geography, therefore, is to investigate, make visible and challenge the relationships between gender divisions and spatial divisions, to uncover their mutual constitution and problematizes their apparent naturalness" (12). This aim is not intended to support gender binaries, but to highlight the binaries still in existence in an effort to continue breaking them down. This is also the goal I will focus on when I critically analyze the adolescent texts covered later in this dissertation. Instead 
of reifying and promoting cultural binaries (whether of male/female, adult/child, home/away, etc.) I will problematize the unexplored connection between space and gender in adolescent literature and show that the relationship between the two is increasingly complicated for adolescent female protagonists. In the following chapters I will present cases of female adolescent protagonists who are associated with many different kinds of domestic spaces, and I will argue that while some characters are limited by their association with the home, others find room for subversion and agency, which works to break down patriarchal binaries of space.

To effect this argument, I will also rely on the ideas put forth by Lynda Johnston and Robyn Longhurst in their book Space, Place, and Sex: Geographies of Sexualities (2010), in which they analyze sexuality within the overlapping fields of gender studies and geography. The authors point out, "sexuality (what we do and what we can talk about) is constantly being remapped across various cultural and social landscapes" (2). Their overall argument throughout the text is that "[t]here are no spaces that sit outside of sexual politics. Sex and space cannot be 'decoupled'" (3). Johnston and Longhurst's perspective on the relationship between gender, sexuality, and domestic spaces is especially important for my argument in this project, because these critics are working toward breaking down rigid binaries. They write:

[a]lthough homes have long been considered to be private spaces, the binary division between private and public is unstable. Geographers and other have been arguing for more than a decade that binary classifications do not hold.... Home, like many other spaces, resists binary classification. It is not necessarily a haven or a private and secure space in which one can 
say and do exactly as one chooses as though the outside, public world does not exist. Even in that most private of spaces within the home, the bedroom, behaviors may be subjected to exterior monitoring and controls.

As I have discussed above, part of my goal in the project is to argue that female adolescent characters are too often limited to the domestic sphere- but I in no way wish to imply that there is a direct line to be drawn between the domestic sphere and the world outside. What I am arguing is that because women have been so long associated with the home, female adolescents in the works of Voigt, Mahy, and Jones are too often restricted to that space, in part because the patriarchal constructions of our society are built around the domestic sphere being only a space of limitation. In other words, remaining in the home does not have to be a form of entrapment, but being only limited to the home is a form of entrapment, reinforced by rigid societal binaries. By using multiple theoretical backgrounds to explore the relationship between space and gender, I will highlight the different ways authors associate their female characters with the home. The different authors I've chosen demonstrate that female characters and the home can be limiting, problematic, or empowering depending on how much room the text accords for agency and the breaking down of binaries.

\section{Adolescent/Subjectivity Theory}

One of the most important connections I am making in this argument involves the crucial interplay among space, gender, and power in adolescent literature. As Roberta Seelinger Trites notes in Disturbing the Universe: Power and Repression in Adolescent 
Literature (2000), "[t]he chief characteristic that distinguishes adolescent literature from children's literature is the issue of how social power is deployed during the course of the narrative" (2). The social construction of power is frequently explored in adolescent literature because these novels compel the adolescent reader to join to ranks of accepted society. Trites specifically argues, the "conflict with authority that is embedded in most texts for adolescents in turn provides the author with opportunities for using ideology to manipulate the adolescent reader ... The mechanisms by which they manipulate the reader to assume subject positions that are carefully constructed to perpetuate the status quo bear investigation" (xii). I hypothesize that while much about literature has changed since the Victorian era, and indeed, since the time Trites published Disturbing the Universe, late twentieth century adult authors writing for an adolescent audience, still tend to uphold traditional gender roles and accept tacitly the separate spheres of influence for each gender. Even now in the twenty-first century, adolescent literature is changing and providing more room for power and agency in a variety of situations for many kind of characters, but the implicit advocacy of traditional gender roles still exists, often in more subtle ways. Moreover, the bildungsroman format common to adolescent literature was in the 1990s and still is a testing ground for children growing into adulthood that is fraught with gender conflicts. Because I know there is not one singular way to grow from childhood into a particularized, stable, adult identity, I look at the importance of adolescent characters' subjectivity, since subjectivity is a concept that allows for multiply-inflected issues of agency and self-understanding. How a character assimilates or challenges gender stereotypes often parallels the adolescent's search to assimilate or challenge social constraints, all of which is involved in subject formation; some 
characters are able to break away from traditional binaries while others retain a problematic relationship with spatial and gendered limits. I argue that for some characters that I am studying herein, the author uses space in the text to create places of empowerment, but this is not always the case; the home, frequently the most complicated space for female adolescent figures, can also be a space of entrapment, particularly in novels by Mahy and Voigt.

Trites' first book, Waking Sleeping Beauty: Feminist Voices in Children's Novels (1997) explores "how feminism and childhood intersect in children's novels" (ix). She argues that "[p]rotagonists n novels influenced by feminism ... have slowly evolved an ability to think about their place in the community without becoming so communityoriented that they become self-effacing" (ix). This book is one of the first to examine gender constructions, subject-formation, and feminism in children's literature in depth and includes feminist readings of many classics in children's literature. Chapter Four of this text, "Transforming Feminine Silence: Pro/Claiming Female Voices" is especially important to my work because of its identification of the limits of female subjectivity in adolescent literature. Trites writes, "too often throughout history, female voices have been silenced. Narratives that depict characters engaging their subjectivity, however, tend to focus on those same characters' articulateness. Such texts provide an important counter-balance to traditional depictions of female passivity" (47).

The connection between language and gender was made explicit by Barbara Johnson in 1987, long before Trites wrote on the subject. Johnson writes, "the question of gender is a question of language" (37). Johnson argues, "there may, however, be something accurate about this repeated dramatization of woman as simulacrum, erasure, 
or silence. For it would not be easy to assert that the existence and knowledge of the female subject could simply be produced, without difficulty or epistemological damage, within the existing patterns of culture and language" (40). In other words, the very language used in literature is steeped in a patriarchal culture, so Johnson points out that the silencing of women in literature is a reflection of the silencing of women in culture. As female adolescent characters attempt to challenge social conventions, they are often repressed not just by gendered norms but by the construction of gender in language itself. Thus the authorial act of constructing a vision of adolescence in literature is also tied to the construction of gender by language and the need to recognize when female voices are being silenced or expressed as powerful challenges to the patriarchy.

Catherine Belsey's Critical Practice, first published in 1980, provides a thorough review of post-Saussurean linguistics and the effects of ideology in literature. Belsey defines ideology as "the very condition of our experience in the world, unconscious precisely in that it is unquestioned, taken for granted" (5). Later, she clarifies that ideology is "inscribed in signifying practices - in discourses, myths, presentations and representations of the way "things are" (43). She also defines discourse as "a domain of language-use, a particular way of talking (and writing and thinking)" (5). These definitions are important because they set up a frame of reference for constructions of adolescent literature. Belsey specifically notes a theme that many scholars will later pick up and complicate; she writes that the "destination of all ideology is the subject (the individual in society) and it is the role of ideology to construct people as subjects" (58, emphasis in the original). In other words, Belsey argues that "[i]t is through language that people constitute themselves as subjects" (59). This process will come to be called 
subjectivity and is an essential part of adolescent literature, a genre which revolves around its intended audience. Belsey's argument is limited in terms of my research because she writes that "[i]t is only with its entry into language that the child becomes a full subject" (60, emphasis added). As my argument deals intimately with gender and the physical relationship between women's body and the home, I am unable to agree with Belsey's overstated assertion that subjectivity is only dependent on language; the effects of the body, or embodiment, are also a crucial part of becoming a full subject.

Other authors specifically focus on children's literature when exploring the relationship between language and subjectivity. For instance, Stephens' Language and Ideology in Children's Fiction (1992) is a linguistically concentrated look at the use of ideology and subject positions in children's literature, which explores the use of language in the novel through signifier and signified. He writes, "[o]nce each signified has become another signifier [a process he refers to as "displacement"], it points on else where, and usually suggests different new signifieds to different perceivers" (274). Stephens is the first theorist to explore the effects of a focalizer and different styles of narration in children's texts. He lists three ways of narrating a novel: omniscient narration, firstperson narration, and focalization, "a subject position [that] is frequently constituted as the same as that occupied by a main character from whose perspective events are presented, that is, readers identify with the character" (57). Although Stephens does not specifically mention subjectivity as a term, his work is an important step in thinking about how literature for children is constructed. By breaking down the process of language, Stephens draws attention to the distance between an object (or subject) and the discourse used to describe it. Many later theorists, including Robyn McCallum, Perry 
Nodelman, Karen Coats, and Maria Nikolajeva, cite Stephen's foundational work in this text.

Pauline Dewan's The House as Setting, Symbol, and Structural Motif in Children's Literature, published in 2004, shares similar concerns. In her book, Dewan first establishes that "[h]ome is indeed paramount in the lives of all children," then explores the ramifications of "the house [as] our first universe," claiming that "it acts as a microcosm of the world and a frame through which we view and interpret the realm outside its walls" (4-5). While Dewan's look at the use of the home in children's literature is an important connection to domestic spaces, I concentrate on adolescent literature as different from children's literature. Dewan's examination of "walls [which] provide the inside-outside boundary that separate its inhabitants from the rest of the world" is centered on the child protagonist who discovers that "to be enclosed in a house is to be protected as well as imprisoned" (6). The work Dewan does is fascinating in terms of children's power relationships with spaces, but my argument is tied to the liminal state of adolescence and the effects the process of gender constructions have on those adolescents and their relationships to the spaces around them. There is not yet a work specifically looking at how gender and spaces are constructed in adolescent literature, which is the focus of my dissertation. I argue that female protagonists are uniquely constrained to the home because of patriarchal power constructions. Children of both conventionally-depicted genders and other might have a very different relationship with the home as a space, but the power struggles and desires of adolescents are necessarily different from those of children. 
Another important voice in adolescent literature looks specifically at the role of identity in the literature written for adolescents. Robyn McCallum's Ideologies of Identity in Adolescent Fiction (1999) synthesizes several other works that previously dealt with ideology. For example, citing Stephens in several places, McCallum challenges and reframes his ideas about subjectivity and ideology. Moreover, McCallum breaks down Bakhtin's and Lacan's ideas about dialogism and subjectivity, comparing their differences and commonalities. She specifically notes that "[b]oth Bakhtin and Lacan see the formation of subjectivity as an aspect in the developmental process of the child, and both are interested in the transition from solipsism to intersubjectivity. These concerns provide a clear parallel with that central preoccupation of adolescent fiction, personal maturation" (74). McCallum's work is pivotal to my research because she specifically theorizes adolescent literature as separate from children's literature. The process of growth, the liminal stage between childhood and adolescence, provides fruitful ground for exploring subjectivity. This process of growth often occurs through the use of language, which connects to the construction of space as a metaphor for that growth process. When looking at how alienation and transgression impact a problematic singleidentity — an essentialist ideology in which an adolescent is expected to grow up to become an person with a single, fixed identity, McCallum cites three narrative strategies which encourage development of a character's sense of subjectivity:

First, to displace a character out of his/her familiar surroundings can destabilize his/her sense of identity and hence undermine essentialist notions of selfhood, though it can also affirm these concepts. Second, such displacement can offer ways to explore linguistic and sociocultural 
influences on cognition and the formation of subjectivity, especially where a character is depicted as learning, decoding and interpreting alien social codes and discourses. Third, representations of transgressive modes of behavior or being in fiction can construct interpretative positions from which to examine and interrogate the limitations that the dominant cultural and social discourses and practices of a given society or cultural place on experience, action and subjectivity. (100-01)

This displacement often happens when the protagonist is away from home, and the process McCallum describes is followed in almost all adolescent texts. The female protagonist has to leave home in some way to destabilize her previously singular identity, explore language as a means to creating herself as a subject, and question the ways she has been limited by culture constructions. ${ }^{5}$ The female protagonist cannot perform this search for subjectivity and interrogation at home, within the physical manifestation of patriarchal dominance; she has to be displaced, to be somewhere else, to begin to understand her thoughts outside of the dominant discourse, as I will demonstrate in subsequent chapters. This is particularly evident in Annis Pratt's female archetypal pattern, in which the female adolescent must leave home, as I will further explore in Chapter Four. While McCallum does not necessarily explore subjectivity as a gendered issue, I hope to bring ideas about gender constructions to McCallum's analysis of

${ }^{5}$ While this isn't the concern of my dissertation, it should be noted that this is also the way male identity is constructed; both male and female protagonists frequently have to leave the home to establish their subjectivity. 
adolescents' experience of subjectivity as an addition to her argument about the process of growth in adolescent literature. Because of the gendered associations with women and the home, female adolescents almost always have to leave the home in some way in order to become a full subject. This does not mean that a female adolescent character has to leave the home, or travel across the world in order to become an adult, but it does mean that learning to destabilize the patriarchal constructs limiting her to the home can be an important part of developing into an adult with a sense of voice and choices about the future.

Looking more at children's literature, other theorists have identified a pattern relating to space that is also significant to my project. Perry Nodelman and Mavis Reimer's textbook The Pleasures of Children's Literature (1992) explores various ways to theorize children's literature for undergraduate students. Nodelman and Reimer highlight the "home/away/home pattern [which] is the most common storyline in children's literature" (197-98). Nodelman and Reimer also cite Clausen's pattern for adolescent literature; he says, "[w]hen home is the chief place from which we must escape, either to grow up or...to remain innocent, then we are involved in a story for adolescents or adult" (Pleasures 198). A quest or journey usually involves leaving home, so that the protagonist becomes involved in a "series of confrontations with the new and strange in which main characters learn to understand both the new things and themselves better" (198). In his much later work The Hidden Adult (2008), Nodelman returns to the home/away/home pattern to create a definition of children's literature. Nodelman begins by examining six works in children's literature, including Maria Edgeworth's “The Purple Jar," Lewis Carroll's Alice's Adventures in Wonderland, Hugh Lofting's Dr. 
Dolittle, Beverly Cleary's Henry Huggins, Ezra Jack Keats' The Snowy Day, and Virginia Hamilton's Plain City. By breaking down all aspect of these texts, Nodelman comes to determine a list "of qualities that they share with each other and that also seem to me to be the qualities that lead to my identification of them as texts of children's literature" (76). As part of this process, Nodelman specifically looks at Hamilton's Plain City in terms of space. However, he points out that Plain City is different from the other texts he uses as examples because it does not follow the traditional home/away/home pattern. As "fiction for "young adults" Plain City moves "beyond the polarity between children and adults that the other texts all establish" (58). The protagonist's choice to return home marks a change; "Buhlaire does just what her mother has advised—and because it is her own choice to remain at home, a space she has now renegotiated to include her own self-governance within it, it is no retreat, but a step forward into maturity" (57). This is a crucial point, especially in terms of my argument about the relationship between adolescent literature and the use of space. Buhlaire's relationship to her home changes because, as an adolescent, she is able to gain the power to renegotiate and determine a new kind of subjectivity. As a text written for young adults, Plain City depicts a connection between home/away and child/adult that is more complicated than that of most children's literature, in many cases because the power relationship between the child/adult is becoming more complicated.

Nodelman then sets an entire section of the chapter aside to explore "Home and Away: Essential Doubleness.” In this section, he writes:

[q]uestions about the meanings of home and away are central to all six of these texts - as they seem to be central to cultural ideas about childhood in 
the time in which specific children's literature has existed, ideas that tend to separate children from other human beings by imagining a space in which it is safe to be childlike and thus also a less safe space beyond it.

Throughout The Hidden Adult, Nodelman examines the significance of adults writing literature for children and the unavoidable effect this has on the ideologies present. By the act of writing for children, Nodelman points out, we are separating children from adults, and that comes to be connected to an idealized home space. In other words, "the primary reason why adults write literature for children - the idea that children are different from adults, and different in ways that require adults to write texts especially for them-marks those texts so deeply that it influences and controls everything they ever are" (63). He goes on to compare the home to children's literature itself:

home is the equivalent to what the text are themselves: a controlled and limited space provided for a child by a more knowing and more capable adult in order to protect the child from the less limited but more dangerous world outside - the world away from home, the worst as represented in literature for adults. As a result, the texts tend to focus frequently on justifying the need for home and the desirability of staying there. Their central thrust is, in a very real sense, a justification of their own existence — a celebration of safely limited places for children. (63) Adolescent literature's place in this binary is in keeping with its liminal status; regardless of gender, adolescents usually move between home and away while they inhabit the liminal space on the spectrum between childhood and adulthood. The role of adolescents 
between the safe space of the home and literature constructed for them by adults, and the desire to become adults with spaces of their own, is enormously complicated, especially in light of gender stereotypes. If children's literature is directly comparable to the imagined safe space of the home, adolescent literature can be compared to the fluid and uncertain space between the home and the outside world. The female adolescent protagonist in novels by Mahy, Voigt, and Jones are often drawn to leave the home to seek out some form of independence; nevertheless, these authors sometimes interrogate the false binary between dependence and independence as a matter of seeking or achieving balance between the two.

Other critics have expanded Nodelman's conception of the home/away/home pattern, especially in terms of the meaningfulness of home as a domestic space. Maria Nikolajeva builds on the home/away/home pattern in her text From Mythic to Linear: Time in Children's Literature (2000). She classifies certain kinds of children's literature as "utopian, Arcadian or pastoral works" (20). These works usually demonstrate the following characteristics of space:

1) the importance of a particular setting;

2) autonomy of felicitous space from the rest of the world;

3) a general sense of harmony;

4) a special significance of home. (21)

These characteristics are important descriptions of home in children's and adolescent literature. Seen as a utopian space of childhood, safe from the dangers and conflicts in the world, home is often depicted as a perfect space, full of adult nostalgias about childhood. A few pages later, Nikolajeva points out that this space often has "garden 
walls or fences [which] are boundaries to the surrounding — adult—world, boundaries both protecting and restricting" (23). These boundaries are the symbol of what a child must pass through to become an adult, but an adolescent female often finds those barriers unyielding. This is a crucial connection to my larger argument: leaving the home is a symbolic step away from childhood, but when women are unable to leave the home, they appear to be unable to mature away from childhood in the eyes of society. This home stasis is, as Nikolajeva points out, "the stage of innocence, where their sexual identity has not yet been discovered...[there] is the overall sense of innocence: sexual, intellectual, social, political; and the intention of the text is to keep the child reader in this illusion" (27-28). One of the perils adolescent females face by remaining in the home is to stay in this state of innocence forever. This is of course a cultural stereotype about childhood built on the idea of the Romantic child as innocent and in need of protection. The connotation that the adolescent protagonists face though is that if they stay in the home for any reason, they must remain innocent forever. That implication is, of course, a false one, as both real and fictional adolescents often inhabit unsafe, unsettling, abusive, and dangerous homes, as Dicey Tillerman learns in Voigt's novels about her, as Mahy's protagonist learns in The Other Side of Silence, and as more recent characters, such as Eleanor in Rainbow Rowell's Eleanor and Park experience.

Clare Bradford's work in Unsettling Narrative: Postcolonial Readings of Children's Literature (2007) further complicates the home/away/home pattern in children’s literature by arguing: “[c]hildren’s texts reinvoke and rehearse colonialism in a variety of ways: for instance, through narratives that engage with history in realistic or fantastic modes; through sequences involving encounters between Indigenous and non- 
Indigenous characters; through representations of characters of mixed ancestry; and through metaphorical and symbolic treatments of colonizing" (3). The trajectory of children's literature is not always a clear path of home/away/home, especially when that home is on the land that has been colonized by others or is in danger of colonization. As Bradford notes, sometimes this colonization can be symbolic, but other times the conflicts between indigenous and non-indigeous peoples are highlighted, as in many of Margaret Mahy's novels. Bradford draws on the work of Homi Bhabha and Gayatri Chakravorty Spivak, on whose work I will elaborate in Chapter Two (8). However, Bradford's focus veers sharply from mine in that she does not include gender or adolescent literature in the scope of her book; while there are some similarities between a postcolonial view of children's literature and a postcolonial view of adolescent literature, in Chapter Two I argue that much still needs to be said about the overlaps between patriarchal colonization, gender norms, and adolescent power struggles. While Bradford's text looks at children's literature, I argue that adolescent literature complicates postcolonial theories and I assert that Mahy uses the space of the home to engage in discourses of colonialism; most especially I argue that Mahy elides the differences between the Maori people of New Zealand and female adolescence.

I will argue in the following chapters that quests for female adolescent protagonists often follow the home/away/home pattern in which protagonists leave their childhood home and end up returning to a home of their own, empowered by their experiences but still limited to a domestic space. All of these elements help challenge "the commonplace notion of 'finding one's self' underlying the idea of the formation of subjectivity as a quest for a stable identity [which] has clear ideological and teleological 
implications" (McCallum 68). I argue that too often the ending of the story is predetermined for the adolescent female protagonist: too often she must experience a return to the childhood home or marriage to begin a new home. However, this sets up another problematic binary; if female adolescents do not leave the home, according to Nikolajeva, they never achieve sexual maturity or grow out of a state of innocence. I argue that because female adolescents have been so traditionally tied to the home, this binary needs to be problematized; fictional adolescents should be able to achieve agency and become full subjects while choosing their own spaces, whether in the home or somewhere else. Unlike adolescent texts with male protagonists, female protagonists usually return to the home once they discover who they are; that discovery signals that they are ready to return to the home to be adult women. This is, of course, often connected with marriage, a return to the family home, and/or children. According to the stereotypical pattern, having reified her stable identity, the female adolescent becomes an adult but remains forever an innocent child, in need of protection and support from the more powerful members of society.

Karen Coats provides another perspective on subjectivity in Looking Glasses and Neverlands (2004). Elegantly analyzing Lacanian theory as it applies to children's literature, Coats writes that “[m]ost studies of children's literature...focus on the formation of identity, which is only part of subjectivity, which is in turn only part of what I would call the self. Identity is psychoanalytic parlance refers to the more public, social presentation of the self- the part over which we have the most control" (4-5). Later, Coats defines "subjectivity...[as] more than identity—it is a movement between that which we control and that which controls us" (5). In other words, the "modernist model 
figures the subject as split, a construction of both natural and cultural influences, of conscious and unconscious processes" (6). Here Coats makes clear the process McCallum describes in Ideologies of Identity in Adolescent Literature, distinguishing the difference between identity and Lacan's definition of subjectivity. According to Coats, identity is the mask we put on for public viewing, while subjectivity is the liminal space between our changing selves and the outside presentation. This is an important distinction because it connects back to adolescent's search for identity. Adolescent literature is not based on a search for one identity; this is an essentialist view of the perilous path of the process of subjectivity which forces adolescent to deal with constructions of power. As the female protagonist is becoming a subject rather than an object, so she is buffeted back and forth among power relationships (her own included) and this struggle is often illustrated in her relationship to space.

In the context of Coats' ideas about subjectivity and identity, feminist geographers provide yet another additional layer of insight. Much of the work done with gender and space overlaps theories of identity formation, including that of establishing subjectivity as multiple identities. Massey notes:

it is often argued...that in societies where early child-rearing is almost entirely in the hands of women, the project of identity construction is different for little girls and little boys...It is the boy's need, growing up in a society in which genders are constructed as highly differentiated, and as unequal, to differentiate himself from his mother, which encourages in him an emphasis, in the construction of a sense of identity, on counterposition and on boundary-drawing. (Space 170) 
The boundary-drawing Massey refers to here is not just in terms of space: it contains the lines between home/not home, public/private, male/female, and parent/child. These constructed boundaries create artificial binaries and the liminal stage of adolescence, itself another cultural construct which has historically been focused on choosing between two options. In a later text, Massey makes her position more clear by insisting that "we understand space as the sphere of the possibility of the existence of multiplicity in the sense of contemporaneous plurality; as the sphere in which distinct trajectories coexist; as the sphere therefore of coexisting heterogeneity" (On Space 9). Massey's emphasis on breaking down binaries and allowing for more choices is an important step in the processes I am analyzing. When the female adolescent characters in some novels are limited to only the space of the home, they are forced into a singular identity; when female adolescent characters are given choices and able to establish their own sense of power, the spaces they choose are not a trap but instead become one option among many. In other words, what Massey terms "contemporaneous plurality" is an open space in which multiple understandings, identities, and constructions can exist, especially in adolescent literature.

Maria Nikolajeva also looks at the role of power and its effect on subjectivity in adolescent literature. Her book Power, Voice and Subjectivity in Literature for Young Readers (2010) explores concepts of subjectivity in children's literature. She specifically recognizes Nodelman's work in The Hidden Adult "to define the object of our studies," but instead "would like to explore possible ways of approaching children's literature from a theoretical perspective, thus responding to the recent tendency to reject theory as such" (1). Nikolajeva also explicitly critiques John Stephens in his work Language and 
Ideology in Children's Fiction (1992) because "[u]nless Stephens has positioned himself against the material he works with (=adopted a theoretical stance), he would not know what questions to ask. That would be exactly the kind of "pre-theoretical innocence'...that we can expect in undergraduate students, but not among mature scholars" (3). After reviewing several other scholars in the field, Nikolajeva moves on to identify "the main thrust of literary work" as the "examination of power positions, the affirmation or interrogation of the existing order of power" (7). She cites Trites's work with power in adolescent literature, but argues that "it is in some way or other present in all children's literature, from ABC-books to young adult novels" (7). Nikolajeva's argument specifically defines "aetonormativity (Lat. aeto-, pertaining to age), adult normativity that governs the way children's literature has been patterned from its emergence until the present day" (8). With this term Nikolajeva asserts, "we are dealing with the imbalance, inequality, asymmetry between children and adults, the way it is presented and assessed in children's books, books intended for the young audience" (8). I argue that this term can also be applied to adolescent literature, which is also written by adults for an adolescent audience. The power imbalance of an adult telling an implied adolescent reader how to become an adult (or to fit into the cultural construction of the author's ideologies) is exactly the same as the patriarchal power imbalance of insisting that women are naturally associated with the home. Both aetonormativity and patriarchal thinking perpetuate the dominant ideology of limitation and hierarchy rather than allowing for fluid subjectivity in the implied adolescent reader.

Throughout the text, Nikolajeva analyzes the power struggle between the adult author and the child-implied reader. In Chapter Six, she specifically looks at setting in 
terms of post-colonialism. Her first examples of orientalism in literature for children have much in common with Bradford's work Unsettling Narratives: Postcolonial Readings of Children's Literature (2007), although Nikolajeva concentrates more on the effect of othering on the implied reader while Bradford sticks mostly to indentifying how othering works in the texts themselves. Unlike Bradford, Nikolajeva does expand her argument to include gender, but she mostly examines female "Robinsonnades" or "girls or young women surviving in an extreme environment" (96). She writes that this “present[s] a dilemma for a children's writer, since they [these stories] are initially a masculine genre, in which masculine traits are of the protagonist are emphasized...[i]n a female Robinsonnade, the character must necessarily hover between maintaining, or even developing, masculine traits and values on the one hand, and, on the other, retaining or affirming her femininity" (96). Nikolajeva does spend some time examining the conflict between authors writing outside of their gendered subject positions (male authors writing female protagonists and vise versa) but she does not make a specific connection between a female protagonist, the spaces in the text, and the search for Power, Voice and Subjectivity.

In this section I have looked at broad spectrum of writing about children's and adolescent novels, especially focusing on issues with power, subjectivity, and gender. I argue in the rest of my chapters that a patriarchal power structure is often reinforced in literature for adolescents, although many authors work to subvert the dominant discourse through acts of domestic labor and care. The novels I have chosen to examine from Mahy, Voigt, and Jones demonstrate a variety of geographic locations and ideologies about gender and space. 


\section{Conclusion}

The ideological and discursive process of subjectivity can be traced in adolescent literature by looking at the spaces in the text as a metaphor for this process of growth. The home is uniquely connected to a woman's body through both cultural ideology (Victorian separate spheres) and fertility (the ability to give birth, a kind of domestic labor). Thus female protagonists in adolescent literature have a special type of relationship to the home in their struggle to travel from object to subject. Throughout the rest of my dissertation, I will rely on the theoretical ideas I have discussed above. Each chapter focuses specifically on one author and the relationship between gender and space in that author's novels. Throughout the dissertation, my goal is to examine the interconnections between domestic spaces as they are constructed in literature and how gender roles are socially constructed with ideological implications for all readers. 


\section{CHAPTER II}

“AND THIS ISLAND IS MINE”: POSTCOLONIALISM AND GENDERED SPACE IN MARGARET MAHY'S ADOLESCENT LITERATURE

Introduction

In this chapter I will look at how theories of postcolonialism in literature overlap and intersect with theories of adolescent literature and feminist geographies. There are problematic binaries inherent in most of the poststructural theories I will be using; these include such binaries as that of colonizer/colonist, oppressor/oppressed, victim/victimizer, and male/female. My goal in this chapter is to push back against those binaries and explore how feminist geographies can help to complicate these issues. I will do this by first reviewing some of the major voices in each field, and then I will identify adolescent literature as a space filled with voices that are silenced by geography in similar ways to those identified as Other by postcolonial theorists. I will argue that while post-colonial criticism is concerned with the claiming of land and the subalterned "other," much remains to be said about the othering of the female adolescent identity and body. Margaret Mahy's work, including The Tricksters, The Catalogue of the Universe, The Changeover, Kaitangata Twitch, and The Other Side of Silence, serve as my case studies because they feature adolescent characters dealing with limitations of space and gender. Ultimately, I will demonstrate a problematic connection between the female 
adolescent body and the colonized Maori land. This connection shows a troubling lack of agency for both the female adolescent and the Maori. When thinking about the relationship between gendered spaces and adolescent literature, I argue that Mahy's novels are reinforcing gendered binaries rather than allowing her female adolescent protagonists to subvert or challenge the dominant discourse. By aligning those with less societal power together, Mahy's novels are missing an awareness of the complications of gendered spaces and the cultural, racial, and gendered difference between the Moari (both females and males) and female adolescents (both Maori and non-Maori). The space associations with the female protagonists in these novels become spaces of limitation rather than spaces of empowerment because of Mahy's lack of subtly. The following chapters in this project will demonstrate that gendered spaces can be subverted, or even powerful, but in Mahy's novels these spaces further disenfranchise the disenfranchised. Mahy herself has written many times about her childhood in New Zealand, and the colonized dissonance she grew up with. Indentifying herself with the European colonizers, Mahy writes that:

...western colonisation ran its troubled and predictable course though perhaps a little more amiably than in many other countries, with the result that here we are in 1979, a country of two races sharing the human involvement and need for stories, but with entirely different traditions in presenting them to our children, for the Maoris have an oral tradition, and the Europeans brought books and literacy with them, along with pianos, tea sets, and other homely things like measles and gin. ("On Building" 104) 
She notices, in 1979, the need for a kind of storytelling that will bring together the two races in New Zealand - the colonizers, and the colonized. Mahy does attempt to bring together the colonizer and the colonized in her novels, but the result instead reinforces the binaries she sets out to break down. By aligning her female adolescent protagonists with the colonized Maori, Mahy is establishing another binary of two groups: those with power in society and those with little to no power. I argue that characters can indeed be both colonizer and colonized, powerful and with little power, depending on many different circumstances. She identifies the Europeans with a literate tradition; Mahy herself mostly read British stories by Beatrix Potter, A.A. Milne, Kenneth Grahame and Lewis Carroll. She says that these stories are part of her "inside landscape" but that she wants stories to match her "outside" landscape, that of New Zealand (Mahy, "On Building" 106). Mahy consistently identifies post-colonial struggles in her writing with the following metaphor: while the interior landscape is British, the external landscape is literally New Zealand ("On Building" 106). Part of the work I will do is the chapter is to find alternative spaces — what Homi Bhaba might call a "third space" (53)—in Mahy's case, a gray area in between British/New Zealand, and many of the other binaries that author sets up. (Even the term "third space" implies a rigid category of geography that doesn't actually exist in most cases.) I specifically rely on Mahy to show that by aligning her female adolescent characters with the binary of colonized, her implicit ideology misses important issues having to do with time, power, privilege, and race, like the difference between a white middle class female adolescent and an entire civilization whose land has been colonized. Many of her female adolescent characters, while certainly struggling with issues of power, are not just colonizers or colonized; they are 
both, and neither. They occupy alternative spaces, a concept I will cover below, but Mahy neglects these spaces in her efforts to break down the binaries she is emphasizing. Although these alternative spaces are liminal and full of contradictions, Mahy fails to perceive the potential complications her own work affords for the differences in circumstances between the Maori and her female protagonists.

The Space of Postcolonialism and Gender

The history of postcolonial theory and criticism has been well covered in many other places, but a specific focus on how postcolonial theory intersects with space and gender provides an important foundation to my analysis of Margaret Mahy's novels. The four most important concepts covered in this chapter are defining the Other, the subaltern, the idea of alternative, in-between spaces (or "third space"), and the concept of unhomeliness. To briefly review these concepts, I draw on the work of Gayatri Chakravorty Spivak and Homi Bhabha. These important postcolonial concepts highlight the troubling connection Mahy makes between an adolescent girl's body and the forces of colonialism. After Edward Said's Orientalism was published in 1978, many other scholars adapted his ideas. First published in 1988, Spivak's article "Can the Subaltern Speak?" brought the term subaltern to prominence in postcolonial theory by redefining and later problematizing the subaltern as "a person without lines of social mobility" (28). Connecting the subaltern with gender, Spivak explains that "both as object of colonialist historiography and as subject of insurgency, the ideological construction of gender keeps the male dominant. If, in the contest of colonial production, the subaltern has no history and cannot speak, the subaltern as female is even more deeply in shadow" (32). This 
shadow has become a blanket dealing with all those outside of the hegemonic powers: they are oppressed with no voice to raise against their oppressors or the ability to join with those who are trying to defend them. As Spivak points out, if the male subaltern is oppressed by the colonizing power, what happens to the female subaltern? Her voice is silenced with no opportunity to resist the colonizer or the silencing of her gender and position in society. One of the ways Spivak suggests scholars address this issue is "by measuring silences, if necessary - into the object of investigation" (emphasis in the original 32-33). In other words, Spivak suggests the goal of postcolonial criticism should be to look at moments of silence as opportunities for empowerment, rather than just as a loss of power, and to complicate the traditional ways of dismissing the female subaltern as only silenced or oppressed. Thinking about the female subaltern and "measuring silences" as a way of rethinking power is especially important with Margaret Mahy's novels. While Mahy's characters are not true subalterns (as Spivak defines the term) because they have some agency and are not formally colonized (unlike the Maori people Mahy often associates them with), they are silenced in a variety of ways and must resist a hegemonic society (usually through various forms of patriarchy). This connection remains problematic, however. While I will demonstrate that Mahy's female protagonists are treated as subalterns in the text, they are not actually subalterns. They are mostly middle class white female adolescents who do suffer a silenced position, not because of their race and gender, but because of their age and gender. This crucial difference is a factor Mahy does not allow for when implicitly comparing the status of the Maori people in New Zealand with her own female adolescent protagonists. In Mahy's novels, methods of silencing and oppression exist both among the Maori people, 
colonized by Europeans, and the female protagonists.

What exactly qualifies as a subaltern has been discussed by many scholars.

Chandra Talpade Mohanty asserts that third world women have more in common with each other than with so-called "first-world" women and that, "[u]nlike the history of the Western (white, middle-class) feminisms, which has been explored in great detail over the last few decades, histories of third world women's engagement with feminism are in short supply" (4). Much of the focus of postcolonial theorization has been on the effects of colonialism on the people and the land, but Mohanty argues that "the way we think about race, class, and gender - the political links we choose to make among and between struggles" is similar enough to argue for a study of the "imagined communities of women with divergent histories and social locations, woven together by the political thread of opposition to forms of domination that are not only pervasive but also systemic" (emphasis in the original 4). In other words, because women in different circumstances are nevertheless socially constructed in similar ways, their oppression, rebellions, and challenges can be discussed together because, as dissimilar as their circumstances may be, they are connected by similar kinds of subjugations. Thus female characters from New Zealand, as Margaret Mahy writes about, may have much in common with other characters across the world. While Mahy does not create any indigenous protagonists, she does connect the majority of her female characters to the Maori people of New Zealand. This is in some ways, a challenge to the problematic binaries Mahy sets out in her article, quoted above; those who are oppressed do have some issues in common, including inhabiting socially constructed subject positions, such as race and gender. However, Mahy does not complicate this connection, so instead, she creates a new set of 
binaries between those with more or less cultural power - and this binary erases the differences between different groups of people.

Mohanty's broad definition of the term third world includes "indigenous peoples in the U.S., Europe, and Australia," which I argue can be extended to New Zealand as well (5). Mahy's novels are an excellent case study for looking at how space and gender interact in adolescent literature because she implicitly connects the indigenous people of New Zealand with her female adolescent characters. Instead of simply exploring how one group oppresses another, Mahy breaks down this binary and complicates the racial, gendered, and geographical oppressions experienced by characters in her novels. As Mohanty has done with her definitions of third world women, Mahy also asserts that female adolescents and the Maori people of New Zealand are "woven together by political forms of oppression" (Mohanty 4). Again, however, this connection skims over the important differences between Mahy's protagonists and the women of the third world; Mahy's protagonists do not all suffer the same kinds of oppression, just as third world women do not suffer the same kind of oppression as women in other circumstances. The binary set up between oppressor/oppressed gets even more complicated because in some ways, the female characters in these novels occupy both spaces; they are privileged in many ways, but are oppressed by similar cultural constructions (to third world women) in others. This binary between oppressor/oppressed becomes problematic because adolescent females eventually grow out of their age-based, aetonormative oppression. As defined by Maria Nikolajeva, aetonormativity is the term for the "adult normativity that governs the way children's literature has been patterned from its emergence until the present day" (8). Because of this power structure, children's literature has been "used for 
centuries to educate, socialize and oppress a particular social group... [however], children's literature demonstrates a constant change of power positions: yesterday's children grow up and become oppressors themselves" (8). While these female characters will suffer from patriarchal oppression all of their lives, Mahy's novels imply that their status as adolescents will change and they in turn will become complicit in the oppression of children. As Nancy Chodorow argues in The Reproduction of Mothering, we cannot deny "the extent to which we participate, often in spite of our conscious intentions, in contemporary sex-gender arrangements" (215). Just as gender stereotypes are often reproduced unconsciously and thus reinforced in society, so too is the cycle of adults disempowering children. In addition to the complications of age are left out of Mahy's new binary, so too is the complicated relationship between races. Race is thus yet another factor in the relationship between the Maori and Mahy's female protagonists, because an adolescent female is not usually subject to the same kinds of political, or societal, oppression. Mahy's new binary, aligning the Maori with her adolescent female protagonists against the rest of society, implies that each group has more in common with each other than might actually be the case; I argue that the mostly white middle-class female adolescent protagonists in Mahy's novels experience a very different kind of oppression than the Maori people and that creating this false binary actually works to further silence those who are already too often culturally dismissed.

Moreover, beyond breaking down the binary Mahy sets up, I would argue that postcolonial theorists set up some binaries which need complicating. In The Location of Culture (1994), Homi K. Bhabha argues for the “'in-between' spaces,” which "provide the terrain for elaborating strategies of selfhood — singular or communal — that initiate 
new signs of identity, and innovative site of collaboration, and contestation, in the act of defining the idea of society itself' (1-2). Drawing out this metaphor, Bhabha quotes Renée Green:

I used architecture literally as a reference, using the attic, the boiler room, and the stairwell to make associations between certain binary divisions such as higher and lower and heaven and hell. The stairwell became a liminal space, a pathway between the upper and lower areas, each of which was annotated with plaques referring to blackness and whiteness. (Green qtd. in Bhabha 4-5)

This metaphor of a physical building to describe liminal spaces is similar to the kinds of metaphors used by Gaston Bachelard and Yi-Fu Tuan. While those geographers use houses to help define metaphorical spaces, Bhabha focuses on how the stairwell of the museum can function:

... as liminal space, in-between the designations of identity, [which] becomes the process of symbolic interaction, the connective tissue that constructs the difference between upper and lower, black and white. The hither and thither of the stairwell, the temporal movement and passage that it allows, prevents identities at either end of it from settling into primordial polarities. This interstitial passage between fixed identifications opens up the possibility of a cultural hybridity that entertains difference without an assumed or imposed hierarchy. (4)

While Bbabha's chosen metaphor of a staircase is hardly an example of a "third space" because of the metaphor's implied hierarchy, it is a spatial metaphor, and the concept of 
"cultural hybridity" helps explain how Mahy's characters react and come to terms with the gendered spaces they inhabit, which I analyze at greater length below. This kind of liminal space becomes an opportunity for contradictions, multiple identities, and many different ways of being far from the limits of male/female, past/future, young/not young, black/white, and native/not native binaries. This in-between space also has another connection Bhabha does not discuss, even when he is comparing the space to a bridge: it creates the possibility of spanning ages as well as genders, classes, races, and nationalities. As a metaphor for liminality, Bhabha's concept of the third space will come up again throughout the rest of this chapter because the possibility for adolescence to serve as a space of liminality is open to many kinds of ambiguities. Bhabha's metaphor of a third space helps to problematize the spaces between what seems like a binary in Mahy's work; the Maori and non-Maori people are no longer separated by a line but are juxtaposed in a state of in-between. This juxtaposition is often instantiated by a female adolescent protagonist who already dwells in that in-between state, so she has the agency to bring many sides together to create a new conversation. Thus, my concern with the third space is to interrogate whether it serves as a space of empowerment for the adolescent characters and what happens to the character when she goes through the bildungsroman process and grows up. This again complicates the relationship between Mahy's female protagonists and the Maori people; most adolescents will eventually grow out of this liminal state to become adults, so the simplicity of separating the oppressor from the oppressed doesn't hold.

Another of Bhabha's theories about postcolonialism provides a link to theories of space and gender by contextualizing the dangers and familiarity of domestic spaces, so 
often connected with the female body. Bhabha identifies many spatial metaphors to analyze how we think about postcolonial lands, but he is as much concerned with domestic spaces and the specific as he is with larger countries and groups of people. When writing about the dangers of romanticizing the past by clinging to "indigenous cultural traditions," Bhabha notes that "[ $\mathrm{t}]$ he recesses of the domestic space become sites for history's most intricate invasions. In that displacement, the borders between home and world become confused; and, uncannily, the private and the public become part of each other, forcing upon us a vision that is as divided as it is disorienting" (9). He calls this process "unhomely ... a paradigmatic colonial and post-colonial condition" that happens when "the enstranging sense of the relocation of the home and world - the unhomeliness ... is the condition of extra-territorial and cross-cultural initiations" (9). Bhabha's definition seems imprecise, but he later provides examples of the damage caused to the domestic setting by the intruding world in another spatial image tied to postcolonialism, and there are gender connotations as well. If the public and private spaces meld, then the gendered divisions of space in society can also become more ambiguously defined, which allows space for more complex definition of power and breaking down of binaries. After providing examples from Henry James' The Portrait of a Lady and Toni Morrison's Beloved, Bhabha draws the threat of unhomeliness together with gender. The collision of the political with the personal is made clear when Bhabha explains:

By making visible the forgetting of the "unhomely" moment in civil society, feminism specifies the patriarchal, gendered nature of civil society and disturbs the symmetry of private and public which is now shadowed, 
or uncannily doubled, by the difference of genders which does not neatly map on to the private and the public, but becomes disturbingly supplementary to them. This results in redrawing the domestic space as the space of the normalizing, pastoralizing, and individuating techniques of modern power and police: the personal-is-the political; the world-inthe-home. (emphasis in the original 10-11)

Making unsafe what is culturally supposed to be a safe space changes everything about a society's conception of spaces. What Bhabha describes as the "unhomely moment" can be read as both disturbing the actual homes of those colonized and disturbing their homelands. Crossing the boundary between these binaries of public and private, colonizer and colonized, feminine and masculine, creates a cultural unsettling that can leave people in a state of ambiguity and flux. Thus, what happens in the domestic sphere is as important to tracking shifts in cultural ideologies as what happens to an indigenous population, and vice versa. And, as Bhabha notes, redrawing the boundaries in between public and private can sometimes be a violent process with ramifications both personal and political. An adolescent female facing such a situation, even many generations removed from the first touch of unhomeliness, will see an endless pool of ripples outside her front door.

Postcolonial theory thus offers several useful terms for the study of Mahy's gendered use of space: the subaltern, third space, and unhomeliness all are terms that highlight the differences between Mahy's protagonists and the Maori people. The lack of power, agency, and states of liminality are not the same for the two groups, and they do not occupy the same kind of gendered spaces. Although some of Mahy's novels do 
mention the Maori people specifically, "Mahy generally chooses not to attempt to show how the human place of New Zealand, and the human place of the adolescent body, are haunted by Maori myth and legend (with the exception of the Māui [sic] myth in The Tricksters, as argued by Lovell-Smith); rather, she shows how they are both haunted by European history, European literature, and European families" (Winters 422). As with many other postcolonial authors have written about, the land in Mahy's novel bears echoes of the traumas it has endured, as do the people most connected to the land. By connecting the Maori people with nature and the female body, Mahy continues to compare the act of colonizing the Maori to the colonization of the natural world and the female body. This is a problematic comparison to make as Mohanty, Spivak, Bradford, and others have pointed out, because the act of silencing a female adolescent and the people of New Zealand are both acts of colonization, a female adolescent will partially grow out of one kind of oppression; that imposed by age.

Postcolonialism and Adolescent Literature

While many postcolonial theorists have looked at adult literature, I argue that adolescent literature needs a closer examination in terms of gendered binaries and methods of Othering. Some critics have written about children's literature in terms of postcolonial criticism, but much still needs to be said about the postcolonial in adolescent literature. One early children's literature critic, Jacqueline Rose (1984) published The Case of Peter Pan: or The Impossibility of Children's Fiction. Using J. M. Barrie's Peter Pan as an example, Rose points out that much of children's literature is based on ideas of childhood formed by Locke and Rousseau; thus “[c]hildren's literature emerges... out of a 
conception of both the child and the world as knowable in a direct and immediated way, a conception which places the innocence of the child and a primary state of language and/or culture in a close and mutually dependent relation" (9). This assumption that children are innocent because they know less about the world is an insidious premise that continues in the culture — and much of the field — today. The most important part of Rose's work, for my argument, is that she is defining childhood as a deliberate construction, something created out of assumptions about language and children rather than a natural stage of development. This construction of the child as Other (different from adults, in need of a specific kind of literature, like Peter Pan) has had a profound effect on our discourses about children and childhood. Rose writes:

What we constantly see in discussion of children's fiction is how the child can be used to hold off a panic, a threat to our assumption that language is something which can simply be organized and cohered, and that sexuality, while it cannot be removed, will eventually take on the forms in which we prefer to recognise and acknowledge each other. Childhood also serves as a term of universal social reference which conceals all the historical divisions and difficulties of which children, no less than ourselves, form a part. (10)

This is crucial to understanding how children's literature and postcolonialism interact; all too often childhood is assumed to be a universal construction, normalizing and erasing differences among children of many different circumstances and lives. Adults, usually responsible for writing and publishing and disseminating most children's literature, often assume that children are Other to adults in their innocence and the way they use 
language - which is a Romanticized and problematic view of childhood. This assumption emphasizes the binary between adults and children and erases differences among the subjectivities and experiences of groups of children. It is my purpose here to complicate this type of binaristic thinking, including breaking down binaries between children and adult, white and non-white, male and female.

In “The Other: Orientalism, Colonialism, and Children's Literature” (1992), Perry Nodelman provides a useful tool for analyzing the relationship between children's literature and post-colonial criticism. Nodelman accurately points out that "children are not the ones who write either the texts we identify as children's literature or the criticism of those texts"; thus we are faced with "the uncomfortable conclusion that our attempting to speak for and about children in these ways will always confirm their difference from, and presumably, inferiority to, ourselves [adults] as thinkers and speakers" (29, emphasis in the original). In other words, as a group with little to no power or voice in any society, children and adolescents have been Othered and continue to be so in the literature written for them by adults. Nodelman then goes on to list "the parallels between Said's descriptions of Orientalism and our representations of childhood," which include "inherent inferiority," "inherently adult-centered," "silencing and inherent silence," and "Other as opposite" (29-32). One of Nodelman's most important parallels between Orientalism and adult/child relationships connects to my argument about the connection between gender and postcolonial theories because of a similar power dynamic. Nodelman refers to Said's Orientalism, noting:

For Europeans for whom the Orient is subject to the gaze, it is therefore, metaphorically, female - and that allows Europe to represent 
itself and its own authority as male. Said describes how "images ... of frank sexual attention to the Orient proliferated" as "scholars, administrators, geographers, and commercial agents poured out their exuberant activity onto the fairly supine, feminine Orient" (219-220).

The parallel holds here also. Whether male or female, adults often describe their dealings with children in language which manages to suggest something traditionally feminine about childhood, something traditionally masculine about adulthood, and something sexual about adult dealings with children. (30)

Nodelman points out the relationship between how our society treats children, women, and the Othered Orient as described in Said's work. Even within this article connecting the racial Othered from Said's work and children, Nodelman recognizes that this connection is problematic. He writes that "[w]hat distinguishes our thinking about childhood from other discourses other otherness is that in this case, the other does quite literally turn into ourselves. All those who survive childhood become adults, adults who tend to think of children as their other" (33). Unlike those who are Othered by poverty, race, geography, or gender, all children eventually become adults and in turn begin to Other children. ${ }^{6}$ As I will demonstrate in Mahy's work, connecting those with little power in society to each other often occurs, sometimes with troubling results. While the female protagonists in Mahy's work may have much in common with Othered Maori peoples, they are not disempowered in the same ways, and in the novels their voices are not given equal weight. While the female characters in Mahy's work are in some ways

${ }^{6}$ As described by Nikolajeva using the concept of aetonormativity. 
Othered by their status as adolescents and by their gender, generally speaking, only one of those conditions will change.

In 2001, Clare Bradford published one of the first texts to focus specifically on postcolonial readings of children's literature, Reading Race: Aboriginality in Australian Children's Literature. Since Bradford focuses her text only on Australian texts, she does not include Mahy in her analysis. Bradford writes:

I want to resist the idea, now widely accepted within critical writing on children's literature, that children and indigenous people occupy comparable positions in relation to structure of power. For example, Jacqueline Rose (1984), Perry Nodelman (1992) and Roderick McGillis (1999) assert that the relations between adults and children, and between children's literature and child readers, are analogous to those by which colonisers maintain power over the colonised, in that children are organised and controlled by members or a dominant, powerful group. The analogy is imperfect for two reasons: first, children's authors were once themselves children...[s]econdly, the comparison between child readers and colonised peoples breaks down completely when texts are produced by colonial writers for the children of colonisers, who are inscribed within these texts as young colonisers, as "us" rather than "them." (1-12)

To be fair, Nodelman does mention one of these issues in his article, but Bradford's points complicate a comparison that has many ambiguities. Unlike a group colonized and/or Othered by their race, as Nikolajeva would later discuss, children can eventually grow up and often begin to replicate the same actions of their previous colonizers 
(Nikolejeva 8-9). Bradford's second point provides more nuance to an increasingly complex issue: that of children's literature being used not (just) to colonize children into adults but to colonize indigenous populations into the hegemony. She also notes that a similar disconnect appears when theorists compare colonization and gender as well. She writes, "the trope of 'child as colonised' elides those discourses of race which constitute one group of people as inherently inferior to another, much as the trope of 'woman as victim' and 'woman as dependent' within feminist work have sometimes elided colonialism and its privileging of whiteness" (12). This is one of the few times Bradford brings up gender, which is an understandably complex topic, given her focus on postcolonial children's literature. Bradford seems to be arguing that when we say "child" or "women" are colonized, we omit factors of race, class, privilege, geography, and other important differences from the narrative of colonization. This is a crucial difference between Nodelman's work and more modern approaches to postcolonialism in children's literature that critique how comparing children to a colonized people is a problematic trope. As Mohanty and others demonstrate, lack of power does not necessarily mean a common condition, and assuming that disempowered groups are all disempowered in the same way is in fact another kind of silencing.

Karen Coats complicates these issues of childhood and colonization more successfully when she explores children's literature from a Lacanian perspective in Looking Glasses and Neverlands (2004). She writes that it is "within the languages and images of a specific culture that the subject must both find and create himself. Lacan's theory of the subject examines the way that dual process is negotiated. His primary focus is the way the subject situates itself with respect to the Other in language and the Other as 
language" (4). While postcolonial criticism looks at the process of Othering people, land, and culture, the literature written for children goes through a similar process. Because children's texts are constructed from language, “[w]hat we get from children's literature are the very patterns and signifiers that define our understanding of and our positions with respect to the Other, and in so doing, structure our sense of self. The literature we encounter as children, then, should be seen as central to the formation of subjectivity" (4). This relationship building between the Other and the self is a fundamental part of all children's literature, and it is also part of the reason why thinking about race, class, gender, and many other factors is imperative to this study. Because the literature for children (and adolescents) is written by adults to acculturate children into their own ideals about childhood, we can assume that when Mahy incorporates the Other into her fiction, she is influencing the reader's "process of collecting the experiences that will shape and define their relation to the Other" (Coats 4). Thus while children's literature tends to treat the child reader as an Other, one who needs to be civilized, literature written about a colonized people is also complicated in depicted attitudes about being "civilized." Nonetheless, the Othering implicit in both kinds of texts works problematically against establishing subjectivity.

No theorist has yet brought together considerations of gender, colonialism, space, and children's literature. While works have been published on individual concerns and different combinations of these issues, no one has yet explored the complications inherent in the postcolonial spaces of children's and adolescent literature in terms of gender. Bradford's Unsettling Narratives: Postcolonial Readings of Children's Literature (2007) discusses space and land only in terms of postcolonialism, which limits the possibilities 
of her interpretations. Bradford cites Doreen Massey's observations about gendered spaces, then transfers "Massey's view," which associates "conceptions of space and the feminine" to The Sign of the Beaver. Bradford writes, "when, at the end of the narrative, Attean explains to Matt that his people must move away to a place where there is 'no more white man,' readers are positioned to acquiesce to Matt's regretful acceptance of a colonial order in which the indigenous fade away into space and hence into a state of powerlessness" (125). Bradford associates indigenous peoples with spaces of powerlessness, but she does not explore how the gender of the characters in the novel relates to this kind of colonization. In her fifth chapter, "Space, Time, and Nation," Bradford devotes an entire section to "Habitation, Home, and Nation." She problematizes the western stereotype of home as a safe space, or a "haven from what is dangerous and unfamiliar. Many homes in contemporary texts are less comfortable and comforting spaces; indeed, many are marked by what Homi Bhabha calls 'the deep stirring of the unhomely,' the moment when a dwelling that might have seemed safe and secure is experienced as uncannily expressive of the psychic and political upheavals of colonialism" (137). ${ }^{7}$ Especially significant is the idea of "unhomely" in children's literature, in which home is usually the place of safety and support one must escape to have adventures. Bradford points out that if home becomes an unsafe space, postcolonial

${ }^{7}$ Slavoj Žižek equates this to Freud's phallic stage of development, which is in fact adolescence — when the evil force, formerly perceived to be external to the subject, is experienced as an internal threat, making the body itself an uncanny space. For more on Freud, see Žižek’s The Ticklish Subject: The Absent Center of Political Ontology. 
children's literature becomes very different from other kinds of children's literature. As I claim in Chapter One, if the masculine adolescent's trajectory is to go from home to away and the female's is to go from home, away, and home again, then colonialism indefinitely complicates this pattern. If home never was a safe space, colonized by intruders and made dangerous (both physically and to a character's identity), then boundaries between home/not-home become blurred. This challenges Nodelman's pattern of home/away/home because home is no longer always a safe space to return to and the definition of home can become fluid and changeable. Bradford gives the example of "a steadily growing body of autobiographical and fictional texts dealing with enforced travel and narratives of escape involving children and adolescents removed from their families and cultures under assimilationist policies" (148). Bringing together theories of children's and adolescent literature with postcolonialism is clearly very complicated, especially when we include an analysis of traditional gender norms as well. The most important consideration for my purposes here is how the existing scholarship is missing a critical look at the overlapping connections between postcolonialism, adolescence, and gender. Both the Maori and the female adolescents protagonists featured in Mahy's books are dealing with power issues, but they live in very different circumstances and are Othered in very different ways.

Postcolonialism, Adolescent Literature, and Gender: Spaces of Oppression and Resistance in Margaret Mahy's Fiction

Margaret Mahy's work provides a solid case study for testing the relationship between postcolonial theories and the study of gendered space, which I discussed in 
Chapter One. By specifically focusing on her texts with adolescent female protagonists, I identify in this chapter the common association between female adolescents and their limited access to power and space. In Mahy's work, these female characters are often under threat from a kind of colonization, whether of the land or their own bodies; however, Mahy problematically conflates this threat with that of the Maori people, who are also already colonized. As I will demonstrate, Mahy's female protagonists are often more connected to natural spaces and nature than other characters, which, in a world of binaries, would mean they are ready to be colonized. However, this binary needs to be complicated; the female characters in these novels are dealing with issues of power, oppression, and agency, but they are also not exactly the same as issues experienced by the Maori people. Their experiences and connections to the natural world also include cultural constructions of their gender, the domestic spaces they inhabit, and their expectations for the future. While the land and the female adolescent body may be under similar threats (of being consumed, for example in Kaitangata Twitch), the danger of overcolonization they face is not the same. The levels of power and agency between the white female protagonists and the almost silent and unseen Maori in Mahy's texts are not equal and do not share the same experiences or relationship to the spaces around them. I have chosen here to include those of Mahy's adolescent texts that best highlight the female adolescent body in space and power, especially focusing on those texts that make specific references to the Maori. 


\section{The Changeover}

Margaret Mahy's The Changeover (1984) begins with a disappointment. Although Mahy's protagonists will face more difficult situations, Laura begins her story disappointed that the shampoo she has been using, although named "Paris," is actually not French. The bottle actually "was forced to tell the truth in tiny print under the picture. Made in New Zealand, it said, Wisdom Laboratories, Paraparaumu” (9). Instead of dwelling on her prosaic life in New Zealand, where she has to face the "facts of everyday life," Laura tries to think her "way into being another person with a different morning ahead of you, or shampoo yourself into a beautiful city full of artists drinking wine and eating pancakes cooked in brandy" (10). Already the reader is being presented with an image of colonization between exotic, Old Word Paris and quotidian, New World New Zealand. Laura dreams that she could be a different person in Paris, but in New Zealand she is stuck being a person whose "hair would not dry in time for school, and she would spent [sic] half the morning with chilly ears" (10). While The Changeover does not overtly reference the Maori people, the novel does demonstrate several of the continuing themes Mahy uses in her books, especially the importance of domestic spaces, roads, and nature. Laura, the female protagonist, is drawn into the world of magic, used as metaphorical power, and discovers that she can draw power from the natural world and her own body. By connecting with different forms of the Other, Laura becomes Othered in multiple ways. Feminine magic represents otherness that is tied to the land, so it also serve as a metaphorical version of an alternative or "third space" which softens some of the potentially appropriative nature of Mahy's portrayal of the land. Her connection to 
the land ties her power to an idealized version of New Zealand, before the land was corrupted by colonization.

Shockingly, Laura's younger brother Jacko has his hand stamped by a mysterious figure, who then begins to magically drain his life force. Deeply concerned for her brother, Laura goes to the only person who can help: Sorenson Carlisle, a male witch and prefect at her school. Sorensen (nicknamed "Sorry") is a witch, although as his mother explains, his magic is "very much a feminine magic...[a]nd Sorensen sometimes resents it. He doesn't like being called a witch, although of course that is really what he is. Sometimes he feels that he's not completely a man or a witch but some hybrid, and he struggles too hard to be entirely one thing or the other" (97). That Sorry is a male witch, drawing on feminine power, makes him all the more attractive to Laura. There is an interesting point to be made here that Sorry is not a patriarchal figure; he is a heterosexual male, clearly interested in Laura, but he balances his power between masculinity and femininity. His metaphorical power is drawn from nature, as is Laura's, which helps to break down gender binaries in the text. His house becomes the most important space of the text because it is so connected to that feminine magic, and most important for my argument, to nature and the natural world. As Laura makes the dangerous walk to Sorry's house, she notes that:

[o]nce upon a time the Carlisle family had lived on a farm at the edge of the city and had owned the whole Gardendale Valley, though they called it by another name. But the city crept out and out, an industrious amoeba, extending itself, engulfing all it encountered.... Every day, in order to go to school, he emerged from behind this woody hedge, flowering with a 
fairy-tale tapestry of Tom Thumb roses in the early summer, and travelled the two miles to school on a small motorbike. (78-79)

The house described, named "Janua Caeli," is an old farmhouse surrounded by the wilds of nature, intentionally left to hide the home from the modern suburb. This house is very much connected to the land of the past, and of the natural world that existed before urbanization, city sprawl, and encroaching civilization. As old Mrs. Carlisle explains to Laura, "[i]t would be easier to explain to you if only you had known the farm in the old days...[i]t's probably a mistake to become too fond of land. But, you know, we loved our farm. Once the whole valley out there was ours, and it was like owning a whole world" (122). Here Mrs. Carlisle is presenting a utopian vision of what their pastoral land looked like before the city began to spread out and eventually surround them. She tells Laura "there are no more private places left. There's always magic, of course, but in the past it was simple and direct" (122). The magic in their family, which Mahy has already identified as feminine magic, is thus linked to their land, the house, and their connection to the natural world. It is especially important that Mrs. Carlisle laments the lack of "private places" because this is one of the most common motifs that often appears in Mahy's work. Characters are tied to a private space of empowerment and usually suffer when that space is lost or violated in some way. For Sorry and his family, it is their hereditary house and land; for Laura, it is the home she shares with her mother and brother. When her brother's spirit is slowly draining from his body, Laura notices that the life is draining from their house. Laura's family is in danger from outside influences, and her formerly happy home "now felt threatening" (108). Her feelings are mirrored in the home, just as Sorry's history is visible on the surface of his space. 
The loss of privacy and the hinted contamination of their land's purity in The Changeover can also be read as a coded allegory for colonialism. The surrounding suburb has colonized their land and home. Sorry's mother Miryam describes the impending construction, telling Laura, "it was like the army of a neighboring country amusing itself in its own way, always maneuvering on the horizon... [but then] the army came closer" (122-23). In order to protect their land from what appears to be an invading army, the Carlisles decide "to raise what we call a cone of power over the farm...[w]e would still be visible, but somehow not observable. The city would know we were there but would pass us by" (123). Here is the struggle of the dispossessed, those without official voices in the hegemony seeking resistance; there is, as Spivak notes, a way to measure this silence. The magical cone of power over their house becomes a way to literally measure the silence of the Othered in the setting because the cone hides them from view while allowing them to be powerful in ways not usually recognized by society. This method of silence becomes then a way of resisting oppression, of claiming agency. Because The Changeover is fantasy, the form of resistance the family takes is coded in magic, but they must hide and protect themselves from outsiders in part because of those same magical powers. Their magic makes them Other. The house and its connection to nature also become the site of a magical conversion that enables Laura to gain the power to save her brother.

The Changeover is especially interesting because it challenges some of the usual gender stereotypes and demonstrates another troubling connection between those gender stereotypes and being Othered by having a connection to the natural world. Sorry is a male witch, which even his mother and grandmother have not been expecting before his 
birth. He has the same ties to nature they do, but because they have not expected a male to be a witch, he has had a troubled childhood (124-25). Laura is expected to have an easier time changing over into a witch, partly because she is both female and a virgin (171). This changing over process, while a magical conversion, is also of course a metaphor for adolescence and the process of growing up. Roberta Seelinger Trites points out that Laura's "transformation is permanent" because adolescent characters must "overcome their tragic vulnerability and avert catastrophe, transforming the tragedy of their own mortality into at least some level of triumph, [so] they experience a heightened awareness of what power they do and do not hold in their lives" (Disturbing 121). Laura's change begins with a bath in which she has repeated visions of nature and is told by Miryam that "[f]or tonight, this room is a crossways of many lines of space and time" (180). As Adrienne E. Gavin has noted, "Laura Chant's ceremonial and quest-like experience of changing over marks clearly the point at which she accepts the supernatural by taking on powers as a witch and signals her entry into womanhood" ("Apparition" 137). Immediately after her bath, a drop of blood is taken from Laura so she is, "[1]ed through her changeover by a drop of blood, suggesting the ongoing rhythms of menstruation" (Lawrence-Pietroni 36). This changeover process is important in terms of the adolescent female body, but also because of its connection to the Carlisle house and surrounding natural land. The dichotomy between the invading army of the city and the pastoral naturalness of the Janua Caeli is being emphasized. As a complicated example of how the masculine and feminine can coexist in balance, Sorry becomes the "Gatekeeper" inside Laura's head, ready to watch over her and help her through the process (Mahy 184-85). The changeover itself becomes a kind 
of dreamscape in which Laura invents her own landscapes, especially the forest around Janua Caeli. Towards the end of her visions, Laura realizes that she has arrived in "the beginning land," which, as Winter explains, is "partly the memory of space we're moving in now...[a]nd partly the memory of all living things. But the forests are all your own, and the bare forest down there stands for the forest that, by some accident, grows green in Miryam, Sorensen and me" (197). This forest ties the supernatural being to the natural world; it is the land before invading civilization took it over. The beginning place is pre-colonization, and it is crucial that this is the place Laura has to find within herself before she can claim the power to save herself and her brother.

When Laura awakens from her dreamscape, she marvels that "[h]er white dress was splashed with bright, clear crimson from waist to hem" (Mahy 199). This once again emphasizes that Laura's maturation "into a witch is also marked by a recognition of her sexual power" and awareness (Waller, Constructing 136). When she looks in the mirror, "by candlelight she saw plainly that she was remade, had brought to life some sleeping part of herself, extending the forest in her head" (200). This quotation is really at the heart of my argument about this novel: Laura's ability to recognize her own power is tied to a domestic space, but also to an earlier spatial representation of New Zealand, before the army, before civilization, before the corruption of the natural world. While Mahy never specifically states that she is referring to the struggles of the Maori people after the arrival of the Europeans, the motif of colonization is tied to the bildungsroman plot. As Laura transitions from 
childhood to adulthood, Mahy implicitly aligns her with the Maori transitioning from before civilization to their current colonized state.

Sorry proves to be a large presence in the book and in Laura's life because he represents an idealized figure of balance and the embodiment of a "third space." However, as a male in a patriarchal society, Sorry is granted different status; he gets to leave home. By the end of the book Sorry tells Laura that he's going away because he's "been chosen as a trainee for the Wildlife Division" (265). As a male adolescent, even one more tied to nature and the feminine than stereotypical male characters, Sorry has to leave home to prove that he's grown up. Although Laura has more school left, she is also relieved to be left at home, so that "[1]ife would settle down again and she would have a little longer to be Kate's daughter and Jacko's sister" (269). Because Laura is a female adolescent, she is too connected with home and the land to be able to leave or even long for the opportunity to leave. She is relieved to be able to stay home and retain her sense of self tied to the domestic sphere. As she is thinking about staying home while Sorry leaves, Laura notes that "[1]ike a holograph, every piece of the world contained the whole of the world if you stood at the right angle to it.... [S]he could see the wall, and somehow, through the wall, a city street and a hurrying figure which she knew to be her own, set in past time to move eternally to Janua Caeli, a name which, Sorry had told her, meant 'the door of heaven"' (277-78). Thus, at the end of the novel, despite her new supernatural powers and maturation, Laura remains at home to take care of her brother. She has been changed by her experiences, and metaphorically empowered by becoming a 
witch, but the cultural expectations for her remain tied to the home and her family. Even though Sorry is able to be both masculine and feminine, a patriarchal society demands that he leave the home to achieve independence; Laura, as the problematic representation of the Other, remains in the home. Mahy's text idealizes Laura's power as connected to the uncorrupted natural world, but just as the Maori people are more complicated than the noble savage, so is Laura's position of power and repression. She inhabits an alternative or "third space," a space of power and powerlessness; it is reductive to say that she is going to be limited by remaining in the domestic sphere (indeed, that she will necessarily stay in her childhood for the rest of her life), but the cultural constructions of femininity tie her to that space, as the Maori are so often tied to the natural land. The Changeover provides a pivotal example for my overall argument; Laura's status in society is more complicated than traditional binaries allow for, while also being more complicated than the binary Mahy sets up between the oppressor and oppressed.

\section{The Catalogue of the Universe}

The Catalogue of the Universe (1985) has similar themes to The Changeover, especially concerning space. The spaces in Catalogue are not supernatural and thus remain tied literally to the physical world; however they do nonetheless retain a power over the female adolescent protagonist. Both Angela and Tycho experience special spaces of power (for Angela, her home at the top of a large hill, for Tycho, his bedroom which connects him to the astronomer is he named for), but their connection to those 
spaces are broken and challenged throughout the novel. My argument is that while Angela is problematically connected to the natural world, like Laura, she is also trying to escape her home and her past which challenges the implied connection between her body and nature. Like the Carlisle family, Angela May and her mother Dido live far out of town, at the top of Dry Creek Road, which itself becomes a force of nature claiming "victims just as if it were a serpent god" (Mahy 5). The home "consisted of two Ministry-of-Works cottages placed side by side making four rooms in all, with a lean-to bathroom tacked on at the end" (39). Angela refuses to let her boyfriend, Robin, anywhere near her home although she says that she is not "ashamed of her funny home, but rather that she loved it and wanted to protect it from being patronized" (40). Despite her explicit claim, Angela is initially ashamed of her home and although she loves the idea of being quirky and old-fashioned, she is not ready to reveal herself and her home in a way that could be emotionally damaging. Similar to an overly self-conscious child, she wishes to show very little of herself to world, not wanting to risk being "patronized" (40). The only person she lets into the home she shares with her mother is her friend Tycho, which tells the reader exactly whom Angela trusts with her secret self and her secret home.

According to Christopher Clausen, the idea of home in children's literature reinforces the significance of physical space in children's literature. In another article, one that explores the effects of space on those with disabilities, Karen P. DePauw mentions Doreen Massey’s definition of space, "not as some absolute independent dimension, but as constructed out of social relations: that what is at issue is not social constructed phenomena in space but both social phenomena and space as constituted out 
of social relations, that the spatial is social relations, "stretched out"' (2). If space is not merely concerned with the physical bodies in the universe but is also considered with social dimensions, then Angela's house becomes even more important to the narrative. Angela's childhood and family are tied up in the home she loves, but at the beginning of the novel she is only willing to share that with one other person. Significantly, that person is not her boyfriend; Angela's love life and her "secret space" life are clearly separated. Tycho has been her friend throughout childhood, a second self, while Tycho as a boyfriend represents a potential adult sexual partner, which scares Angela. As the novel progresses, Angela is no longer able to hold the world at arm's length and both she and Tycho must reexamine their "social relations."

Tycho, or as Angela calls him, "Big Science," challenges these definitions a little. Although he is very fond of his room, Tycho is dedicated to studying the universe. From his small room plastered with quotations from famous philosophers and scientists, Tycho enjoys "struggling with the mystery of a mysterious world," and he chases "elusive clues through fairy-tales, novels, romances, accounts of the behavior of birds, of chromosomes, or quarks" (27-28). Tycho's dreams can be measured only in terms of infinity, but he uses those dreams to wallpaper the walls of his room. He is literally building a universe inside his secret space, and he feels that Angela is the only one with whom he can share his dreams. With Angela, Tycho can share his wildest and most far-flung ideas, but until there is a crisis he cannot open the door to his inner emotional space. Tycho as a male adolescent exists primarily in the "away" part of the home/away/home pattern. He is seeking an escape from emotions and childhood, and so he looks to outer space but safely contained within the walls of his room. For Tycho, outer space is a fairy tale of unlimited 
possibilities, but is also removed from the world of realities. By dreaming about absent philosophers and the outer reaches of the stars, Tycho can safely remain in his secret space of childhood.

Not content to retreat to a childish vision of safety like Tycho, Angela is determined to find out the truth about her family and unsettle her roots. When Angela embarks on a doomed mission to seek out her father, she also comes to a crisis. After experiencing several self-destructive hours, Angela appears back at Tycho's house. The pair is finally able to let go of their constraints, and they share physical contact for the first time. Angela and Tycho are able to reveal their emotions to each other, and their union takes place in Tycho's most intimate space - his room, next to his copy of The Catalogue of the Universe. Trites explains that "for many characters in YA novels, experiencing sexuality marks a rite of passage that helps them define themselves as having left childhood behind" (Disturbing 84). Tycho and Angela thus have created a physical experience — and a memory — together that allows them to define themselves as adults. This sexual experience takes place in Tycho's childhood room, linking their physical relationship to his idealized dream world; the pair are still in the process of experiencing adolescence and not quite ready to let go of their spaces of childhood.

While Angela has been able to face her fears about her father and come to terms with them, Tycho has yet to meet his fears about inadequacy. After several pages of foreshadowing, Tycho and Angela watch a car plunge "right through the narrow border of unfurling bracken...straight through the worst fence in the world and... [fly] off effortlessly into the space beyond" (145). After a lifetime of exclusively thinking about the universe, "Tycho thought he should not consider what he might find in the car" (149). 
The couple work together to save the brothers trapped in the car, and Tycho becomes a fame-worthy "three minute hero" (169). In spite of his anxieties, Tycho is able to be brave, decisive and heroic in a life-threatening situation. Dry Creek Road has been described as ominous and menacing throughout the rest of the novel. Dido tries to warn Angela "the road is very greasy at the present and I just get the feeling it's - it's looking for someone... that it wants blood" (72). The road, metonymically connected to the indigenous land, finally reaps its vengeance in a way that allows Tycho to finally cross over into being an adult. The road itself appears to fight back against the colonization of the cars, tamping it down and throwing off its oppressors, in this case when a car slides off over the edge of the hill because the road suddenly seems to shift. Rather than a symbol of the colonizer, Dry Creek Road becomes the land's method of revenge against the colonizers by fighting against everyone who attempts to climb it. Mahy implies that Dido and Angela are safe because he female body is aligned with the natural sphere; others, however, are not. In this case, instead of traveling to the stars Tycho dreams of, he proves his masculinity and establishes a sense of self away from home. Finally out of his room, Tycho is able to prove himself and start to envision a life in a third space between his womb-like room and unlimited outer space. Angela gives him the emotional space to come to terms with his newly discovered sense of self and, mirroring his earlier actions, waits for him to be ready to visit her secret space.

While Tycho's masculinity is launched away from home, Angela discovers her emotional growth in her home; the domestic sphere she has been hiding (and hiding from). In The Catalogue of the Universe, Angela's process of maturation is explored through spatial relationships in the domestic realm. Angela and her mother share the 
"funny home" at the top of Dry Creek Road, and they are very close. Their house, however, is really two separate houses pushed together; they are a pair living together by mutual consent but not really sharing anything besides a superficial space, a porch that wraps around the outside. At the beginning of the novel the mother and daughter live very different lives. Angela is slightly ashamed of her mother, saying that she is "a bit weird" and that acts "as if she was on loan from another planet, almost like ours but not quite" (40-41). After Angela learns the truth about her father, and Dido is able to be completely honest with her, the mother and daughter draw closer together. Dido even suggests "searching for a builder who'll put a door between" the two separate houses - a door that will abolish the secret spaces of childhood and allow both women to live more honestly and openly with each other. ${ }^{8}$

Mahy's effort to define Angela and Dido's lives in terms of space is most evident at the beginning and ending of the novel. The Catalogue of the Universe begins with Angela waking in the middle of the night. She stumbles to the window and pauses "for a moment to feel the glass eyes, bald ears and unraveling nose of her old teddy" as well as the other objects that have a connection to her childhood and life with her mother. Mahy describes Angela's room drenched in moonlight and uses tactile imagery to establish memories and a history between Angela and Dido. She especially notes the "bowl of potpourri she and her mother, Dido, had made together, [as she] sifted the dried paper

\footnotetext{
${ }^{8}$ There are connections here with Holly Blackford's exploration of The Myth of
} Persephone in Girl's Fantasy Literature, especially in the physical separation of mother and daughter. 
petals" between her fingers (1-2). Even though Angela's special place is separate from her mother's, they are interwoven and the spaces between the two overlap more than they exist independently.

The novel ends with a conversation between Dido and Angela, during which they discuss the past, present, and future. As they bring their dirty plates in from their meal outside, Dido notices the things she has collected along the windowsill. Connecting to Angela's midnight exploration, Dido notes a similar collection of "a little seahorse," "a helical shell curled round and round itself," and "bunches of papery flowers hung upside down, drying at the window" (176). These little items next to the window bring the story and the mother-daughter relationship back full circle. They reaffirm that Dido and Angela will forever be part of each other's shelves, lives, and spaces because of the bond they share. Both women are drawn to nature and beauty, so the dried flowers not only emphasize their common characteristics, but also the passing of time. Angela's journey through the liminal space of adolescence is highlighted in this novel by her relationship to Dry Creek Road. As a liminal space itself, the road is open to many kinds of danger and isolation, which Angela must overcome to be at peace with her home, her mother, and her future.

\section{The Tricksters}

The protagonist of The Tricksters is Harry (Ariadne) Hamilton, an adolescent middle child overshadowed by her beautiful older sister. Harry spends much of the novel hiding in the attic of her family's holiday home, named Carnival's Hide. The attic is Harry's secret space; it is only accessible through a trap door and is where she keeps her "secret" 
passion. She is "writing a story of mysterious and threatening love," and "sometimes behind the written lines there was the space she longed for, and all of it seemed to be hers" (13-14). Harry's secret space is intertwined with her writing; she reverts back to her secret childhood space and seeks to create and control her own world. The story Harry is writing, however, is affected by, "the house [which] had groaned and murmured to her, peopling her dreams with old Edward, the builder of the house, meeting her eye and gesturing grandly at the sea, or with Minerva, his daughter, who had lived and been forgotten, and Teddy his son, who had died and been remembered (12). The house's memories become part of Harry's imagination, which in turn becomes a part of her story. When strange visitors from the past appear, they also become a part of this puzzle. In her article "On the Gothic Beach: A New Zealand Reading of House and Landscape in Margaret Mahy's The Tricksters," Rose Lovell-Smith argues that "Mahy's use of the house, however, while accommodating that classic trope where described details of the house suggest the bodies and being of its main inhabitants, makes a further radical change. I believe it is primarily Harry's body and Harry's sense of being which control, and ultimately wield power over, the symbolic field of Mahy's ... Gothic home" (106). The house begins to display these changes because of Harry's ability to manipulate spaces. Harry creates a world suited to her liking, and she discovers that she has to work to regain control over her creations. As Massey and McDowell have noted, houses and the home have historically been female spaces, tied to the female body and childhood. As Harry is exploring the changes adolescence brings, her relationship to the home starts to change. An author comfortable with ambiguities, Mahy doesn't limit the spaces in the text to just one interpretation. As much as the house is connected to Harry's body and 
her liminal adolescent state, there are others who argue that Mahy uses Carnival's Hide as a metaphor for a larger post-colonial struggle.

Mahy sets up a dichotomy in The Tricksters, written not long after Mahy noted, "the function of art, or one of the functions of art in the community is [...] to discuss through a series of images the nature of reality, and perhaps countries with a colonial history are particularly aware that what seems simple and straightforward is not simple and straightforward at all" (105). The landscape metaphors Mahy constructs in The Tricksters appear simple on the surface - just a house and a beach - but Mahy problematizes this simplicity by aligning the house with the English colonizers, and the beach with the Maori (Lovell-Smith 93). The beach serves as a boundary, separating the Other from the people held within the boundaries of the home; Mahy ties this complicated space of contradictions to the story of an adolescent girl.

When the Hamilton family arrives at their beach home to spend their Christmas holiday, it is a balmy summer in New Zealand. The house has a tragic past, but the Hamiltons joke about a possible ghost and treat the story like a tourist attraction. When "three strange men" appear suddenly on the beach, Harry "knew at once that they had crawled out of a wrong gap in the world" (53). Uncertain if these men are ghosts, wanderers, or perhaps characters from the novel she writes in her secret attic space, Harry remains convinced that she has had a hand in their creation. Carnival's Hide, always a lively house, has begun to change as a result of the three Carnival relatives. Harry's mother Naomi first asks "Who was the idiot who pulled the furniture round?" (69). Next, Robert (a family friend) wants to know if "things look a bit funny [...] someone's shifted the chair about or something" (99). Harry does think things look funny and notices that 
the living room "had indeed altered again. The flow of the furniture was unfamiliar, as if all the chairs had taking one pace back and a half-turn to the right" (100). Soon the three tricksters notice that "the room's changed" and Hadfield, the most vocal trickster asks his brother "Is it you doing that?" Ovid replies that they are all doing it and notes that "we must make an almighty displacement" (107). Once again, Harry hears the house talking to her from the attic while everyone is asleep. On Christmas morning:

...the Hide murmured around her, giving an uneasy greeting, for now it never slept. A missing part had been restored to an old machine, the wheels of memory had begun to turn, and when people were asleep, the house tried to twist itself back to another time. During the night Harry had woken to hear it mutter and groan. Drawers and cupboard doors chattered urgently, cups and saucers down in the kitchen chinked like startled birds. Carnival's Hide was being stretched and strained by a natural power.

When Harry emerges from her attic the next morning, she is stunned by the transformation "as the house tried to move back to what it had been in its very beginning" (145). Harry realizes that the tricksters have not magically changed the house, but that they have caused the house to "reform around a core of memory, recharged by the presence of Ovid, Hadfield and Felix, whatever they might turn out to be" (148). The house, first so connected to Harry and her female body, has been colonized by these mysterious male figures, and in a mocking nod to adolescence, have made literal to the house the changes taking place in her body. 
There is another important space in The Tricksters that is tied up with Harry and her quest to be both an adult and find a sense of control over the world; Harry's experiences in the novel demonstrate Mahy overlapping the Othering of the Maori and the female adolescent. Carnival's Hide is a beach house, and many of the book's most important scenes happen on the beach. Harry first makes a connection with the Carnival brothers on the beach by sticking her arm in the underwater cave and grasping a hand. The brothers first appear to Harry on the beach, which they refer to as "Teddy Carnival's beach" (53). In "Aliens in the Landscape: Maori Space and European Time in Margaret Mahy's Fiction," Sarah Fiona Winters makes a case for the beach and the trickster Carnival brothers as a representations of the Maori. She says that several of Mahy's novels, including The Tricksters, "construct the Pakeha [those living in New Zealand of European descent] as formed at the intersection of Maori space and European time by the uneasy relationship of the landscape and literature" (Winters 408). Lovell-Smith also notes "the beaches are where Maori met Pakeha; where they talked and translated and traded and fought" (93). Thus Carnival's Hide houses the Pakeha (non-Maori people, usually European), and the beach below signifies the original New Zealand, or Maori people. In other words, the beach is a physical embodiment of the "third space" Bhabha describes; a liminal space of interaction and exchange between dichotomies. Mahy does not try to explicitly tell a story about the Maori people, "but she does tell stories about the Pakeha's response to a country and a landscape re-envisioned as specially Maori” (Winters 409).

The role of the beach and ocean as Maori land also connects to the Carnival brothers (the ghosts) as tricksters. The three Carnival brothers (as three parts of the 
original Teddy Carnival) are a lost son, emerged "from (is reborn from) the sea" (LovellSmith 94). Lovell-Smith relates the tale of "Maui, the Polynesian trickster [who] was born incomplete...wrapped in his mother's topknot and thrown into the sea...finally recovered for humanity among the seaweed and wreckage of the tideline" (94). As tricksters, the brothers are "brought back to life by various factors which include, I think, the presence of a relative, a descendant of Teddy's sister Minerva, on the beach—a clear echo of Maui's story" (Lovell-Smith 97). Thus the tricksters are re-born from the water as a native son of New Zealand and the ghost of Carnival's Hide onto the beach, an alternative, almost physical third space. Race, plot, and the supernatural all meet in this space, which is not quite land, not quite sea, but a space in between: of neither and both.

The connection between Mahy's concerns about the Maori people and her female protagonists is made more explicit through a building that stands between the beach and the house. Winters notes that the only appearance in the novel of the word "Maori" is in reference to the whare (412). Jack (Harry's father) explains that "whare" is a "Maori word for house - in this case a little, old hut" (Mahy 19). Later in the novel, the trickster brothers stay in the whare instead of the main house, and Winters claims that "the manner in which the family invites them to do so indicates a devaluing of the structure...the whare is not valued by the Hamiltons as the Carnival's Hide house is" (412). By connecting the Carnival brothers with the whare and thus with the Maori, Mahy is free to explore the relationship between the Maori and the Pakeha without specifically historicizing the story.

The climax of the novel centers on Harry not only discovering the true identity of the tricksters, but also revealing a family secret. When Harry's literary space, so 
intimately connected to her imagination and her secret hiding space looking down on everyone, is discovered by her older sister and read aloud to a mocking audience, Harry retaliates. She reveals that their father, Jack, has had an affair with one of their friends that has resulted in a child. When Harry does this, "Harry is repeating the magic that she used to create Ovid, Felix, and Hadfield through writing daring stories about them. The power of her word makes things happen in the real world" (Waller, "Solid" 81). Winters says by the end of the novel, "Harry has colonized the New Zealand beach with the words of European narrative and is thus free to face her future in the attic rather than the whare. Her pen-line has made for her a fence between European time and Maori space so that she is able to grow into adulthood unthreatened by dissolution" (413). I disagree with part of Winter's analysis; Harry is able to start writing again at the end of the novel, but she has never been in any danger of being banished to the whare. Harry's space in the attic is never threatened because it is so connected to her gendered space in society. Throughout the novel Harry is able to retreat to the attic space, so her ability to return there only is a sign that she is still comfortable with her childhood secret space. Harry may have colonized the beach with her narrative, which continues my argument about the spaces in between the binaries of colonizer/colonized, but her growth from child to adult has been at stake, not her nationality. In the beginning of the novel, Harry is overshadowed by her older, prettier sister but then steps into her own adulthood by asserting her right to control the story. In some ways, Harry's return to her childhood space is not necessarily a defeat; she has been transformed by her experiences and has rescued her home and family from some destructive forces. Unlike the Maori people, Harry is in a completely different state of power and while she has been temporarily 
Othered, she has not been colonized and is in no danger of disappearing. Her experience in adolescence is temporary; that of the Maori people is not. Harry's explorations of the world will continue, after her transformation in this third space of liminality so she remains neither (and both) colonizer and colonized. Her journey has been one to regain her family's holiday home and the safety it represents, and so her form of empowerment through writing also ties her closer to domesticity as well as her goal to become a writer.

\section{The Other Side of Silence}

Broken up into five parts, and then further subdivided into sections labeled "Real Life" and “True Life," Mahy’s The Other Side of Silence (1995) is perhaps one of her strangest novels. The novel's female protagonist is Hero, the daughter of a famous educational theorist and younger sister to Ginevra, a complicated and overly dramatic woman who has gotten revenge on her family by emigrating to Australia (7-10). Hero, seeking to take power and control in the face of her sister's drama, doesn't speak. As she clarifies on the first page of the novel, "[w]ell, I almost never spoke. I had somehow magicked [sic] myself into silence. All the same, even in the heart of my silence, I was still a word child" (3). This means, as we come to find out later in the novel, that Hero loves words and will eventually assert her own voice by writing a novel. At the beginning of her story however, she seeks solace in the forest surrounding her home. Of all Mahy's female protagonists, Hero is the most connected to nature, the most driven to seek out what she believes is her true self, "the true child of the wild woods" (6). From the top of the trees she climbs, Hero spies on Miss Credence, the owner of a house in the middle of the woods, which "looked like the house in a storybook" (4). It is important to 
note that from the beginning, Hero sees Miss Credence as living "in a different space from the marvelous child I became every morning, dancing between sky and garden” (5). When Miss Credence, aping her father's mannerisms and personality, asks Hero to take a picture of her with a dead cat, Hero is horrified. She takes the picture despite her fear while listening to Miss Credence explains that "[t]his whole country was a country of birds once.... [t] hen people brought cats, and cats are not just murders, they're torturers, too. My father kept this garden strictly free of cats, and I maintain his standards" (54). As an allegory for colonization, the dead cat is not subtle, but it does provide an interesting moment of complication in the text. Miss Credence claims to be killing the evil intruders to protect the land, but she is taking on the role of a patriarchal figure to do it, all the while forcing Hero to document her actions. Hero often flies among the trees pretending to be a bird but cannot accept this violent act of rebellion against the colonizing influence. The layers of metaphor, space, gender, and identity become very mixed and muddled in this moment, and it takes Hero until the end of the novel to realize that the birds, the cats, her own body, and Miss Credence are all under threat by the same force.

Although The Other Side of Silence is another of Mahy's texts that does not make specific references to the Maori people, Hero's place of escape and power is clearly tied to nature and the land. She has already fled her home by seeking nature, just as so many of Mahy's other female characters have done. In an intertextual reference, Hero's inner monologue illustrates the home/away/home pattern by noting, "[i]n fairy tales, girls and boys leave their homes in mills or castles or hovels or whatever, and set off into forest where they find wonders.... Or perhaps these lost children become children of the forest, 
and learn its secret roadways" (9). Hero seeks refuge and safety in the forest, but because she is a female adolescent her fate is tied to her home, the place she must ultimately return. That her body is under threat of colonization is not as clear at the beginning of the novel but is explicit by the end.

Writing about voice and agency in children's literature, Trites emphasizes, "too often throughout history, female voices have been silenced" (Waking 47). Although Hero has chosen her silence as a measure of declaring agency, she is still left with only two options: to not be heard (a state of little power) or to be silent (a way of claiming power). This is a perfect example of the type of silence Spivak writes about in her work on the subaltern. That Hero chooses a method of silences means that, as Spivak suggests, her silence can be measured; silence becomes a choice, an act of agency, a substance that can be measured rather than an absence or a lack of something. Even the language used to describe this act goes from passive to active: Hero is not silenced in the text, she is silent. When her mother remarks on her silence, Hero finds her "looking at me as if my quietness were something mysterious, something to be really proud of. It could that was the exact moment in which I began to proud of quietness, too" (69). Wilkie-Stibbs identifies Hero's "elected silence as a perverse kind of power and control, a verbal anorexia with which she mutilates not her body but her speech in an act of personal rebellion" (65). While WilkieStibbs goes to examine the intertextual contexts of the novel (and there are many), the point I want to emphasize is that Hero is disempowered in many ways. She is overshadowed in her family by parents and siblings who are flamboyant; she is a female adolescent, and she is a child connected to nature. All of these factors lead to her choosing silence within the family and the world; this is her own decision, and a method of claiming agency by not 
speaking. Hero, concerned about her place in society and her developing identity, only feels like herself when she is silent and when she is close to the natural world because silence and nature are her refuge from a disempowering and patriarchal society.

The issues of silencing present in The Other Side of Silence recur in both feminist and children's literature, as Trites notes when the references Sandra Gilbert and Susan Gubar's The Madwoman in the Attic. Trites notes that "aphasia, or speechlessness" is "one of the defining literary metaphors of nineteenth-century feminine repression" (Waking 47). Jane Eyre, featuring the madwoman of the title of Gilbert and Gubar's text, serves as a kind of template for Mahy's novel, which also features (several) madwomen, one of whom is even housed in the attic. ${ }^{9}$ While still being silent, and perhaps because of her silence, Hero gets a job working for Miss Credence, owner of the house in the middle of the woods. Miss Credence, a figure who proves to be increasingly strange, is a woman and so Hero fails to observe that Miss Credence is a threat to her for much of the novel. She is initially drawn to Hero because the girl doesn't talk; Hero is "puzzled by her sudden, odd, eager expression, the expression of someone coming upon something that nobody else wants, and seeing a special way of using it” (Mahy 19). Miss Credence emphasizes her need for privacy, which Hero identifies with and immediately understands (20-21). Seeking "paths of my own," Hero keeps returning to Miss Credence, despite later coming to think of her as a villain (49-50). As she makes one last

${ }^{9}$ The Other Side of Silence also makes a reference to "the secret garden" (14) another novel often compared to Charlotte Brontë's Jane Eyre, most notably in Ann Thwaite's Waiting for the Party: The Life of Frances Hodgson Burnett, 1847-1924. 
journey to the house, Hero looks back and realizes that she has changed and that "I didn't know it then, but it was the last time the trees would ever work their spell on me. I would never be that wild child again" (80). Through the process of growing up, Hero becomes separated from her former space of empowerment and is forced back into the home. The event that forces Hero to grow up in a twisted version of the events in Jane Eyre, only this time the madwoman is locked in an attic by a woman so twisted by circumstances and the patriarchy that she emulates the worst parts of the latter. Hero notices that "Miss Credence ... had copied her father's triumphant pose, but somehow her head had had the same twisted tilt to it as the head of the stag" (82). Corrupted by her father, Miss Credence becomes both the victim and oppressor who reenacts the damages inflicted on her own psyche. Hero figures out "that Miss Credence was not only keeping the house going ... she was keeping something of her father alive, as well” (89). Miss Credence has been tied to the home by her father's wishes, and it is not until Hero follows the voices inside her urging her to explore the rest of the house that the reader finds out the real reason behind Miss Credence's personality changes and eccentricities. As Hero climbs into the (literally) forbidden tower, she "looked across the room into blue eyes, and knew immediately that I was looking into the eyes of the true Jorinda," Miss Credence's illegitimate daughter (141). Here Hero has found an actual madwoman in the attic in the most unhomely of all unhomely spaces. The intertexual references crash into each other in this moment, and layers upon layers of pain and memory overlap, forming an endless echo of trauma. Hero sees herself in the girl chained to the bed "like a terrible kind of twin," and she knows "that Rinda had been held like this [chained to the bed] for so long she had taken on the pattern of her chaining" (143). Most important for my postcolonial 
argument, the entire room is painted covered with a single color: white. Everything in the room - even the bars on the windows, the glass in the windows, the walls and the floor-is painted white so that "[a]11 she could see was whiteness...a complete blankness" (142). Miss Credence locks Hero in with her daughter, so both girls are trapped in the attic, just like Bertha Mason. The aggressively white walls can be interpreted in a variety of ways: as the ultimate statement of colonial whiteness, as a means of enforcing their blankness and silence, as an erasing of their stories, and even as the opposite of everything Hero loves about nature.

Trapped with the silent Jorinda, Hero is also trapped within a patriarchal narrative and both her identity and physical body are at threat. Once Miss Credence admits that her father blamed her for getting pregnant, "as if it was my fault, as if I'd corrupted Clem, his friend," she keeps reminding herself of the same old narrative which she "had said over and over again, night after night, wandering through the rooms of Squintum's House, telling herself her own story" until she "turned herself into her father's ghost by wearing his cloak and smoking the same kind of cigarettes that he had smoked (146-47). Wilkie-Stibbs emphasizes "the manifestation of the double aspect of language and madness. Silent Hero who ratifies her own identity by choosing not to speak sits in opposition to mad Miss Credence, a woman who defines herself through meaningless utterances and whose subscription to patriarchal language has paradoxically silenced her intellectual genius" (67). Miss Credence has been so overwhelmed by her father's patriarchal views that her physical body becomes a site of occupation. She has been colonized and, in turn, seeks to colonize those who challenge her power. That all of these events take place in the Credence home is important as well; the home has not been 
changed since Miss Credence's father died and she has been playing his role in the home since then. The space itself has been a symbol of patriarchal rule, which Miss Credence is first punished by, then turns into a punishment for her daughter. Jorinda is locked up so that no one will ever know her secret, and Hero is imprisoned so that she cannot speak the truth. Once again, a patriarchal figure is isolating and attempting to contain that which does not fit into civilization; by locking the two girls in the tower, Miss Credence is separating them from natural spaces and trying to control that which challenges her understanding of the world. Hero comes to understand in the tower that she and Jorinda are both silent, "but with a huge difference in our silences. I had chosen mine. Rinda had never been able to choose" (148). Hero thus recognizes her own power and agency and finally uses her voice to try to escape. Hero has to become a hero and save herself and Jorinda from their imprisonment, “I didn't hesitate. I spoke out as if I had never, ever been silent" (157). The silence comes full circle when Hero and Jorinda finally escape; Miss Credence tries to shoot herself with her father's gun but an ambulance "took her to hospital where they worked hard and saved her life. Not that she could do anything with what they saved. She just lay there in the hospital for the rest of her days, staring up at a white ceiling. She lay there in utter silence" (168). Trapped by the sins of her father, Miss Credence is punished by a mockery of the life she has made her daughter lead. While Hero is the protagonist of the story, all three women suffer punishment, silence, entrapment, and trauma. The method of control Hero turned to as a child to seek power has been visited on an oppressor; in both circumstances, silence is a reaction to something, and varies in effectiveness to resist someone else's control. While Hero finds power in silence, in resisting her family, Jorinda's silence, although not of her own 
choosing, further entraps her. Finally, silence is used as a punishment for Miss Credence, as a complete absence of power. Apparently, she will never speak again. This is another example of the complicated nature of the binary Mahy has constructed; while both Hero and Jorinda are oppressed, they are oppressed in vastly different ways even though they are both adolescent females. Hero's connection to the natural land, the color white, and the echoes of the past are all signs that the traumas of colonization are being tied to the adolescent female experience through multiple generations, but even without explicitly stating the effects of colonization, Mahy is omitted in the vast differences between different types of oppression.

\section{Kaitangata Twitch}

Published in 2005, Kaitangata Twitch is the most recent of Mahy's work included in this chapter. Meredith, the female protagonist of the novel, is consistently tied to the land (as are all of Mahy's other female protagonists), but she is also much more explicitly linked to the Maori people. This connection between Meredith and the land is significant to my argument because this novel is the most explicit of Mahy's problematic binaries. Meredith is magically connected to the island and the threats of colonization, but her experience and status is society is very different from the colonized people Mahy aligns her with. The very first lines of the novel show that the land is speaking directly to Meredith in her dreams. She is awoken by the Kaitangata Island calling out: "'Need!' whispered the voice. 'Need! Need!'” (3). Meredith, already a sleepwalker, is troubled by nightly visions of the island but doesn't know why. Very quickly she realizes that Marriott Carswell, a name that "suggested power and money" was putting up signs "out 
on Kaitangata too, labeling and dividing up her private world" (6). Meredith feels that the island is her special space of escape and is horrified to learn that Marriot Carswell, a developer who has a nasty history with Meredith's family, has purchased the small island to build houses on. This is the most literal act of colonization in all of Mahy's novels: the island is an unsullied, natural space with a Maori name under threat of capitalized colonialism. Meredith is very attached to her secret space in the natural world, and so the island begins talking to her, seeking help. This differs from The Other Side of Silence, in which silence as a form of resistance is emphasized; in this novel, Mahy gives a supernatural voice to a land and female body in need of power. In both cases however, the female adolescent body is tied to the natural world and the threat of colonization when they are actually experiencing different kinds of oppressor/oppression relationships far more complicated than just those at threat of colonization versus those who colonize.

As with some of the other novels covered in this chapter, Mahy uses the land as a supernatural metaphor made literal. For example, the island's voice calls out to Meredith until she finds herself standing on the island. The moment she steps onto the island, "something seized her ankle. Looking down, she saw the fingers of a pink rubber glove gripping her leg" (7). This glove, evidence of people's litter traveling through the water to contaminate nature, holds Meredith in place:

... as if that seemingly empty glove was really a hand, powered by a secret muscle running the whole length of the beach. She screamed. Sand seemed to fall away around her, as if the island were opening a mouth. (Flick! "Feed!” demanded that voice.) "Help me! Help me!" she called.... Now she was chest-deep, then chin-deep, in sand, sticks and shells, 
struggling, writhing, as she felt other hands tightening on her, tugging her down, down and further down.... Struggle as she might, she was being drawn into the very stuff of the island. (7)

This dreamed moment makes it clear that Meredith both has a special connection to the island because she is the only one who can hear it, but also that that the connection is a danger to her. Under threat, the island in turn threatens Meredith. The troubling similarity among the female characters of Mahy's novels is brought into light in Kaitangata Twitch; by suffering similar threats, both the land and Meredith are brought into similar dangers. Meredith's body is in danger of being absorbed into the island unless she can rescue it from being colonized by the white man. As Winters observes, "Meredith's relationship with the island blends Maori space and language with European time and literature" (416). Her female adolescent body is in danger of being literally absorbed by the Maori land unless she can muster enough agency to rescue the island and herself. In this case, the native land is fighting back and forces Meredith to become its voice against the white man threatening to colonize the land. My concern here is that Meredith, an adolescent female, is the only one to have this connection to the island, and is threatened by the connection. The island is speaking to her because Mahy has constructed Meredith as a similar being, also threatened by patriarchal forces.

Kaitangata Twitch also features an explicit connection to the Maori people. Meredith has several visits from her great-uncle, Lee Kaa. It is significant that all of these visits take place on the beach, the space between the civilized town and the wild island (19). At a meeting later in the novel, Lee tells Meredith and her sister, “...I remember a lot of things you don't. I remember how we old-timers had to get used to 
you lot" (52). This seems mysterious at the time, but the mysteries keeps building; at another beach meeting, Lee says, "See, I've fought my own wars...won a few, lost a few" (67). This is when Meredith realizes that Lee can hear the island as well and so knows what is happening to her in her dreams (69). The beach location of these meetings, similar to the beach in The Tricksters, becomes a liminal space between the native island and the house: what Bhabha calls a "third space." Both of these characters then become connected to the island: Meredith because she is a female adolescent already attached to her natural private space and Lee because he is Maori. When Meredith asks him about the voice she is hearing, he admits, "[t]hey say it's a Maori thing.... But Pakeha, Maori, I don’t think it matters too much” (75). Now the alliance between Kaitangata and Meredith becomes clear; not only is she connected to the island by her gender, the liminal state of her body, but she is also connected by her ancestry as well. While Mahy never makes this explicit in the text, Meredith does seem to have Maori ancestry, which makes her the only female protagonist in Mahy's novels who actually belongs to the population so often alluded to. However, Meredith's circumstances are very different from the traditional Maori people (as represented by her Great-Uncle); I would argue that Mahy's implicit connection between the Maori and her female adolescent protagonists just becomes explicit in this novel. Meredith's story and family are much closer to the white middle class circumstances of Mahy's other protagonists; thus her connection with the land continues the problematic binary set up in her other novels. Although this connection between the female body and nature has been seen as powerful in many of Mahy's other novels, the implied threat is made clear here: if the island is not saved, it will literally consume Meredith's body. After she has another 
vision of being swallowed by the island, Meredith's father tells her " $[\mathrm{k}] a i$ is the Maori word for food, of course, and tangata means people.' 'Food-people! People-food!' said Meredith aloud. 'Oh yes. Lee said the Ngai Tahu had killed people there—and eaten them" (101). By the end of the novel Meredith is able to rescue herself and the island from the clutches of the rich white businessman. When Marriot tries to claim the island by shouting, "And this island is mine - mine, d'ye hear?" Meredith responds with silence; a powerful and subversive tool in the face of colonization (152). Within that silence she finds that the island "had chosen her and was speaking through her," but silence itself is not a powerful enough force to fight against Marriot (152). Instead, the island literally consumes Marriott by performing the eponymous Kaitangata twitch. A cave appears, and Marriot tries to seize "Kaitangata itself...the weight of it all—grass, gorse, headlands, tide lines, and even that rock fist. It was the island itself he was pulling down around him ... Kaitangata swallowed him" (159). Meredith knows that "Lee Kaa was right. Kaitangata had been threatened. It had wakened; it had stolen her dreams. And perhaps, in some mysterious way, it had used the power of her dreams to save itself" (172). Meredith is in physical danger because the island has been calling to her, and because of her love of the land. Her connection to the Maori people and land lead her to be under threat of colonization, both by the island and the white male colonizer. This illustrates the dangers of being so connected to the land and of not just being colonized but of watching others be colonized. That these female characters, the colonized land, and indigenous people are threatened by patriarchal powers is apparent in Mahy's novels, but the dangers they face are not always the same. 


\section{Conclusion}

Over the course of her long career, Margaret Mahy has progressed to include more specific references to colonization and the Maori, although it remains problematic for her to equate the female adolescent body with the indigenous people and land, especially when they are not subject to the same kinds of disempowerment or subversion. While the female adolescent characters in the texts are able to claim agency and a voice by the end of their stories, Mahy does not allow the Maori to have a story or space of their own. Beginning with The Changeover, Mahy's binary between oppressor and oppressed is set out but never really complicated or broken down. Laura's story allows for her to find agency in becoming a witch but doesn't explicitly acknowledge the difference between Laura's situation and the land she connects so deeply to. In The Catalogue of the Universe, Dido and her daughter Angela thrive on the top of the hill protected by a dangerous road but ultimately are in very different circumstances than the land which lies under their home. The Tricksters begins to deal more directly with the turbulent history of New Zealand's colonization but still does not allow the Maori people their voices. Harry is sympathetic to the Others appearing on the beach, but ultimately her vacation will end and she will return to civilization. She struggles to find a voice within her family, but her circumstances are very different from those who are silenced on the beach. The Other Side of Silence shows the dangers of patriarchal oppression but elides the difference in power between choosing silence and being silenced. Finally, Kaitangata Twitch specifically recognizes the Maori in the figure of Great-Uncle Lee but most problematically ties the female adolescent body to the threat of colonization, which reinforces the binary between oppressor and oppressed Mahy perpetuates in her novels. 
In Mahy's adolescent literature, gendered spaces are used as a metaphor for the limited space for female adolescents in society, but the implications of race in Mahy's texts are too often intertwined. As Mohanty writes in the introduction to Third World Women:

Firstly, resistance clearly accompanies all forms of domination. However, it is not always identifiable through organized movements; resistance inheres in the very gaps, fissures, and silences of hegemonic narratives. Resistance is encoded in the practices of remembering, and of writing. Agency is thus figured in the minute, day-to-day practices and struggles of third world women. Coherence of politics and action comes from a sociality which itself perhaps needs to be rethought. The very practice of remembering against the grain of "public" or hegemonic history, or locating the silences and the struggle to assert knowledge which is outside the parameters of the dominant, suggests a rethinking of sociality itself. $(38-39)$

Mahy's characters work through these types of resistance but they are not third world women, which is itself an act of silencing. 
CHAPTER III

“MY MAP! I DON'T EVEN KNOW WHERE WE ARE. HOW COULD I FORGET

THE MAP?": DOMESTIC LABOR, ABJECTION, AND SUBVERSION

IN CYNTHIA VOIGT'S ADOLESCENT LITERATURE

Introduction

In Chapter Two, I argued that Mahy's novels are problematic in terms of the intersections among gender, race, geographical space, and concepts of agency. In this chapter, I argue that in two of Cynthia Voigt's adolescent literature series, the female adolescent body is connected to abject fluids and domestic labor. Herein, I will analyze this pattern in Voigt's Kingdom Series and in those books of the Tillerman Cycle in which Dicey is still an adolescent female. Unlike many of Mahy's characters, Voigt's characters in these novels subvert traditional stereotypes through the domestic labor they perform. This becomes most clear in an examination of the relationship between domestic labor and abject bodily fluids. Abject fluids-like menstrual fluid or amniotic waters or breast milk — have traditionally been associated with women's bodies.

Moreover, in many cultures women have been either linked to the home or metaphorically tied to it because dealing with the aftermath of these abject fluids has traditionally been designated to be women's work. In most cultures, it is rare that men have been tasked with dealing with the effluvia of menstrual fluids; and in many western 
cultures, dealing with the contents of chamber pots (or the like) has been relegated to women, and in many cases, to male servants of a lower caste than the men they serve. Sometimes, some of Voigt's characters are trapped in the home by domestic work, including performing the work of disposing of or cleaning up abject fluids, but in significant passages, they are able to subvert that entrapment and claim domestic agency through the specific kinds of labor they perform. This agency is complicated by the continually gendered nature of the worlds in these texts. Although the female protagonist is usually able to assert her own voice in some way, the agency she achieves is not always permanent. ${ }^{10}$

I work to identify how issues of domestic labor and abjection can be seen in Voigt's work, especially with The Kingdom series and with the female protagonist of the Tillerman Cycle, Dicey Tillerman, while she is still an adolescent and how these characters are able to achieve agency through subversion. ${ }^{11}$ While The Kingdom series is set in an imaginary fantasyland and the Tillerman Cycle takes place in twentieth-century

${ }^{10}$ It is to be noted, for example, that for much of The Homecoming, Dicey and her siblings exist in a liminal space that precludes domesticity; similarly, Dicey's mother has specifically elided domestic labor by fleeing the family home.

${ }^{11}$ For my purposes in this chapter, I will only be discussing Dicey's journey as an adolescent, including Homecoming and Dicey's Song. The other books in the Tillerman Cycle feature other protagonists in the family, and while the last book in the Cycle, Seventeen Against the Dealer, returns to Dicey as the protagonist, she is not dealing with issues of identity formation, but instead she is facing economic issues of adulthood 
New England, the female characters face parallel issues, including struggles with power issues and their desire to subvert dominant cultural systems defined by males. The physical spaces in the text (usually homes) are domesticated by female characters seeking agency. That these female characters are able to subvert their entrapment may be why scholars such as Roberta Seelinger Trites refer to Voigt's books as "a feminist children's novel...in which the main character is empowered regardless of gender" (Waking 4). However, I argue that the form of empowerment in these novels is very much tied to gender: they seek empowerment specifically through gendered labor and feminist ethics. By using the stereotypically feminine responsibilities of cooking, cleaning, and caring for children to their advantage, each protagonist becomes empowered because of her gender. When Dicey runs away from the house to work on her boat, or, when Birle works on an herbal book as part of her domestic duties, or when Elske safely delivers a baby, they are using labor typically associated with femininity as a form of power. One character, Gwyn, even cross-dresses to become a local folk hero, challenging her culture's traditional gender stereotypes. Thus, through a gendered version of labor, these female protagonists assert their worth to highlight both the limitations of stereotypical gender roles and the struggle female protagonists in adolescent literature often seem to have as they try to assert new kinds of identities.

Literary critics have typically focused on the ways in which female characters are limited by gender and spaces in children's and adolescent literature. As I noted in

(building a business especially). The novel's focus is thus outside of my specific argument here. 
Chapter One, Lissa Paul mentions the association of women and children in connection to the home in her article, "Enigma Variations: What Feminist Theory Knows About Children's Literature." She notes, “[w]omen in literature are disproportionately shown as physically trapped in rooms, attics, in their father's houses, or in their husband's" (188). Child protagonists in children's literature, "though they have to deal with the same (often overlapping) forms of physical, economic and linguistic entrapments that women do, they are not yet closed in by the rules of adulthood"; thus, they are able to escape the space of entrapment - the home (Paul 188). Female adolescents occupy a slightly different place in between both of the these positions; they are no longer trapped as children but some are on their way to being trapped as adult women in the responsibilities and restrictions of the home. Paul references Annis Pratt's influential text Archetypal Patterns in Women's Fiction, which also discusses the tenuous position of adolescent protagonists. Pratt devotes a chapter in her examination of the patterns in women's fiction to "The Novel of Development," including the bildungsroman structure common to adolescent literature. She notes, “many eighteenth- and nineteenth-century women's novels that dealt with feminine conduct become a highly popular way of inculcating the norms of womanhood into young readers, mixing fiction and prescription in a manner that fascinated them while pleasing their parents" (Pratt 13). Although Pratt cites novels from the eighteenth and nineteenth centuries, this pattern still exists a full century later in many of Voigt's adolescent novels. While the Tillerman Cycle and the Kingdom series were published from the 1980s to the late 1990s, the female characters often work to please either their parents and/or conventional expectations the implied reader might have. The novels emphasize the home as a place of responsibility and restriction while the world 
outside is depicted as both dangerous and free. The struggle between these two spacesand the responsibilities inherently tied to their gender-are a part of most of literature that portray female adolescents. Nevertheless, I argue that some female adolescent characters face different circumstances and stereotypes than others because they occupy both the liminal space of adolescence as well as a tenuous position in patriarchal societies. In the Tillerman series, Dicey also struggles with patriarchal norms or with values that seek to maintain men in positions of power, because she feels expected to care for her family, but she also longs for freedom. For a brief time she defies both genderbased and age-based norms to become the head of her family, leading her siblings from New England to Maryland in search of a home with their grandmother. Significantly, when they find a home there, Dicey still is most comfortable outside of the domestic sphere. These issues that I highlight in the Tillerman Cycle continue throughout the Kingdom series, reinforcing the author's depiction of female adolescents struggling to find a balance between agency, identity, and domestic space.

\section{Domestic Labor}

Historian Tim Meldrum defines domestic labor in his text Domestic Service and Gender. He examines the roles of gender, domestic service, and power and quotes S. Wallman who writes, "work is 'about' control—physical and psychological, social, and symbolic," but Meldrum then adds that is also “"about' power in Foucault's sense that it generates discourses of authority and subordination. This perspective assists us in understanding a major concern of the Marxist-feminist 'domestic labour' debate, the power relations that created sexual divisions of labour" (135). These gender 
constructions, whether of space or labor (on in this case, both), are inextricably entwined with issues of power. Meldrum does resist the monolithic view of historical change and notes that the "latest research tends to undermine" this kind of thinking (135). However, looking specifically at the "English metropolis," he writes that "continuities in patriarchal gender relations and therefore in sharp sexual divisions of labour were more striking than structural shifts in society or economy" (136). So while many men (especially those employed as servants) have performed domestic labor in many cultures, the societal norm in most Euro-American middle- and working-class cultures has been for domestic labor to fall primarily under the woman's sphere of influence. In fact, as Coats points out, if male participation in domestic labor is limited to the servant class, then women, who traditionally perform that labor whether they are servants or not, become the equivalent of servants, no matter their class. Moreover, as I have pointed out in Chapter One, within the scope of Tuan and Bachelard's very gendered theories, if women's bodies are traditionally associated with the home, all of the labor performed in the home thus becomes tied to a woman's body. It should be noted that the premise that domesticity is tied to a woman's body is therefore not true for everyone, but is a construction of most Western societies and "embedded in contexts of gendered social relations" (Meldrum 137).

Moreover, in her book Domesticity and Dirt, Phyllis Palmer connects the workings of the home to women by specifically looking at dirt in the house: "[T]he work carried on in the home is ... identified with dirt and decay, which threaten to taint the character of the woman who does it" (138). According to Palmer, women's connections to the home and domestic labor result from their associations with common dust and dirt, 
with fertility and sexuality, and with birth (especially the process of labor). All of the fluids connected to a woman's body eventually became a correlation to the "[h]ousework [which] took care of those things that society found most unappealing, embarrassing, and tainted" (Palmer 146). The concepts of the female and femininity are tied to the home because of the connection between childbirth/maternity and abject fluids; thus the domestic labor performed by women is also associated with these fluids. Women are often regarded as a symbol of home not only because their bodies give life, but also because they are responsible for the domestic labors and abject fluids associated with menstruation, sexuality, child-rearing, and general house-cleaning (including cleaning up or disposing of human waste).

Abjection, Abject Fluids, and Adolescence

First published in France in 1980, Julia Kristeva's Powers of Horror: An Essay on Abjection lays the groundwork for theories about abjection. Drawing on work done by Jacques Lacan, Kristeva notes that abjection is "neither subject nor object" (1). She goes on to describe different kinds of abjection, starting with the "improper/unclean," which includes, "[1]oathing an item of food, a piece of filth, waste or dung. The spasms and vomiting that protect me. The repugnance, the retching that thrusts me to the side and turns me away from defilement, sewage, and muck.... Food loathing is perhaps the most elementary and most archaic form of abjection" (2). In the process of abjecting this food, Kristeva notes that:

... since the food is not an "other" for "me," who am only in their desire, I expel myself, I spit myself out, I abject myself myself. That detail, 
perhaps an insignificant one, but one that they ferret out, emphasize, evaluate, that trifle turns me inside out, guts sprawling; it is thus that they see that "I" am in the process of becoming an other at the expense of my own death. During that course in which "I" become, I give birth to myself amid the violence of sobs, of vomit. Mute protest of the symptom, shattering violence of a convulsion that, to be sure, is inscribed in a symbolic system, but in which, without either wanting or being able to become integrated in order to answer to it, it reacts, it abreacts. It abjects.

This section is dense with mentions of abjected fluids and the connections between those fluids and the body. Significantly, the fluids Kristeva describes as abject often have to do with the body: she references spoiled milk, sobs, vomit, blood and pus, sweat, and a decaying human body (1-3). These fluids are part of the body that we can never separate from. Just as Kristeva describes the longing to expel the soured milk, she also feels the longing to expel a part of herself. As she notes later, the subject "finds that the impossible constitutes its very being, that it is none other than abject" (5). This important because so much of the abject deals with trying to expel that which is not acceptable or that which we want to pretend doesn't exist. The very act of trying to push something away means that it is often a part of us. That which is abject "simultaneously beseeches and pulverizes the subject," because abject fluids are of the body and yet the body is repelled by its own fluids (5). Kristeva connects this process of attraction and abjection to "maternal authority" which is "the trustee of that mapping of the self"s clean and proper body" (72). More examples of the types of abject fluids she mentions in 
connection with the body are "excremental and menstrual. Neither tears nor sperm, for instance, although they belong to the border of the body, have a polluting value" (71). She goes on to explain that these two types of defilement "stem from the maternal and/or feminine, of which the maternal is the real support" (71). This "fear of the archaic mother turns out to be essentially fear of her generative power" or the ability to give birth (77). That these abjected fluids are connected in the Western conscious with the maternal body underlies many of our assumptions about what is clean and unclean and what should be abjected from society. While Tuan and Bachelard align the home with a mother's body (implying that both women and the home contain and protect life), abjected fluids are the unacknowledged glue that binds this problematic association. The maternal body and the home are covered in these fluids which have been abjected by society, thus the continued devaluing and abjection of the spaces associated with women. Karen Coats' work in Looking Glasses and Neverland: Lacan, Desire, and Subjectivity in Children's Literature breaks down Kristeva's argument that abjection is tied to the Mother, and the Mother's body. I quote at length because of the importance of Coats' argument to my focus in this chapter:

Caregivers pay more attention to certain parts and processes than to others, and they code those parts and processes as dirty and untouchable or as pretty and acceptable, according to the patterns of their culture. In Western culture, for instance, products of elimination (waste, vomit, menstrual blood) are accompanied by disgust, and breasts generate images of eroticism rather than of sustenance. Since a child's primary caregiver is usually a mother, the mother, who through giving birth and feeding is 
already intimately connected with the body, is also, Kristeva emphasized, the first arbiter of culture convention and law, the first embodiment of the other that the child has to contend with. Her body literally enabled the baby's corporeal existence in the first place. (139-40)

As Coats explains, during this process in Western society, the child is taught to abject certain fluids as part of the process of learning what is good and acceptable to society and what is not. This becomes a gendered issue, because those fluids are connected with the mother's body and so the child must abject him/herself away from the source of these fluids - a source which society abhors. This occurs during the course of growing up, so "[f]or the baby to become a subject, the mother must become an object...the child must expel as abject those things that violate the purity and stability of his subjective boundaries - among other things, feces and the maternal breast" (140). Thus the mother's body and the feminine spaces it inhabits become the symbols of that which a child must reject to become an adult or to claim agency in society. To become acculturated in Western society is to abhor abject fluids, and so those associated with the fluids are similarly abjected. This process has a significant impact on Western culture's assumptions about the stage of adolescence in which a child becomes an adult by learning what to abject from society. The process of abjection is also tied to gender, because many of the things associated with stereotypical femininity are so closely tied to motherhood and domesticity both of which are full (almost literally) of abjected fluids. The ramifications of abjection and abject fluids appear in many novels, but most especially for my purposes in adolescent literature when an adolescent is going through the process of figuring out what should be abjected (Coats 141). 
Coats expands on her point about abject fluids to look at the process of abjection, the "expulsion that enables the subject to set up clear boundaries and establish a stable identity" (140). It is not an accident that Coats links the process of abjection to the process of growing up and exploring identity; her chapter on abjection deals with adolescent literature, so "just as we abject the unclean and improper evidences of the body's physicality in order to constitute a clean and proper body, so in the social realm we abject the unclean and the improper, again often on the basis of physicality in order to constitute the boundaries community and nature," which Coats argues is what happens in adolescent literature (141). She writes: "the psychoanalytic component of abjection ... underwrites the social structures of power and domination so prevalent in the genre" (138). This is not a reification of binaries, but instead an intense negotiation: "[s]triving for social recognition but not wanting to stand out, locating with specificity their status as sexual subjects and objects, seeking the terms of individuation within affiliative groupings, adolescents are intensely involved in the construction of social boundaries and in reaffirming their distance from the socially abject" (Coats 142-43). Adolescence is a time for girls to learn both what is socially acceptable and socially unacceptable, which is also related to the fictional events that female adolescent protagonists tend to experience in adolescent fiction. Through the process of abjecting the Other, adolescents also are dealing with gendered norms and cultural stereotypes. To challenge or subvert patriarchal strictures, female adolescent protagonists deal with their relationship to the home, the labor they perform in the home, and cultural expectations for their future. 
In Practice: Domestic Labor and Abject Fluids in Cynthia Voigt's Series

In Voigt's novels, the female protagonists chafe against the domestic labor they must perform according to their gender. While this theme continues in varying form throughout her novels, I argue that Voigt's work demonstrates how female characters are often tied to abject fluids through their labor; even as the characters rebel against stereotypical jobs, that very rebellion reifies the divisions of gendered spaces. When female characters and femininity are tied to the home because of the connection between childbirth/maternity and abject fluids, the domestic labor performed by women is also associated with these fluids. While much has been written many other aspects of Voigt's novels, no one has specifically addressed the link between abjected fluids, domestic labor, and the female protagonists in Voigt's novels. In that way, I am challenging the ongoing conversation because I argue that while the spaces in the text reinforce gender stereotypes, the female protagonists are able to use domestic labor to subvert the patriarchal order in which they live. My argument is that there is a variety of complex spaces between the binaries of powerful/not powerful here-and that these female adolescents are working within the system to achieve the only kind of independence their culture will afford them.

\section{The Kingdom Series}

When thinking about how different types of labor are gendered, I note that types of labor almost always correspond to the spaces in which they are performed. In other words, the cultural construction of gender categorizes work performed in the home as women's work while work performed outside of the home belongs to the masculine 
world; this is true of the fantasy world of The Kingdom, but also as a reflection of the culture Voigt inhabits. Cynthia Voigt's The Kingdom series is a quartet of loosely related fantasy novels for adolescents. The novels are set in a fantastic land, the Kingdom, which is sometimes a harsh reality and sometimes a misty dreamland of fair treatment and ideal living conditions. The novels are complicated by many factors including fictional geography, gender, narration, focalizer, and social class. All four novels in the series adhere to the bildungsroman format common in most adolescent literature, and feminist ideologies are also frequently present.

In The Kingdom series, Cynthia Voigt fights back against gendered binaries like women naturally being drawn to the home or being most suited to serving others by both depicting her characters participating in and subverting stereotypes by her female adolescents' relationships with the home. Each novel features one or more of these female adolescents who performs domestic labor but also destabilizes her culture's gender binaries and changes the patriarchal restriction implied in a female space. That Voigt's female protagonists subvert their gendered labor is a double-edged sword though; as powerful females they are fighting for their agency and ability to control spaces. This is a significant type of agency, although it is admittedly a limited kind of agency because they can only hope to control certain kinds of spaces, as I will demonstrate below.

\section{Jackaroo}

The first novel in The Kingdom series, Jackaroo, deals with this type of gendered space in a country inn. Gwyn, the Innkeeper's Daughter (an alternative name for her throughout the novel), is unhappy with the few choices she has in life. She has three 
choices, one of which she rules out immediately, "because service in a Lord's house was unimaginable" (2). Gwyn has to make a decision soon, between saying "yes to some man, or let Da announce her intention never to marry" (2). In either case she will be dependent on a man; either her husband or her father and eventually her brother. At the inn, a commercial extension of the home, Gwyn is frustrated by her the tasks the women must perform, as "Gwyn's mother worked furiously...keeping Gwyn hard at it, washing sheets and hanging them by the first to dry, baking bread and the apple pastry of which she was so proud" (67). Here both Gwyn and her mother are responsible for the domestic chores of both the household and their business. Gwyn's only options in life are to marry or work for her family; she knows it is "a hard thing to be a woman" and "there was nothing else for her" but to marry (2). Gwyn is already frustrated by her lot in life and being limited by her gender; on being informed that she will have a masculine escort on her errands one day, she immediately imagines "herself fighting off men, while Burl cowered behind her. She heard the thud of the heavy staff as it knocked against a man's skull and smiled at the vision of Burl's face lit with timid gratitude as the attackers ran off over the snow" (48). This reversal of gendered norms heavily foreshadows the ways in which Gwyn will subvert the limitations of her gendered labor.

In Jackaroo, Gwyn becomes stuck in a small cabin with a young member of the upper class (the Lordling) during a sudden snowstorm. The Lordling teaches her to read, a skill forbidden to "the people" because they "need all their time for labors" (114). This begins a pattern of literacy in the series and forms one of the strongest connections between the four books. The ability to read and write is prized in this world, and it usually belongs only to the ruling class. However, Gwyn's education is only a part of the 
changes she undergoes in the cabin. The cabin is a prototype of a female, enclosed domestic space; its former inhabitant was an old woman in charge of some sheep. While Gwyn is trapped there she wants to avoid boredom, so she starts to clean. Many pages of this section are devoted to Gwyn's cleaning of the cabin and the rest of her domestic duties (which she performs not just as a female for a male but also as a servant to a lord). She uses this occupation as a rebellion against the Lordling, reminding herself: "[h]er job was the keep him fed and to serve his needs, as he required of her. No more. It gave Gwyn pleasure to hear his restlessness behind her as she worked placidly at her chore" (126). Continuing to work at cleaning out a cabinet, "Gwyn took a bowl of warmed water and a cloth" (126). This water is part of her domestic labor cleaning the cabin, and it symbolically becomes abjected fluid as it holds the dirt and grime of her cleaning. She notices "her hand met a wall, much deeper back than that of the other cupboard" (126). Reaching inside she finds a blanket covering something hard; when she pulls the cloth aside, "[s]he felt smooth leather, which ended on top of something silky, and then hard metal, long and sharp, too long for a razor-a sword?" (127). Eventually, Gwyn realizes that the sword and the material she finds is a Jackaroo uniform, the costume worn by the local folk hero, who is part Robin Hood, part trickster. Originally dismissed as "[j]ust an old story," Jackaroo is a mythological figure who is the only one "bold enough, brave enough, to stand for the poor when the Lords get greedy, or when times are bad" (19-20). The first action of the mysterious Jackaroo in the text is to "slit the bag of the greedy Bailiff, so that every coin the Bailiff put into it slipped out as he rode away...Jackaroo emptied the Bailiff's bag, returning to each man just that which he had unjustly paid, no more nor less" (27). Although Gwyn never meets this figure, she has grown up with the 
stories of a hero helping the poor and stories of his transgressions. Gwyn's gendered and classed labor is what gives her the opportunity to escape her culture's stereotypes.

When putting on the Jackaroo uniform for the first time, Gwyn hides her feminine self and claims a new masculine identity. The costume includes a mask that covers her hair, a classic symbol of both femininity and fertility, and her face, thus obscuring both her gender and her identity. Although the costume was made for a man, "[h]er breasts and the curve of her hips were all concealed under the straight tunic" (195). Throughout the rest of the novel, Gwyn experiments with this new masculine heroic identity and tries to fight the injustices she sees in her society. It is important to note that Gwyn discovers the uniform while performing domestic labor. She is still tied to the home during this scene and works to remove the dirt and keep herself busy. She does her job and does it well, but seeks another form of agency, another way to change the world she knows into the one she thinks it can be. Gwyn's experiences in the first novel of the series are perhaps the most difficult to categorize because her experiences subverting gender norms are clothed in masculinity; she finds the costume by performing domestic labor, but then seeks agency as a masculine figure — not in a role that is historically feminine within her culture. Towards the end of the novel, Gwyn actively challenges stereotypes by wearing and fighting in the Jackaroo costume. She realizes that she has been hurt by looking at her left leg and noticing the "blood [which] streamed out from the split leather. It ran down over the shoe, thick and red" (324). In a twist on traditional patriarchal stories, Gwyn has fought to save her male love interest. She becomes distracted as she is trying to escape by the grapes in the vineyard, thinking about her wish to "put a grape in her mouth and feel it burst there with sweet liquid," connecting her thoughts to other kinds of 
bodily pleasures, perhaps even connoting orgasm and jouissance (325). Gwyn is in shock during this scene, bleeding freely from the leg, but she is also feeling connected to the literal fruits of the land (grapes) while she simultaneously recognizes the pleasures her body can experience. Finally, as she emerges close to the house, she "came to stop against the goat pen and pulled herself up on again onto her knees" to "vomit"—an abject image if ever there was one (326). Whether the bursting grape connotes orgasm or an explosion of blood, the imagery invokes abjected fluid, either way.

Crucially, Gwyn experiences all of these abject fluids outside of the home, and she also experiences them during actions she has taken to save the man she loves, Burl. Blood, vomit, and the "sweet" juice of grapes are all connected and associated with the labor of the home, but Gwyn's experiences subvert the dominant discourse by locating those fluids outside the home on her cross-dressing adventure. That these abject fluids are located outside of the home is representative of her potential ability to escape the domestic sphere and the labor associated with it, even if only temporarily. At the end of the novel Gwyn has traveled from place (her father's inn) to space (her adventures as Jackaroo) to a new space (an inn to run with her new husband). Although Gwyn conforms to the female trajectory of growth by traveling from her childhood home to starting her own home as a mature woman, her ability to cross-dress as a folk hero and work to change society subverts this archetype. Looking at her new home, Gwyn thinks about "how much there was to do and how the work would suit her, and how the holding with its deep hearthstone would suit her, house, fields, forest, and river; and the man, too; the man especially" (358). Here Gwyn's domestic labor is emphasized but also her choice; she knows that the future is one that will suit her, and that the work will fulfill her 
goals. The spaces she mentions especially are not limited to just the home; the hearthstone is important but the house, fields, forest, and river are a part of her new life as well. In conclusion, the female adolescent protagonist's agency in Jackaroo is defined by her choices; she chooses to have adventures as a folk hero, but she also chooses to return home and start her own family. While she may be subjected to gender stereotypes with her decision to marry, she has also asserted her own agency using domestic labor to meet her goals.

\section{On Fortune's Wheel}

Another of Voigt's female protagonists deals with the struggle between longing to escape domestic drudgery and becoming reconciled to the gender norms of her society. Birle of On Fortune's Wheel, the second book in the Kingdom series, hates working in her father's inn. (She, like Gwyn is sometimes known as the Innkeeper's Daughter.) When she follows a thief to her family's canoe and gets swept along in the river with him, Birle "recalled the morning chores" she was missing but decides, "[l]et someone else do them, for once, and scold her later. Aye, and they did that anyway. Her brothers and $\mathrm{Da}$, and Nan [her stepmother] drove her through the days, scolding. Why should she want to hurry back to that?" (13). Of the many female characters in The Kingdom series, Birle and Gwyn are the most alike; they both begin as innkeeper's daughters chafing under the restrictions of the gender and domestic duties. Both Gwyn and Birle live in the "cradle of the house" as Bachelard would phrase it, but long to escape to Tuan's "space" outside the home; Birle knows her "life at the Inn did not suit her. She wore it somebody else's cast-off boots, which pinched and chafed" (27). Here Birle is chafing against not 
just gendered norms but her sense that she lacks identity outside of her domestic duties; the work she is doing is not just traditionally women's work, but also work she has not chosen, and she feels initially that she is known more as someone else's possession than as herself.

Voigt continues this theme of domestic labor and subversion in On Fortune's Wheel. As previously discussed, Birle runs away from her father's inn to follow Orien, thinking he is a thief but discovering him to be the disguised heir to the Earldom. In her search for agency and freedom, Birle travels to a southern land and is sold into slavery, purchased by a man named Corbel. Obviously, as a slave, Birle is without any choices and has less agency than at her father's inn. Instead of being a domestic servant, Birle is a domestic slave and has a long list of tasks to do. When she first arrives at the home of Joaquim to be his slave, she opens a trunk to find women's clothing she can wear. Within the trunk, "tucked in a corner, [is] a package wrapped around in a piece of old linen. The cloths, Birle saw, [were] for a woman's monthly time- - but these were softer than any she had ever before used, as soft as moss" (197). These cloths are in keeping with Voigt's recognition of the realities of life (she also includes scenes of going to the bathroom in almost all of the novels in this series), but they also firmly connect Birle to her new place as a servant of the home and of abject fluids. As foreshadowing, the clothes are softer than anything Birle has used before, but they are a reminder that her role in this home is to be a woman who serves her master, however soft the job may be; but nonetheless, she must serve a master: Joaquim or her own body and/or society in which she lives. In this culture, Birle's choices are limited between which kind of master to serve, so to have any kind of voice she must work within the system. 
Similar to the scenes of cleaning and labor in Mag's cabin in Jackaroo, Voigt writes whole pages about the domestic labor Birle performs as a slave. The house she is to take care of "had accumulated years of dirt," and Birle also "made the meals," "scrubbed clothing clean," "sewed," and worked in "the laboratory [which] too required cleaning" (208). She works everyday until her "back ached," and "[y]et she welcomed the work. The heavier her duties, the more tired she would be. The more tired she was, the more easily sleep came to her" $(225,227)$. Again, Birle is performing domestic labor for a man in a place where she feels trapped. Associated with the dirt and bodily fluids she cleans every day, Birle fulfills the stereotyped feminine labor role set out for her. However, Birle's ability to read and write helps her to subvert her status as a powerless female slave.

Joaquim, the man who purchases Birle at the slave market, is secretly creating a book in which he plans to:

...write down all I know, the appearance and use of each herb, [so] that [the] books will make life easier for all men, in all times. That book will be better than a child, to keep my name alive long after I have gone from the world... A greater goodness. I'll illustrate the appearance--the young plant, the plant in flower, the plant in full leaf, its roots. I'll write out how to prepare and how to apply it. (221)

The book Joaquim is working on is a form of subversion itself because he is supposed to be studying alchemy to discover the secret of gold; this is why Corbel has purchased Birle and continues to fund Joaquim's research. Birle's skill at literacy, usually only allowed to the ruling class, uniquely suits her to expand the type of labor she performs as 
a slave. As soon as Joaquim discovers Birle can read and write he involves her "with the works of the Herbal, as he named it ... Birle drew the herbs, so that any who saw her pictures could identify the plants. She memorized all Joaquim told her of an herb's goodnesses, and at night wrote it all down in carefully shaped letter” (237). Birle quickly takes on the project; she spends her days in the usual domestic labor required of her, and then spends her evenings working to create a book of healing. This is another example of a female adolescent protagonist not only finding agency through domestic labor but also subverting society's expectations of her as a female and as a slave. She is intelligent and is able to not only perform domestic labor dealing with many abject fluids, but also to read and write to help her master in a different way. That she is working on a book of healing, still intimately tied with the body and abjected fluids, is another way she asserts her femininity as powerful. Although Joaquim is creating the book, Birle is claiming agency by helping in unexpected ways and claiming the body for more than just domestic labor. Birle is powerless as a slave but she finds a way to satisfy herself through multiple kinds of labor.

At the end of the novel Birle is reunited with her lover, but wonders if she should take him back into her life. She asks, "What of her own life? What of her own work?" Then Birle realizes that because of her journey and experiences, "[s]he had gone beyond a place where the world could tell her must" (399). Affirming the agency she has built up over the course of the novel, Birle decides:

... she would grow the herbs and prepare the medicines, she would be herself and his wife too, and the mother to Lyss...[s] he would be each of these...[a]nd maybe too, she would undertake the Philosopher's task: to 
write an Herbal. Not so that her name would live, but so that the knowledge would live. That would be work worth doing. Her life was in her own hands. (399-400)

This passage exemplifies clearly the point I am trying to make: Birle in no way abandons or gives up the domestic labor she is tied to, but she also has something else, something that is not typical or gendered. As Gwyn has with the Jackaroo costume, Birle finds a vocation in addition to the gendered responsibilities she has now as a woman and mother. Voigt consistently begins to align her characters with stereotypically gendered expectations then subverts that expectation with the character's own sense of purpose, with an experience, and with a different type of work.

Unlike most of the other female characters in the series, Birle comes to term with her childhood home and makes peace with her domestic duties. After a long series of adventures, Birle returns to the inn of her childhood. As an adult now, she has completed the home/away/home pattern and is pregnant. Birle sets up her own home near the inn and works with her stepmother to put the house in order. The two women "worked-to carry the mattress outside, to wash floors, cupboards and walls, to unpack the household supplies and clothing" while discussing Birle's plans for the future, including planting a garden (376-77). Birle has fulfilled the home/away/home pattern and also transitioned from place (home) to space (freedom, although adventure might be a better word for Birle's experiences) and place (home) again. It is not a coincidence that Birle returns home pregnant, ready to start her life as a parent. She is now the adult, ready to raise a child of her own and be a part of the domestic world she previously shunned. Birle's experiences help to further prove my point that there is a continuum between completely 
escaping the domestic space and being trapped within it by a patriarchal system. Because Birle is able to choose her new home, and the person she shares it with, she is able to achieve a measure of agency, although she does not completely overthrow the patriarchal constraints of her particular fictional culture. Most important to my argument: like Gwyn, Birle's choice is what matters; she remains within a domestic space but is no longer a slave or working for someone else.

\section{The Wings of a Falcon}

Unlike the first two books in The Kingdom series, the third book breaks the pattern of involving a plot about only a single female protagonist. I argue that even without a single female protagonist, this novel follows the pattern set out in the rest of the series of agency achieved through subversion. Moreover, the narrative also does not open with a stifling domestic scene. The Wings of a Falcon is the only novel in the series without a female protagonist; instead, the novel follows the journeys of Oriel and Griff. The two adolescents escape from a small island of boys, run by the cruel and sadistic Damall. Much of the narrative focuses on the pair's journey from being boys to men but there are female characters within the story. As Trites notes in Waking Sleeping Beauty:

[a]lthough The Wings of the Falcon focuses on the friendship between two males, by the time Beryl enters the text in the final third of the narrative, Voigt's feminist agenda is clear. The boys have already encountered a transvestite woman who passes as a man to gain power in her community, and Beryl teaches them to treat women as equals... And most important of all: the gender of Beryl's child (who will be the next ruler of the 
Kingdom) is never revealed. The text's silence on this issue implies that gender is immaterial. (147)

While the transvestite innkeeper is certainly an example of a subversion in that fictional culture's notions about domestic labor, I would like to focus on Beryl, who is the continuation of the adolescent female characters set up with Gwyn and Birle from the previous books. Beryl, first seen "turning the heavy pages of a book," lives on a homestead alone (281). She takes care of the house, heals Griff and Oriel, and is a puppeteer. The book she is reading is the book of healing written by Birle, and Beryl has inherited her gift of both literacy and healing. Like the women who have gone before her, Beryl has demonstrated that she can perform domestic labor well (taking care of the house alone), but when she leaves the home she also other options. She continues to follow the gendered stereotype set out for female space and labor, but she subverts the stereotypes through knowledge and vocational skills. Beryl does seem to be improving on the female adolescents who have come before her (in the series at least) because she is able to stand up for herself in a way that Gwyn and Birle do not. At the very end of the novel, she challenges the men of the ruling council who insist she must speak, "'Why must I?' Beryl asked. 'I will speak when I have something to say. What is this must? What I must have is the right to decide when I have something to say, and when I do not, that is my must"” (466). I want to emphasize here that Beryl, Birle, and Gwyn all challenge the gendered space and labors not just of the fantasy setting in the novels, but also of any traditional, patriarchal society. Significantly, the gender issues in the text are not immaterial, as Trites claims, but instead are of the utmost importance to the 
characters and the implied reader. These adolescent females have as much to say to the people in the text as to the reader.

\section{Elske}

Elske, the last book in the series, begins with the most graphic and bloody episode in the entire series. Raised in the land to the north, Elske lives in a severely misogynistic society; when female children are born (conceived through rape, always), they are put out in the woods for the wolves to feed on (7). Elske's grandmother is in charge of this duty but tells Elske stories of her homeland, the Kingdom. Elske is chosen as the Death Maiden: she who must be raped by the Volkking's captains, murdered, then "follow the Volkking into Death's great halls and serve him there" (3-4). Instead, Elske's grandmother (Tamara) schemes to take her place. In planning for the switch, Tamara and Elske hope, "that the two sharpened knives the old woman had strapped to her own feet, invisible in the night, would lie undisturbed in the ashes of the Death House, as unrecognizable as the grey hair Tamara had stained dark with the blood of the slain babes" (11). Clearly here Voigt is both emphasizing the ritualized disempowerment of women in this society as well as the extreme violence against them. However, Voigt specifically highlights the abject blood of the thrown away (and therefore abjected) female children (who are part of Tamara's domestic responsibility) and whose blood is used to disguise the ultimate symbol of femininity (Tamara's hair). Although Palmer probably did not have this particular scene in mind when writing about the fluids associated with domesticity, it is certainly an example of the symbol she is referring to. 
Just as women in this novel are abjected from all society, so are the female children and the blood they are covered with.

After Elske's escape she eventually becomes the personal servant of Beriel, exiled and deposed queen of the Kingdom. Elske is in charge of Beriel's domestic life as her servant, and one of her first duties is to remove the chamber pot and empty it into the privy (107). It is unusual in adolescent literature for an author to include such specific information about bathroom habits. While this happens throughout the series, it is particularly evident here that bodily fluids are connected to Elske's status as a domestic servant. When Elske discovers that Beriel has been repeatedly raped by her cousins and is now pregnant, the first concern the women have is hiding the pregnancy. Beriel asks Elske, "Do you know nothing of how servants gossip? If I never once have my woman's bleedings, do you think they won't notice, those washerwomen? And haven't you sent in your bloody clothes, and haven't they been washed and folded and returned to you?" (144). Once again though, bodily issues usually glossed over in adolescent literature are brought to light here, and connected with domestic labor. Beriel is conscious of both how her body works and how female servants (note that she mentions "washerwomen" particularly) discuss their labor and the aristocrats they labor for. Of course the menstrual cycle is a part of a woman's fertility and Beriel's lack of cycle indicates that she is pregnant. Although Beriel is an aristocrat who does not perform domestic labor, she is aware of how it is done and that her responsibility is to direct and manage the household staff. This is a clear example of domestic labor tied to bodily fluids; the girls are also locked into a suite because of Beriel's propensity to run away, thus completing 
the connections I've theorized above. Domestic labor and female space (here, an entrapment in the terms Lissa Paul employs) are connected through a woman's body. While this text is the most violent, graphic, and bloody (and maybe because of these factors) of The Kingdom novels, it also provides the strongest critique of gendered space and labor. Having escaped the cruel lands of the north, Elske works as a servant for two different families. Elske continues the tradition of literacy and also is multilingual, a skill which she uses throughout the novel. When she works as a serving girl at an inn, the owner of the inn (Var Jerrol) teaches her to use her skills for him. When Elske is serving (another form of domestic labor), "[t]hese merchants were cautious when Var Jerrol sat with them but if he was called away they would speak unguardedly in Souther. Afterwards, Var called Elske into his chamber and asked her to recite what the merchants had said when they were alone and, as they thought, unheard" (74). Elske realizes that she has been brought to the house for a purpose and "that information was her true work for his [Var Jerrol's] house" (75). Elske is a very good servant and know how to perform her domestic labor, but she also has another vocation for which she is uniquely gifted. Voigt again sets up a female in a restrictive domestic space, then subverts that restriction by providing another type of work. This new vocation (spying, creating a book of healing, etc) is always related to the domestic labor, but challenges stereotypical gender restrictions and allows the female characters to assert their independence. She remains in the domestic sphere but performs as a spy and uses her abilities intellectually to work for a figure of patriarchy, rather than performing only physical labor.

The last book of the series also gives Voigt the opportunity to create the most 
powerful and independent adolescent female in the series. Although the novel is focalized through Elske, Beriel becomes the agent of change in the novel. As the future queen of the Kingdom, Beriel is both manipulated and assaulted because of her gender but also freed from traditional gender norms and empowered to rule because of her gender. For example, when discussing her unwanted pregnancy with Elske, Bereil describes her need for revenge against, "[m]y brother, who led them to me, my cousins, who raped me, again and again, until they had filled my belly_-" (118). When Elske asks Beriel why her brother wished to ruin her, Beriel replies, "[b]ecause I am the Queen that will be. And my brother-he is the King that wishes to be, although I am the firstborn, and thus named royal heir, by law. But I am also the first female to claim my inheritance through this law" (119). Beriel is the result of three other books leading to this point; she is going to be the first female ruler of the kingdom despite the child she will be forced to bear. Throughout the rest of the novel Elske is impressed by Beriel's ability to lead, order, and plan in preparation to take back her throne. Beriel is neither limited by her femininity, but she is not masculine either. Interestingly, Beriel is one of the only female characters in the series to perform no traditional domestic labor; however, she is part of the extreme upper-class. All of the other characters have been working class or middle class. Unlike Elske, Beriel does not achieve agency by subverting domestic labor, but instead embodies the series' most powerful female figure. Class issues are an important consideration here because without her royal status Beriel would probably have to perform domestic labor, but her steadfast refusal to let her brother take over her kingdom becomes her form of rebellion. Born to be a ruler, Beriel is a woman and a ruler, not one or the other. On their journey to restore Beriel to the 
throne, "Elske did not need to be told when they had to cross the borders into the Kingdom. Beriel shone with it, like a sun, the Queen in her Kingdom. It was as if each breath she drew increased her pleasure, breathing that air" (225). Unlike the other female characters in the series, Beriel's female space of empowerment is not a home; her space is the Kingdom itself. Having born a child, Beriel's story begins with the end of other stories. It is only after the birth, the ultimate fulfillment of maternal labor, that Beriel can return to her Kingdom to rule. When she leads soldiers into battle, Beriel says "[s]ideseated is a weak position from which to wield a sword. So I fought among my soldiers, beside my own men" (293). A true warrior queen, Beriel is the best hope Voigt can provide for a female adolescent unlimited by gender norms. She has been raped, is a mother (although she gives away her child), yet returns triumphant to her kingdom and there performs all kinds of labor in defense and support of her land. Unlike Gwyn in the first book of the series, though, Beriel's ability to fight with her men and assume control of her kingdom is not a kind of crossdressing, or putting on a costume of masculinity; Beriel does not hide her gender. Just being a biological mother is important, but Beriel's ability to attract followers, treating others with kindness and respect, all the while making the best decisions for her kingdom, demonstrates that she is balancing the needs of others with her own needs (an important element I will cover more extensively in Chapter Four). Although Beriel remains very feminine in her manners and dress, and is as vulnerable to the dangers of the world as anyone else, she is also a commanding queen whose connection to the land is demonstrated through her insistence on fighting alongside her soldiers. She is a woman, in control of her body, her land, and her people and does not need to hide beneath a costume. 
It is fitting that the Kingdom series ends with Elske and Beriel's stories. These two female characters represent the best of Voigt's models of feminine agency. They are both strongly feminine and also powerful in a world dominated by patriarchal constructs. There is a trajectory over the course of the series of female protagonists asserting themselves and rebelling through domestic labor, but Beriel especially is the strongest example of a character refusing to be limited by her gender. Not only do the female characters over the course of the series rebel against the constraints of their home, the very definition of home is expanded in this fantasy universe to include an entire country by the end of the series. Beriel's home is the land she cares for and rules over, which establishes for the first time in Voigt's canon that the home does not have to be a space of limitation.

\section{The Tillerman Cycle}

While I argue that the Kingdom series progresses along a continuum, featuring the most powerful female character in the last book of the series, Cynthia Voigt's other books feature different kinds of characters from the Kingdom series. While the Kingdom series featured a variety of female protagonists with varying levels of agency and domestic labor responsibilities, the Tillerman Cycle focuses on the Tillerman family over the course of many years. Although I argue that the Kingdom series features progressively more powerful female characters, in the Tillerman saga Dicey continuously struggles to define herself as a individual and a member of a family. Part of the reason for this difference might be the change in genres; the Kingdom series is a fantasy with more room to challenge traditional norms, while the Tillerman Cycle is a series of 
realistic fiction. Dicey Tillerman, of the Tillerman Cycle, consistently struggles to adhere to gender norms, and at times she vacillates between being the patriarchal head of the family and being a scared young girl who doesn't want to be responsible for anyone else. The Tillerman Cycle, starting with Homecoming published in 1981, is a very different genre than Voigt's the Kingdom series as it is fairly contemporaneous with the time of publication. Victor Watson writes that the "series works by resisting or undermining fictional norms and challenging readers' expectations" (86). Dicey, a featured protagonist in several of the books, is the female character with the most significant relationship to domestic labor. Her journey from child to adult is rife with trouble and difficult responsibilities, so her experiences through the Cycle will be my focus here. I argue that Dicey is able to subvert the dominant patriarchal discourse by choosing forms of domestic labor which ultimately allow her to rebel against gender norms. Through her journey to find a home for her family and her boat building, Dicey's connection to abject fluids does not limit her actions.

\section{Homecoming}

As with the female characters of the Kingdom series, Dicey Tillerman as an adolescent female has to subvert traditional gendered expectations through domestic labor. Just like the female adolescent characters discussed above, Dicey is often connected with abject fluids but finds a space of empowerment where she is not limited to just being one kind of person. Dicey eventually settles into a space in which she can be both powerful and connected to her family, but first she has to find that space for herself. The first book in the series starts the story of the Tillerman siblings; they are 
abandoned by their mentally disturbed mother in the parking lot of a mall in New England. Dicey, the eldest, takes charge of her three younger siblings and leads them on a quest for a home. Suzanne Elizabeth Reid points out, "Dicey's first home was in Provincetown on the beach, nestled among the dunes, but...it was a home without roots" (35). When their mother abandons them in the mall parking lot it is not the first sign of unease and unhappiness in their family. During their quest, Dicey takes care of her siblings while dreaming of a place where they could be safe. The first night they spend on their own in the mall parking lot, Dicey wakes up from a dream "about a big white house that faced the ocean. Aunt Cilla's house" (36). This dream of a home, or a safe space, embodies Tuan's description of place not only as "a pause in movement" but also a place to be cared for, and to be dependent on a "caring adult [which] is for him a source of nurture and a haven of stability" (138). Dicey takes on the responsibility of her siblings because she loves them, but she is searching for a parent, someone else to take on the role of being independent and maintaining a place for Dicey. This struggle between independence and dependence is one of the central conflicts of adolescence, a liminal time (and space) to swing from being dependent and independent, or sometimes both at the same time. As the children prepare "to set out" to continue their journey, they are "reluctant to leave their sanctuary," a spot that feels relatively safe and like a temporary home (Voigt 36). Significantly, it not just a place the children are looking for, but a person; they desire someone to be dependent on so that they can be cared for and thus achieve that sense of place and home. Phyllis Palmer defines housework as "the quintessential 'woman's' work—regularly identified with women of all groups and social classes. No matter what other jobs women may have, they are expected, in addition, to 
see that houses are cleaned, meals are cooked, and children are cared for" (xi). This classification of woman's work is not meant to align with an essentialist binary, but instead reflects the cultural construction of gendered labor. As the eldest, Dicey automatically assumes responsibility for her siblings, even as she dreams of finding someone else to accept this labor; she accepts that she is now responsible for the woman's work her mother has abandoned.

Similar to The Kingdom series, the Tillerman Cycle doesn't neglect the realities of life, even while the children are traveling. The children stop frequently "to go to the bathroom" and frequently worry about money, water, food, safe places to sleep, and maintaining the illusion that an adult is traveling with them so they don't attract too much attention (51). Significantly, when the children are attempting to recover from their travels one day, Dicey "gives her orders for the morning. James and Sammy were to fish, while she and Maybeth washed out the clothes they had been wearing" (60). Even though Dicey has a great deal of power in this situation, she does not try to challenge gendered norms in the division of labor; the boys go fishing for food, while the girls do the laundry. Age-based norms also accrue to this foursome: the two older siblings are care-takers for the two younger ones. These characterizations reflect the gendered norms associated with domestic labor. As Robyn Longhurst writes:

Women are often understood to be in possession of insecure (leaking, seeping) bodily boundaries; in particular they may leak menstrual blood, and milk from their breasts. It is commonly thought that such bodies are not to be trusted in the public spaces of Rational Man. Men, on the other hand, are often understood to have secure (anonymous) bodily 
boundaries - bodies that are "in control." In some ways these conceptual codings of bodies have little to do with the actual flesh and blood of women and men but in constructing relationships to space they are a powerful force. (2)

As Longhurst explains, these fluids are often tied to the way women's bodies are constructed as a space of fluids, therefore the environment they inhabit becomes also tied to the those fluids. As Dicey demonstrates in this passage, laundry is a task for herself and her sister, an unconscious adherence to the bodily fluids in the laundry and her own body. The fish the boys catch are also connected to a fluid environment, but the water itself is not an abject fluid; they are performing a domestic task but one more in line with the gender stereotypes of the culture in which they live.

The gendered issues in the text can also be seen in the children's missing mother. The story is told from the point of view of the children so the exact problems with their mother (Liza) and her reasons for abandoning them are unclear. Later in the text, when they children think they've found a possible home with their Cousin Eunice, they finally hear news about their mother. After hearing the news from a police officer, Dicey tells her younger siblings, “'Momma's gone crazy,' Dicey reported in a flat voice, 'and they don't think she'll ever get better. She's in a mental hospital. She was in Boston'” (204). Although they do not know the reason (or diagnosis) the children point out "Momma had four kids and no job. Our father walked out on her" (205). This statement is not proof of a specific illness, but Voigt is leading the reader to believe that the responsibility of raising four children on her own may have driven Liza to madness; there are many official diagnoses that could help explain her situation (including untreated post-partum 
depression), but Voigt does not focus on that. In a way, the only thing that matters to the children is her absence; without a mother they are homeless and must search out a new domestic space. This foundation of the first novel (without their mother, the children are homeless) reinforces the patriarchal binary Tuan and Bachelard set up of the home being the mother's body. That their first home has been unstable and dependent on a mentally ill mother (and absent father) shows that the domestic sphere is not a simple binary of there or not there; they must seek out a place where they can grow and work together, something which they do not find at Cousin Eunice's house. Moreover, it is interesting to note both that the father-as well as the mother-has abandoned these children, and that all of the potential subsequent homes for the Tillerman children are the homes of female relatives; in this way Voigt is also breaking down binaries by demonstrating that not all females are suited to caring for children because these female relatives do not turn out to be viable homes, and in fact the final home they settle in is not a perfect domestic space but instead a compromise of balanced needs.

On the road again, Dicey leads her siblings in search of a new home, different from her original dream of the seaside white house. They leave Eunice's to journey to their grandmother's house, hoping that she will be able to provide them a place to call home. While on the bus, Dicey falls asleep and goes through a transformation:

It was as if, during that nap, Dicey has traveled days away from Cousin Eunice's house in Bridgeport. That time now felt like a distant memory, something so far behind them that they didn't have to concern themselves with it, not anymore... She thought about Momma, and it seemed to her that she almost understood why all of this had happened to them, to the 
Tillermans, all this sadness and running away. She thought about the long walk from Peewauket to New Haven, and the grandfather who had tipped them two dollars and Stewart with his blue-gray eyes; then her mind switched to the journey ahead of them, as if the future were a road stretching ahead, twisting and turning. What did it matter where they were going, as long as they were going? (218)

Unable to find the right domestic space for her family, Dicey once again takes up the mantel of domestic responsibility and leads her siblings back out on the road. Taking a mental review of the past, present, and future, Dicey feels empathy for the weight of responsibility her mother felt. Dorothy G. Clark argues, "Homecoming presents a critique of patriarchal family models and of the possibility of mothering in a patriarchal world" (191). The series and the circumstances the Tillerman children are forced into represents a failure of patriarchal family models, which would have had a father present and in control of the family. When the patriarchal system fails, as it does in Homecoming, the Tillermans' world falls apart and Dicey has to assume the responsibility for her family. Travel in this novel is Dicey's domestic labor and she recognizes that her journey won't be over until she can find the right home for her siblings because their parents have failed their traditional responsibilities. And, as the passage above demonstrates, for awhile Dicey is just happy to be on the road, traveling in hope of a better future and away from all of the limitations and sadness left in their old home.

Dicey's feelings throughout Homecoming tend to be ambivalent; while she wants to find a home for her siblings and someone to take the responsibility for their welfare (or 
at least their material comfort and physical safety), she also enjoys parts of the journey and the role she has assumed as powerful head of the family. Close to the end of her long journey, Dicey is not only responsible for her siblings but is also responsible for evaluating their new potential home to see if it is the safe space Dewan describes, an extension of the family she hopes to keep together. Instead of assuming she has found safety, when Dicey and her siblings finally arrive in the area near their grandmother's house, Dicey's fears about the future increase. She becomes plagued with doubts about their reception at their grandmother's home and what kind of life might be in store for them there. After their long journey and disappointments along the way, Dicey is worried about handing over the responsibility and care for her family to a virtual stranger. Before even venturing to the house for the first time, Dicey decides that she should go by herself to check out the situation. When her brother Will tries to argue with her, Dicey explains her fears about the dangers of finding a home:

“...but inside of houses—-no matter what they look like from the outsideeven that one"- the car sped past a tall brick house, surrounded by old elm trees and seeming serene and wise, as if it had stood there for so many years that nothing could surprise or hurt it—“you can't tell what's inside. You can't tell what might happen. How do you know how to trust when you meet people? How can I tell about this grandmother?" (306)

Finding a place and a person who can understand their family, keep the children together, and not hide devastating secrets is Dicey's goal but she knows that people aren't always what they seem. Already disappointed by many family members (her mother, father, and cousin), Dicey is not willing to risk home, a place "charged with great emotional 
significance as the focus of all that is most important and influential in their [children's] lives" (Dewan 3). The home is "indeed paramount in the lives of all children" and "more than anything else, home is an extension of family" (Dewan 4). Dicey knows that a real home is important for her siblings but that many homes hide secrets and scars behind their closed doors. As she starts to approach the house, Dicey asks herself "How would she know if their grandmother's house was safe for them? What questions did you ask a person to find out if you could like one another? If she could be trusted?" (Voigt 312). Most significantly, when Dicey actually finds her grandmother's house, she also sees a space for herself. Outside of the farmhouse stood a "lopsided barn. It had once been red, but the paint had weathered, faded and peeled, until it looked pink as a bad sunburn. The tin roof was rusted in large patches" (329). This space becomes very important to Dicey over the course of the series, partly as a space of her own, and partly as a representation of the new kind of labor she is going to take on now that her siblings have found a place to call home. This journey leads the children to a new stage in life and allows Dicey to inhabit the contradiction of being both a female in charge of a family and an adolescent leading the ultimate rebellion in searching for the right place to live. Unlike the other examples of domestic labor in Voigt's book, Dicey's does not take place in the home; instead her labor is to find a home. In other words, unlike the immobile maternal place Tuan tries to define, Dicey's domestic labor to find a home, especially one not connected with the maternal body (her grandmother is anything but traditionally maternal and future books in the series reflect on her struggles to raise her own children), challenges the gendered norms of spaces. 


\section{Dicey's Song}

Suzanne Elizabeth Reid describes the boat Dicey finds in her grandmother's barn as "her prize if they can stay, her prize for holding on until the family finds a home...For now, working on the boat in the barn, scraping off the old paint and sanding it, offers Dicey respite from the constraints of taking care of her family. She escapes to the barn and begins to relax enough to learn about reaching out" (37). The barn housing the boat becomes one of the most important spaces in the Tillerman Cycle because it is Dicey's space of empowerment. She has found a home for her siblings so the form of domestic labor driving her across New England has ceased; now she can stop taking the place of their mother and discover what other forms of labor there are in the world.

Dicey's Song, the next book in the Tillerman Cycle, deals with a close look at Dicey's adolescence now that she has safely delivered her siblings to their new home. The prologue to the first chapter serves as a brief summary to the previous novel in the series, but also highlights many of the issues Dicey is concerned with over the course of the series. Standing in the barn outside of her grandmother's farmhouse at night, Dicey reflects on her past:

You never knew where a road would end, Dicey thought, the breeze curling around her ears, you just knew that roads ended...But the Tillermans traveled on a road, and roads ended. Dicey's road, and James's, Maybeth's, Sammy's, had ended here. The Tillerman's road had rolled up against Gram's house... So they were going to live here, on the rundown farm, with Gram-Dicey's heart danced again, inside her, to say it to herself like that. Home. Home with their momma's momma, who 
was also a Tillerman. Home: a home with plenty of room for the four children in the shabby farmhouse, room inside, room outside, and the kind of room within Gram too-Dicey had seen Gram and how she listened when Maybeth sang, how she talked with James, how her eyes smiled at the things Sammy said and did - the kind of room that was what they really needed. One of the lessons the long summer had taught Dicey was how to figure out what they really needed. (Voigt n.p.)

The road here is a literal description of the path the Tillerman siblings have traveled to reach their grandmother's house on their own, but it is also a metaphor for the end of another kind of journey for Dicey. Even when their mother was nominally taking care of them, Dicey has carried more responsibility than most adolescents, and once she has taken charge of leading her three siblings across several states to find a new home she has become the sole caretaker of the family. Now established in a real home, Dicey is able to give some of that responsibility to her grandmother and discover some important things about her own growth as an adolescent. Instead of worrying about a mentally ill mother or where they are going to sleep at night, Dicey can "reach out beyond the small circle of her family, finally able to share the responsibility for her sister and brothers with Gram, finally sure enough of her home to reach out, first to Jeff through music, and then to Mina and others through her own medium, writing" (Reid 37). Gram's house is the home of family and safety Dewan describes, so now Dicey can be an adolescent.

Once the book starts, though, Voigt doesn't let the reader think the Tillermans are in for a perfect happy ending. In fact, the novel starts with the sentence "And they lived happily ever after," but Voigt immediately contradicts this in the next sentence by writing 
"Not the Tillermans Dicey thought. That wasn't the way things went for the Tillermans, ever. She wasn't about to let it get her down. She couldn't let it get her down-that was what had happened to Momma" (1). Although the prologue leads the reader to believe that everything is fine now that the Tillerman siblings have found a home, Dicey knows nothing will ever be solved. Their mother is still missing, her siblings still have their own issues to deal with, and Dicey herself has to figure out what her life looks like now that she can share the responsibility for her family. The spaces in Dicey's Song are different from Homecoming as well. Whereas the first novel has dealt with a difficult journey across states, the second takes place in a very small town in Maryland. Similarly, Dicey's space shrinks from mapping a quest for a home to an area just outside of her grandmother's house: the barn.

Although her labor has changed from the walking and surviving of the first book, idleness does not set well with Dicey. The first description of Dicey in Dicey's Song is of her resting outside of the barn, wearing, “... only shorts in the hot midday air. Her arms and chest were spattered and streaked with red paint and the barn was completely painted, top to bottom, all four sides, patched and painted and looking good. The paint and the sweat were drying on Dicey's body. She could hear the buzzing of insects and nothing else" (Voigt 1). This image of Dicey is important for several reasons tied to both domestic labor and gender issues. Dicey is challenging not only gendered norms by not wearing a shirt, she is also challenging age norms; by wearing only shorts she is denying that her body is sexually maturing or that she is any different from a boy doing the same kind of labor. It's important also that Dicey's body is spattered in red paint and sweat, creating a visually potent image of fluids on her body. The red paint on her body serves 
as a connection to blood, one of the most common of the abject fluids; the red paint mixed with sweat marks Dicey as covered, from the first page of the novel, in abjected fluids. She has just finished painting the barn, and so is marked by her new form of labor while claiming her new space. Dicey prefers to be outside of the house- -"[o]utside was better than inside, Dicey always thought that"- but she is tied to the home by family, her age, and her responsibilities (Voigt 16). Because Dicey challenges many forms of gender stereotypes she performs this labor outside of the home (just barely) without a shirt on, but the fluids mark her body as female and abject.

One of the reasons the barn is so important to Dicey is because of what it contains inside: an old sailboat to be labored over and repaired. Working on the boat becomes part of Dicey's daily routine, otherwise filled with school and domestic tasks dedicated to taking care of her siblings. Dicey hates her home ec class because "she had much better things to do," than "stupid things" like "sewing" (19). Instead, she:

... had her own routine. When she rode home from her job, Dicey would work for an hour on the boat, scraping off the old layers of paint, before going inside to help Gram with supper or some other housework. After supper, she would listen to Maybeth read for awhile and help her review the list of words. Then she would dash off the busy work her teachers gave as homework and spend an hour studying the boat books. (19)

Dicey spends all of her spare time working on the boat or learning more about boats in an attempt to dedicate herself to a new kind of labor. This obsessions with the craft of making and repairing boats has some interesting implications; Dicey specifically chooses a hobby outside the house where she can physically labor in the open air, but yet she 
remains connected to the home and doesn't plan to escape with the boats. Margaret Meek and Victor Watson point out that:

... at the end of the novel [Homecoming], the fact of having a home becomes, for her [Dicey], associated with repairing the boat she has found there and perhaps sailing it. But there is something odd here: sailing is for Dicey a frequent metaphor for life, providing an alternative conceptual mode to both the linear journeys by road and the fixity of having a home. And yet ... there is no true sailing anywhere in the series. Boats and boat restoration are for her ... a matter of refuge and discovery; building them, as we later learn in Seventeen Against the Dealer, is problematical and dangerous. But sailing them does not happen. (87-88)

The boats are a symbol for Dicey of her independence and rebellion against traditionally gendered forms of labor, but as Meek and Watson point out, Dicey doesn't ever set sail to strike out on her own. Later in the novel, though, Voigt challenges the idea that sewing is only an activity for girls when the home ec teacher gets annoyed with Dicey's attitude. Miss Eversleigh tells Dicey, “[t]he materials we cover in this course are skills. I have spent years protesting the exclusion of boys from my courses ... I have always believed that there is as great a disadvantage to not being able to perform domestic skills as to not being able to perform intellectual skills, or athletic, or social" (112). Miss Eversleigh is clearly arguing here that domestic labor should not be gendered and that the skills to take care of a home are just as necessarily as the skills to take care of life outside the home. Later Dicey starts to reconsider her rebellion against traditionally gendered tasks but is never very interested in going beyond what she needs to know to survive (160). There is 
an interesting conflict here between the author's different implicit ideologies; on the one hand, she is implying that domestic labor is a valuable skill, but on the other hand, Dicey continues to have no patience for domestic tasks she sees no use in. In this way, Dicey is partially reclaiming domestic labor from a feminist perspective because her motivation comes not as much from cultural norms but also from the necessity of completing the task to take care of herself and others.

The Tillermans have become a matriarchal family and as much as Dicey wants to do more interesting work outdoors, her chosen form of labor is still very much connected to her family and the domestic realm. Throughout Dicey's Song, Dicey keeps trying to set down the burden of taking care of her siblings in her mother's place, but she is never quite able to. At one point she even wonders, "'how long was she going to have to spend worrying about her brothers and sisters?' 'It's for as long as you live,' Gram said, as if Dicey had spoken aloud. 'That's something I learned, even though I didn't want to. For as long as you live, the attachments hold"' (70). Those attachments are part of being in a family but they are also part of the gendered responsibilities held by Gram, Dicey, and their mother who could not handle the strain. In the end, Dicey realizes that she misses the "wildness" of their journey across distances from the previous summer, "[a]nd she missed the sense of Dicey Tillerman against the whole world and doing all right" because "[s]he knew she would never have it again" (201). Dicey as the head of the family, provider, and leader is no longer the person she was, and is not yet the person she wants to be. She is content to give up that labor to her grandmother but she misses the freedom of challenging the adult world on her own. She ultimately decides that a "boat at anchor" is the perfect image for her to hold on to, and in some ways it is the perfect metaphor for 
Dicey's journal in the Tillerman series; she has experienced the most frightening kind of freedom and will never be able to return to the constricts of the home. With all of her experiences over the course of her adolescence, Dicey does not want to be limited to a restrictive space. Instead, she settles for something in between; with the option to run away and be on her own, she is able to settle into a life somewhere in between the home and the wider world. Dicey challenges the female stereotypes associated with domestic labor, but doesn't sail out into the patriarchal world; she thinks, "a boat at anchor wasn't planted there, like a tree. Furled sails were just waiting to be raised, when the sailor chose to head out again. And even trees and houses weren't as planted as they seemed to be, and maybe nothing was" (202). She will never abandon the family she has fought so hard to pull together into a home but she can never really let go of the idea of escaping all of her responsibilities and taking to the open sea. In this way, Dicey's emotions remain as ambivalent as they are at the beginning of the series; she loves her family and the new domestic space they have built together, but she also longs for something outside the home. Just like the female adolescent characters in the Kingdom series, Dicey attempts to subvert traditional forms of gendered labor, but she nevertheless remains entrapped by a patriarchal culture, with a dominant discourse of restriction and limited spaces.

\section{Conclusion}

In each novel of The Kingdom series and through Dicey in the first two books of the Tillerman series, Voigt presents a female character (usually the protagonist, but not always) bound to domestic labor, who subverts her gendered social status. Domestic labor is connected to the female body through fertility, and the image of the home is 
associated with a woman's body. Bodily fluids and domestic responsibilities are emphasized throughout these novels but are not the only form of labor the adolescent female characters perform. By including other types of labor not limited to the feministic domestic home, Voigt is metaphorically commenting on gender restrictions both with the setting of her fantasy series and the realistic setting of modern adolescents in the United States. By using domestic labor, and in some cases abject fluids, the female characters in Voigt's novels are able to assert their agency both inside and outside of the home. In some ways, Voigt's novels are very different from the others covered in this project; neither Mahy nor Jones deals so explicitly with bodily functions and abject fluids. However, the domestic labor performed in Voigt's novels is very similar to some of the labor performed by female adolescent characters in Jones' novels. I will discuss in the next chapter how domestic labor can serve as more than just subversion and instead be a source of balanced agency. The spaces the protagonists inhabit in the Voigt novels I've covered here can be seen to be as limiting as the spaces in Mahy's novels, but the way the protagonists deal with those spaces is very different. By taking an active stance in the work of their bodies, Voigt's protagonists are able to break away from some of the problematic binaries in Mahy's books. The Kingdom series and the Tillerman Cycle (at least, those novels focused on Dicey's adolescent experiences) also serve as examples of subversion existing across genres; the characters are able to go through similar experiences even in very different genres. 


\section{CHAPTER IV \\ “CONCENTRIC CIRCLES OF CARING”: DIANA WYNNE JONES' \\ HOWL SERIES AND CARING AS AGENCY}

Introduction

While my second chapter analyzes Margaret Mahy’s problematic relationship between the female body and the colonized land of New Zealand, and my third chapter argues that female characters in Cynthia Voigt's texts seek agency through domestic labor while being abjected from society, the goal of this chapter is to provide a slightly more optimistic view of the relationship between female adolescent characters and the spaces they inhabit. Each chapter so far has progressively looked problematic depictions of female adolescents being limited to certain kinds of spaces by looking at examples of problematic gendered spaces in Mahy's novels and then using domestic labor to subvert their association with the home and abjection fluid in Voigt's novels. The progression from Chapter Two to Chapter Three shows that while gendered binaries still exist in Voigt's work, they are not as problematic as those reinforced in Mahy's novels. The gendered construction of spaces, especially the home, is similar in both Mahy and Voigt's texts, but the circumstances and room for agency are different. I would argue that the protagonists in each of the previous books have little to no choice in their associated spaces; Mahy's are connected to the land, and Voigt's are connected to the 
domestic sphere but the protagonists are able to choose to use the labor of their bodies for something they care about. In this chapter, I change my focus to specifically challenge the space of the home as only being a trap or limiting. This is very different from my work so far in this project, and in this chapter I emphasize the elements of choice and the issue of care, especially as a form of agency balanced on a continuum. Using the theories of feminist ethics of care, I argue that the female characters in many of Diana Wynne Jones' books seek agency through care and relationships.

Following the work of Carol Gilligan, ethics of care theorists, such as Nel Noddings, argue that it is morally right for people to care for themselves and others; feminist ethics of care theorists specifically focus on reclaiming the traditionally labeled female acts of care (that of domestic labor, child rearing, and care for others) as a kind of agency. These acts of care can be moral, right, or good (as opposed to instinctive, unthinking, or animalistic), but we also have an ethical responsibility to care for others because of the interpersonal nature of this ethical responsibility. They point out that these are moral acts, beneficial to the world, and that the person performing these acts is doing so out of an ethic of care. By labeling these acts as "feminine," many cultures have historically devalued the contributions of female care to the world. What is very important to recognize here is that these "feminine" acts are actions; that is, they are determined by actions, not biological sex. By reinforcing the value of this kind of ethics, I am in no way attempting to reify essentialized gender binaries. Indeed, as Nel Noddings notes at the beginning of her work in Caring A Feminine Approach to Ethics and Moral Education, "an ethic built on caring is, I think, characteristically and essentially feminine - which is not to say, of course, that it cannot be shared by men" (8). 
Virginia Held also points out, "[a]s a feminist ethic, the ethics of care is certainly not a mere description of generalization of women's attitudes and activities as developed under patriarchal conditions. To be acceptable, it must be a feminist ethic, open to both women and men to adopt" (20). Instead of reinforcing a false binary, Noddings and Held emphasize here that ethics of care, while a feminist ethic, is open to both men and women. Just as both men and women labor in the home, so too have some men shared in the work of caring for others. Noddings also specifically points out that care of the self is just as important as caring for others and that people cannot truly care for others unless they have also cared for themselves. This contrasts with the other perspectives I have taken on domestic labor, gendered spaces, and the role of adolescents. Rather than problematically connecting the female body to colonized land as Mahy does, or subverting abject fluids and domestic labor to claim agency in patriarchal societies as Voigt does, ethics of care provides a pivotal lens of equality and active power within the home for the female protagonists in Diana Wynne Jones' Howl's Moving Castle and its sequel House of Many Ways. ${ }^{12}$ These books feature two adolescent female characters, Sophie and Charmain, who perform domestic labor and acts of care but not out of selflessness or oppression. Instead, both characters enact a active method of taking care of others, even those they outright dislike, as a way of caring for themselves and those around them. Most crucially for my argument about gendered spaces being limiting for

${ }^{12}$ There is a third novel in the Castle series, titled Castle in the Air (1990), but it focuses on a male protagonist; my focus in this chapter is on the specific struggle female protagonists face in light of an ethics of care. 
adolescent characters, these two young women take over and occupy the most unusual types of homes: those that have formerly belonged to male wizards. Their labor in the homes and care for the stray people, animals, magical beings, and current occupants of the home demonstrate their own power (used metaphorically as is common in magical fantasies) and equality with others. ${ }^{13}$

\section{Feminist Ethics of Care}

As I have discussed in Chapter Three, domestic labor is often associated with gendered spaces inhabited by those who perform the labor; constructions of domestic spaces then are often gendered as female because females are associated with the labor performed in the home. The culturally constructed work of women in the home is often seen as limiting by a patriarchal society, and indeed as Lissa Paul put it, "[w]omen in literature are disproportionally shown as physically trapped in rooms, attics, in their father's houses, or in their husband's. In those enclosed spaces women go mad or silent, or they die" (188). However, "most feminist forms of ethics ... focus on women's concerns that have been ignored or neglected by more male-centered philosophies and an attempt to develop new ethical theories either arising from these issues or from

${ }^{13}$ In Constructing Adolescence in Fantastic Realism (2009), Alison Waller discusses how fantasy "can, for instance be read as a radical and resistant genre that challenges the dominant ideologies represented through realism. Its fantastic tropes (such as magic powers and gifts) might represent allegories for the material and psychological opportunities available to teenagers" (91). 
reconceptualizations of what a system of ethics should be" (Moran, "I'll Never Be" 52). In other words, while patriarchal traditions have constructed the labor done in the home as routine and unchallenging women's work, a feminist view of ethics argues that this work can be done as an act of empowerment, as a way of caring for relationships and of oneself. That female adolescent characters are not necessarily limited by the choices they might make to care for others is a view different from other feminist arguments, and indeed my own arguments, so far in this project. As Held notes:

Traditionally, women have been expected to do most of the caring work that needs to be done; the sexual division of labor exploits women by extracting unpaid care labor from them, making women less able than men to engage in paid work. "Femininity" constructs women as carers, contributing to the constraints by which women are pressed into accepting the sexual division of labor. An ethic of care that extols caring but that fails to be concerned with how the burdens of caring are distributed contributes to the exploitation of women. (16)

If, for example, a female character decides to stay home, or start a new family rather than escaping to seek out the myth of independence, she is may be engaging an ethics of care; this is not necessarily always the case in all situations, but viewed within this particular context can be seen as a way to care for the self and others. This theoretical point of view argues that everyone is dependent and that female characters who choose to recognize that dependence are not necessarily giving up or trapped by society. Instead, they are performing an act of caring for others and, most crucially, themselves by caring for and maintaining relationships with others. 
Joan C. Tronto explores the historical basis of ethics of care and argues that the eighteenth century was a crucial century in terms of western ideas about gender and ethics. She points out that:

[S]ince women were asserting new public roles for themselves in the eighteenth century, these demands had to be contained and were contained by arguing that women naturally belonged in the household. Another side of this picture is important: the locating of moral sentiments within the household.... [A]s the century progressed it fells to women to provide the automatic sentiments of sympathy, benevolence, and humanity....Women, firmly contained within the household, were viewed as the protectors against the creeping values of the corrupting market and the vanity of the public world. Sentiment found its home at home. (54-55)

That the home became the place for moral sentiment and women were placed in charge of that morality has always been part of the discussion about the Victorian split between separate spheres. Both genders had a sphere of influence, and women thus became stereotyped as the source and enforcement of moral thinking. To challenge the construction that morality is a natural, inborn quality of women, an essentialist pattern, often identified as "the angel in the house," ethics of care argues "for ethical choices that preserve or nurture relationships while at the same time challenging essentialist assumptions that women naturally care for others and that they alone bear this responsibility" (Moran, "I'll Never Be" 51). As Held writes, "the autonomy sought within the ethics of care is a capacity to reshape and cultivate new relations, not to ever more closely resemble the unencumbered abstract rational self" (14). The emphasis of 
this kind of morality is thus on making choices to be ethical and to share the responsibility for care and relationships with others.

\section{Gilligan's text In a Different Voice: Psychological Theory and Women's}

Development (1982) is often cited as one of the first books to explore what ethics of care means, especially in relation to women. In a 1993 letter to the readers prior to the body of the text, Gilligan addresses some of the controversies surrounding her ideas, especially the reaction against the angel in the house trope. Gilligan writes about the consequences of the Women's Movement:

many women [who] were openly questioning the morality of the Angel in the House - that nineteenth century icon of feminine goodness immortalized by the poet Coventry Patmore: the women who acts and speaks only for others. Discovering through experience the consequences of not speaking in relationships - the trouble that selfless behavior can cause - women were exposing the morality of the Angel as a kind of immorality: an abdication of voice, a disappearance from relationships and responsibility. The voice of the Angel was the voice of a Victorian man speaking through a woman's body.... [B]y restricting their voices, many women were wittingly or unwittingly perpetuating a male-voiced civilization and an order of living that is founded on disconnection from women. (x-xi)

The key facet Gilligan is focusing on here is the trouble the emphasis on selflessness causes; to only care for others and not for the self is an impossible goal, and one that harms both women and men. Caring for others is important, but just as important is 
caring for the self. Gilligan also clarifies that voice, the feminist concept used so often to indicate an actual word spoken and the ability to assert agency, is a quality both human and relational. She writes, "[t]o have a voice is to be human. To have something to say is to be a person. But speaking depends on listening and being heard; it is an intensely relational act" (xvi). This really is a key part of Gilligan's argument and part of what I will be focusing on in this chapter; that these female adolescent characters need a voice is already well established but that they need to establish relationships in order to be heard is intensely important because it challenges previous assumptions about independence and power.

The other aspect of Gilligan's work in In a Different Voice that is important to my argument here is her exploration what happens to the female voice during adolescence. Building on Nancy Chodorow's work, Gilligan writes, "for both sexes the primary caretaker in the first three years of life is typically female, [so] the interpersonal dynamics of gender identity formation are different for boys and girls" (7). This is not a universal truth, but is frequently the case in most patriarchal societies; thus when children are growing up, "girls, in identifying themselves as female, experience themselves as like their mothers, thus fusing the experience of attachment with the process of identity formation" (7-8). Boys, however, "in defining themselves as masculine separate their mothers from themselves"; thus their identity formation is built on being different from their mother and on separation from her rather than attachment to her (8). This process has consequences for the adolescent stages for boys and girls, and their subsequent experience of relationships. During adolescence, a phase important to identity formation, teenagers begin to display sharp difference between the genders in terms of how they 
construct relationships. Gilligan writes:

For girls and women, issues of femininity or feminine identity do not depend on the achievement of separation from the mother or on the progress of individuation. Since masculinity is defined through separation while femininity is defined through attachment, male gender identity is threatened by intimacy while female gender identity is threatened by separation. Thus males tend to have difficulty with relationships, while females tend to have problems with individuation. ...Women's failure to separate then becomes by [patriarchal] definition a failure to develop. (89)

Although Gilligan's writing may seem at times to reinforce gender binaries, my argument will deal with the gendered constructions of ethics, including femininity and masculinity in acts of care. That is to say, while feminine ethics of care most definitely should not be attached to women only, the act of caring for another has been culturally and historically been constructed as tied with femininity. Gilligan's work here neglects to note the differences between sex and gender, although she does use the word "tends" often to attempt to soften the binary she is setting up. Following Noddings, I argue that when a man performs an act of care, he is performing a feminine act in the socially constructed definition of femininity of a patriarchal society. The binary between separation and attachment Gilligan describes is better seen in a continuum (or in Noddings' later metaphor, a circle), with the extremes of masculinity and femininity on either side; an ethic of care in fact should argue for a balance between the two extremes in all people. Within the Castle series, as both Sophie and Charmain travel through the process of 
adolescence, they experience the desire to strike out on their own and individuate which helps to balance the masculine/feminine split described above. However, their process seems to be halted by having to care for others, build relationships, and discover more about themselves. In terms of Gilligan's argument, this does not mean that they have failed to become adults but instead that they have failed to fulfill an impossible standard of separation, perpetuated by patriarchal norms. Of course, some separation is required for most people in order to grow and change in the world; however this can be balanced by maintaining healthy relationships. All humans need relationships in their lives, but patriarchally-influenced literary constructs often emphasize the individual search for ultimate freedom from dependence as a stage of growth, devaluing those very relationships. That independence and dependence are set up a opposite binaries again is not optimal; a balance between adolescents' search for independence while maintaining dependence with relationships helps to blur the lines between traditionally constructed masculinity and femininity. Maintaining relationships, caring for the self, and caring for others too often are depicted as problematic: “[w]omen's moral weakness, manifest in an apparent diffusion and confusion of judgment, is thus inseparable from women's moral strength, an overriding concern with relationships and responsibilities" (Gilligan 16-17). In other words, the qualities traditionally associated with women that have been dismissed by some men, like caring about relationships and responsibilities to care for other, should actually be highly valued by both men and women. When female characters in adolescent novels choose to remain in the home, or to maintain relationships rather than strike out on their own, they are only failing the patriarchal expectations for their moral journey, but not necessarily sacrificing their own quest for an adult voice. 


\section{Noddings' book Caring: A Feminine Approach to Ethics and Moral Education}

(1994) expands on Gilligan's earlier theories; Noddings' focus shifts from the concept of "voice" to the concept of "caring" and the role of caring in ethical morality. Rather than looking at the stages of growth and gender, Noddings proposes to focus "our attention ... upon how to meet the other morally. Ethical caring, the relation in which we do meet the other morally, will be described as arising out of natural caring — that relation in which we respond as one-caring out of love or natural inclination" (4-5). Noddings' focus on caring and relationships is especially important to the process of growth in adolescent literature; instead of focusing on individual freedom and independence, the female protagonists in Diana Wynne Jones' novels are instead consumed with taking care of others. This is not a defeat or even a conflict, however, nor does it delay their growth as characters; instead it is important part of their development as morally ethical adults. Noddings defines what she means by "care" in contrast to "a state of mental suffering or of engrossment"; instead she argues that "[o]ne cares for something or someone if one has a regard for or inclination toward that something or someone ... to care may mean to be charged with the protection, welfare, or maintenance of something or someone" (9). I connect this kind of care to the labor usually performed by women in the home; the labor traditionally performed by women has been devalued. Just as important as the effort to reclaim that labor is the effort to reclaim what caring is and why it is important. ${ }^{14}$ When

\footnotetext{
${ }^{14}$ For more on the ethics of care, see Held, Ethics of Care; Moran, "Use Your
} Head, Judy Girl,”; Ruddick, Maternal Thinking; and Tong, Feminine and Feminist Ethics. 
female adolescent characters, such as those in Diana Wynne Jones' novels, live and work in the home, they are actually performing powerful acts of care and learning to determine their own futures.

The active method of taking care of others described above is what I am going to highlight in two novels by Diana Wynne Jones. I argue that although the two female adolescent protagonists take care of others, they also maintain a balance by taking care of themselves. This connects to my overall argument because the work done in the home is so closely tied to gendered assumptions about the home; the domestic labor done in the home has been devalued, along with the home itself. This leads me to another overlapping area between gender studies and ethics of care: that of geography. While much of my focus so far in this project has been on feminist geography, space also has a particular connection to ethics of care, especially when we think about degrees of care. Noddings refers to this as "concentric circles of caring" because "[i]n the the inner, intimate circle, we care because we love" (46). As the circles move outward, "we encounter those for whom we have personal regard" where "[p]ersons in these circles do not, in the usual course of events, require from us what our families naturally demand" (46). She asks though, "[b]ut what of the stranger, one who comes to me without the bonds established in my chains of caring?" (47). Michael Slote works to answer this question in his book The Ethics of Care and Empathy (2007). Slote discusses his theory of "the ethics of empathetic caring" as different from the ethics of care covered by prior theorists. Slote's empathetic care has much to do with "spatial distance" (21). He writes, "[s]patial distance and (decreasing) empathy do in fact correlate with one another across a wide range of cases, and that very fact may have helped to obscure the role empathy 
potentially has in explaining the sorts of distinctions people intuitively, or commonsensically, want to make" (22). In other words, the closer you are to someone (both physically and emotionally), the more likely you are to emphasize with him or her, and thus care for him or her; in other words, those who live closest to you in the home are most likely to be those you care for (as a transitive verb) the most. This is a fascinating connection to the gendered spaces of the home I have been discussing because the home, the work and care done in the home, all tend to be devalued in a patriarchal society because they are all ostensibly "only" the realm of women. While both feminist geography and ethics of care theorists recognize the devaluation of feminine spaces and labor, my point is that women, the home, and the work they do in the home are culturally constructed in similar ways. In Philosophy and the Maternal Body, Michelle Boulous Walker traces the evolution of the build up of the inside/outside metaphor in Western philosophy. She writes:

what is important for our purposes here is that Irigaray insists on the masculinity (i.e. the sexual specificity) of this movement. She argues that it is based on denial in that it depends upon, and yet represses, its debt to the maternal body. Rationality results from a process of transcending its material/maternal origin and this places the entire philosophical enterprise between itself and this (unacknowledged) debt. Because of this we can no longer simply portray philosophy and its repressed other as spatially distinct regions, i.e. one inside, one outside. We must realize that philosophy's other — and here Irigaray refers to the maternal body, the feminine, or more problematically woman—occupies a place internal 
to philosophy's own logic. (15)

The home is also a place where childhood is largely spent for many children; moreover, childhood, can also be a time of disempowerment and entrapment. Children are often the cared-for in a patriarchal society, which can be restricting, especially if they are not able to care for others or the self. The balance, or circle, here is important again because as a child develops into an adolescent, the balancing of the kind of work and care done in the home tends to change. This is especially the case when cultural constructions of masculinity and femininity are reinforced, so a female adolescent has to come to terms with the spaces and expectations constructed around her, balancing care with control. The circles of care Noddings refers to are often centered on the home, and immediate family; then as the circles ripple outwards, levels of care and expectations of empathy shift and change.

One of the issues with ethics of care is that it can be hard to identify what caring looks like, especially when we think about the difference between caring for others and caring for the self (although these may not always be different things). In her book Moral Boundaries: A Political Argument for Care (1993) Tronto, with Berenice Fisher, sets out the "four elements of care," which "provide a good starting point to describe some elements of an ethic of care" (127). These "four elements of care are: caring about, noticing the need to care in the first place; taking care of, assuming responsibility for care; care-giving, the actual work of care that needs to be done; and care-receiving, the response of that which is cared for to the care" (127). The last step in these elements of care is what I find the most important in terms of my argument here; not only does care need to performed, it needs to be noticed and responded to. I will use these four elements 
to identify the ethical choices Sophie and Charmain make in their respective novels, especially emphasizing the role choice, not innate morality, plays in their decisions. As Mary Jeanette Moran writes:

[s]ince women have become identified as caregivers largely within a patriarchal context, reductively aligning women and care risks reifying restrictive stereotypes of femininity. For example, because caring for others has been one of the few ways that women could find meaning in their lives or contribute to society, far too many women - both real and fictional - have devoted all their time and energy to taking care of other people at the expense of their own well-being. In order to enact an ethic that is feminist in reality as well as in name, then, people must avoid the trap of sacrificing themselves in order to meet the needs of others. ("A Word" 11)

In many ways, this last element ties together the two ways of caring Nodding sets out: both caring for others and caring for oneself. It is crucial for these female adolescent characters to not just care for others as a way to selflessly serve the world, but that they also to learn to care for themselves and to build a relationship balanced between those two ways of caring.

Annis Pratt and the Female Archetype Pattern

When Annis Pratt charted "The Novel of Development" in 1981, what she saw was that "the novel of development portrays a world in which the young woman hero is destined for disappointment" (29). Instead of the female protagonist escaping from her 
childhood home to a world of freedom, "[e]very element of her desired world—freedom to come and go, allegiance to nature, meaningful work, exercise of the intellect, and use of her own erotic capabilities-inevitably clashes with patriarchal norms" (29). This description can also be broadly applied to most children who are contained and controlled within the home. What makes this different for a female adolescent in a patriarchal society is that she, like most children, is expected to remain in the home and not seek out the freedom to come and go. The dangers of the patriarchy stifling development have been covered in many places, including other chapters in my current project, but I'd like to look at Pratt's archetypal pattern through the lens of care. I hope to make the point that even though the female heroine doesn't necessarily leave home or find independence, she still might be able to achieve agency and find a voice of her own through care. I specifically see a space for this agency within Pratt's female archetypal pattern of rebirth, or "an outline of women's quest for rebirth that seems to parallel in its figures and sequence such formulae as Jung's quest for individuation, Campbell's adventures of the hero, and Frye's romance journal" (138). Pratt's pattern follows five steps, including: "Phase I: Splitting off from Family, Husbands, Lovers," "Phase II: The Green-World Guide or Token," "Phase III: The Green-World Lover," "Phase IV: Confrontation with Parental Figures" and "Phase V: The Plunge into the Unconscious" (139-41). If a female hero can follow all of these steps, she can achieve rebirth; however, Pratt warns that:

the rebirth journey entails risk and psychological danger, as likely to lead to madness as to renewal.... The problem, as we have seen, is that "insanity," whether literary or clinical, is often a perfect mirror of the 
feminine persona's place within society, an image of the enclosure and of its victims, and thus the transformed hero who has survived this layer of her unconscious is unlikely to be able to reintegrate herself fully into "normal" society. (143)

I would argue that the idea of rebirth itself is problematic because so often for female characters that means she has to give birth herself, to a new family, a new life, and a new home. That this pattern so often ends with the female hero returning home or creating a new home of her own means that, in many ways, she has succumbed to the limitations of a patriarchal society by returning to the only socially acceptable space. I in no way mean to imply that returning home (whether to that of the family or the lover) is always a failure, but that the pattern so often ends with this step indicates how limited many authors are in imagining alternative choices for their characters. As Pratt warns, "[w]omen heroes often blame themselves for their own normal human desires, warping their quests for Eros, for example, by internalizing patriarchal norms about feminine sexuality" (141). I would argue that the freedom to explore feminine sexuality, and freedom itself, is what is so often lacking in the pattern of the female hero. Roberta Seelinger Trites cites Pratt's pattern as a demonstration of "how often the so-called growth of the hero of a female Bildungsroman is marked by her retreating from life rather than becoming fully involved in it" (64). However, ethics of care points out that caring for the self and a necessary connection to others is a valid and even needed way of ending a quest. Renewal, rebirth, and a return to the home is not necessarily a failure (although it is problematic if it is the only choice consistently given for female characters); instead a female character can follow the steps of Pratt's archetype pattern and remain (or 
become) an individual fighting against gendered restrictions. For example, in light of Anne's decision in Anne of Green Gables to remain at home with her adopted mother, Moran argues that "Anne ... manages to move beyond the angel-in-the-house mentality; her decision 'is no sacrifice,' not because it privileges the needs of others before her own, but because it allows her to strengthen the caring relationship between herself and Marilla, while maintaining their community at Green Gables, and studying Latin and Greek on the side - thereby keeping her options open" ("I'll Never" 54). Both of Diana Wynne Jones' books I focus on in this section end with the female adolescent firmly entrenched in the home, fitting Pratt's pattern; however that both homes are magically unique and travel through time and space encourages agency and freedom for those characters.

Ethics of Care in Diana Wynne Jones: Circles of Agency and Care

To provide some examples of the use of ethics of care in adolescent literature, I will be looking at Diana Wynne's Jones' novels. Not all adolescent literature provides a model of balancing between care for others and care for the self, but Jones' novels provide a particularly powerful example, partly because of the unique spaces available to the characters in a fantasy world. Howl's Moving Castle, first published in 1986, begins by establishing a fairy tale tradition while at the same time mocking those traditions. The first line of the novel places the story "[i]n the land of Ingary, where such things as seven-league boots and cloaks of invisibility really exist" (Jones 1). ${ }^{15}$ The narrator

${ }^{15}$ Jones was writing well before the publication of the first Harry Potter novel (1997), which also features a famous invisible cloak. 
quickly establishes that while Ingary is a land with magic, magic does not always mean wish-fulfillment. Sophie and her sisters are happy although they bicker about the youngest being predestined (by fairy tale lore) to marry a prince (2). Carolynn E. Wilcox notes, "Jones takes traditional fairy tale elements and adapts them to fit what appears to be, at first, a typical portal fantasy in which the characters can move from one world to another through a doorway.... Sophie's casual acceptance of her 'fate,' combined with the 'normal' treatment of such outlandish things as magic and seven-league boots sets the tone for the book" (160). Sophie, the adolescent female protagonist, is the eldest sister and thus despairs of marrying a prince or being special in any way. Her story really starts to take off though when the Witch of the Waste places a spell on Sophie, telling her "By the way, you won't be able to tell anyone you're under a spell" before Sophie even knows what the spell has done (27). Soon Sophie realizes that her physical form has been changed when she "puts her hands to her face" and "felt soft, leather wrinkles. She looked at her hands. They were wrinkled too, and skinny, with large veins in the back and knuckles like knobs. She pulled her gray skirt against her legs and looked down at skinny, decrepit ankles and feet which had made her shoes all knobby. They were the legs of someone about ninety and they seemed to be real" (27). Unlike a stereotypical fairy tale transformation, Sophie is turned from an average young woman into an elderly woman, but she is relieved by the change. When Sophie looks in the mirror, "[t]he face in mirror was quite calm, because it was what she expected to see" and even tells her reflection, "this is much more like you really are" (28). She is elderly, but not enough to hamper her movement as Sophie notices when "she was relieved to discover that she was 
quite a half old women. She did not feel weak or ill, just stiff" (28). "In fact," David Rudd points out:

it is precisely because Sophie is prematurely aged that she is freed from the standard patriarchal plot that enslaves most young females. As the narrator explains, "It was odd. As a girl, Sophie would have shriveled with embarrassment at the way she was behaving. As an old woman, she did not mind what she did or said. She found that a great relief" (66). We are thus made to rethink the traditional Bildungsroman in which we follow a character (male, usually) from their young days to a coming of age in marriage and good fortune. Sophie, though, moves the other way: for most of the novel she is an old woman (as noted above, she acts like this even when young), only becoming truly rejuvenated in the book's closing pages. To adapt a Bob Dylan line, she was "so much older then," she's "younger than that now." Sophie therefore functions as her own fairy godmother, artfully influencing her own future. She thus disrupts masculine notions of a linear, cause-and-effect conceptualization of time, itself associated with a masculine Bildungsroman, counterposing it to what Julia Kristeva termed "Women's time," more attuned to the cyclic, seasonal, and repetitive aspects of life. (257-58)

Pratt and Rudd both challenge the concept of Bildungsroman as patriarchal, and Sophie's journey works against the typical male novel of growth; she doesn't have the impetus to leave home and seek her adventure until she is magically transformed into an old woman. She immediately leaves home and sets out into the world, freed from concern and 
timidity by the appearance and feeling of age.

What makes Howl's Moving Castle an especially good example of ethics of care is what happens to Sophie after she leaves home. One of her first acts upon leaving town is to heave upright "the bottom end of an old scarecrow someone had thrown into the hedge" (Jones 29). This becomes the first of many acts of care Sophie performs throughout the novel. It is important to note that Sophie does not automatically care for the scarecrow; it is not her child, or emotionally attached to her in any way. When she sees that it has "a withered turnip for a face" Sophie does find "she had some fellow feeling for it" but she makes the decision to set the (seemingly) inanimate object to rights because she actively cares for others. With this one simple action Sophie has already gone through the first four elements of an ethic of care, described by Tronto above. Sophie notices something that needs care, assumes the responsibility for that care, and does the actual work that needs to be done. The last element, and perhaps the most important one, is the response of that which is cared for to the carer; this happens when it turns out that the scarecrow is actually part of a missing prince under a spell. Right after helping to right the scarecrow, Sophie discovers "a thin gray dog" stuck in a thorny hedge by a rope tied around its neck (30). Sophie crawls under the hedge and labors to free the dog despite it being "very wild" and growling at her (31). When the dog is finally free Sophie tries to share her bread and cheese, "[b]ut the dog just growled at her, forced its way out through the opposite side of the hedge, and slunk away" (31). At the very end of the novel, in the usual Diana Wynne Jones pattern, Sophie (and the reader) discover that both the dog and the scarecrow contain parts of missing people. The scarecrow tells Sophie, "I was guarding his [Wizard Suliman's] bushes from the birds in the Waste when 
the Witch caught him. He cast all of his magic that he could spare on me, and ordered me to come to his rescue. But the Witch had taken him to pieces by then and the pieces were in various places" (316). The undoing of the spell completes all four elements of Sophie's ethics of care; the Wizard and the Prince respond to Sophie's care by returning to their original selves, free from the interference of the Witch of the Waste. This example is only one of many from Howl's Moving Castle; Sophie consistently stops to take time and care of others throughout the novel. There's also another important aspect to Sophie's care here: it takes place on her journey, almost as soon as she sets off away from home. Sophie's real journey over the course of the novel is to learn how to take care of others while taking care of herself, and she has to travel through many lands and one castle to do that.

When Sophie catches a ride on the moving castle wandering around outside of her town, she poses as a cleaning lady. Disguised as an older woman, Sophie quickly decides to start really cleaning the inside of the castle, which is filthy. This domestic labor Sophie performs is a kind of care, but unlike the other acts of care Sophie has done before, this labor is care for herself and others. Now that Sophie has successfully skipped that awkward adolescent stage by simply accepting her elder form, she also begins to accept other things about herself, including that she can take control over her environment. Rather than simply accepting the state of the castle, Sophie "tied an old rag round her wispy white hair, she rolled the sleeves up her skinny old arms and wrapped an old tablecloth from the broom cupboard round her as an apron" (62). When the current occupants of the house, an apprentice magician named Michael and a fire demon named Calcifer, protest, Sophie "replied firmly... 'the place is a disgrace" (62). She even 
asserts to a curious passerby that "I'm the best and cleanest witch in Ingary" then "cackled to herself a little, quite unrepentant" (63). This turns out to be at least partially true, because Sophie is actually a witch, although she has been hiding it from herself (along with her attraction to Howl). During her cleaning mania, Sophie manages to convince Michael to get her "an old folding bed, a straw mattress, and some rugs" for a small private area (67). Sophie is performing domestic labor in the house, but not because of her gender or because she has been told to; instead she cleans with strength and vigor to ensure a place for herself where she can care for others. This domestic labor can also be seen in other novels covered in this project: the Kingdom series especially demonstrates the tricky nature of taking care of others, which all of the female protagonists do, but also taking care of the self. By skipping over the usual Bildungsroman journey, Sophie is able to have a voice and act for herself and others; this is made very clear in the text when she admits "[a]s a girl, Sophie would have shriveled with embarrassment at the way she was behaving. As an old woman, she did not mind what she did or said. She found that a great relief" (64). Sophie has tried to be invisible, or at least barely visible, for a long time, but with the removal of her adolescence, she finds that being an older woman makes her feel powerful. Because of her now advanced age, Sophie is able to begin to take care of herself by making a place to be comfortable in. By cleaning the castle to make the space more comfortable for herself and others, Sophie is working on establishing her own voice, an activity she only feels safe to do in the guise of an older woman. Sophie travels though this period of questioning and doubt, but comes to understand that instead of focusing on herself, she must start to take care of others while also taking care of herself. She is thus able to develop a powerful voice (and 
because this is a fantasy, her voice turns out to be literally powerful in terms of her gift as a witch).

The moving castle itself is most important to my discussion about care, voice, space, and gender. Sophie runs away from home and happens to find herself right next to the castle she has feared from town. Just as she realizes she needs a place to stay the night, Sophie sees "Wizard Howl's castle was rumbling and bumping toward her across the moorland. Black smoke was blowing up in clouds from behind its back battlements. It looked tall and thin and heavy and ugly and very sinister indeed.... She was not particularly frightened" (Jones 35). Indeed, when Sophie shrieks "Stop!" at the castle, it does (35). Not only is Sophie using her voice to control a powerful moving castle, but she also is able to face her fears. This house becomes Sophie's space in many ways, including being a space of relationships and caring. By cleaning the house and asserting her need to care for herself and others, Sophie develops her own sense of power and belonging; no more is she a child doing what her stepmother tells her to do because she now has a space of her own. Unlike Pratt's description of the masculine Bildungsroman though, Sophie is not sentenced to a limiting life of separate spheres and caretaking just for others as sometimes happens to a female character in a masculine Bildungsroman journey. By building relationships with others (the scarecrow, the small gray dog, Michael the apprentice, Calcifer, and Howl) Sophie is able to find a place for herself where "the fire warmed her aches and the chair supported her back and she knew that if anyone wanted to turn her out now, they were going to have to use extreme and violent magic to do it" (39). At the end of the novel, when Sophie has realized and accepted her gift to talk life into things, she is able to care for Howl by replacing his heart, freeing 
Calicifer, and helping defeat the Witch of the Waste's fire demon (322-24). Through care, Sophie has saved those she loves and herself. Moreover, just as things begin to settle, 'Howl turned to Sophie just then. 'Gray doesn't really suit you,' he said. 'I thought that when I first saw you...[w]ould you call your hair ginger?" (327). The aging spell, which Sophie has been holding onto with her own magic, has faded in the face of her new empowerment and the use of her magical voice. Everyone around her recognizes that "the lady of the house is Sophie" because Sophie's story doesn't just end happily ever after (to be continued in the next book in the series) but also with more potential for growth. She knows that "living happily ever after with Howl would be a good deal more eventful than any story made it sound, though she was determined to try" (328). The riff on fairy tales throughout the book ends here with Sophie knowing that living happily ever after doesn't mean the story or problems end; rather she has found her "circle of caring" as Noddings puts it. Of course, all of this takes place in a castle that not only walks around the countryside but also has doors that open into different lands. Thus, even though the end of Sophie's journey is in the home, she has experienced a rebirth of adventure and excitement, not a patriarchal ending of silence.

House of Many Ways, advertised as the sequel to Howl's Moving Castle, takes place several years after the events of Howl although it was published much later in 2008. House of Many Ways returns to the world of Wizard Howl, through the story of Charmain (often misheard as "Charming") Baker. A resident of a High Norland, a neighboring kingdom to Sophie and Howl's Ingary, Charmain lives at home with her parents and is utterly spoiled. Charmain prefers to eat her father's pasties, read, and never be bothered (2). When her mother and aunt decide that Charmain should take care of her Great-Uncle 
William's house while he is gone, her Aunt Sempronia says, "What I do know is that she [Charmain] never has her nose out of a book, never does a hand's turn in the house, and is treated like a sacred object by both her parents. It will do her good to do something normal for a change" (4). Charmain is initially thrilled by the idea of having a whole house to herself, but not because she wants to help; she tells her mother, "You know I'm not kind" (5). Charmain is not really selfish at the start of the book; she's just never been exposed to any different kind of life. Her parents do not expect anything of her, so she continues to indulge her passions (eating while reading) and ignoring everything else. She does have a secret though:

The truth was, this was the chance she had been longing for. She was tired of her respectable school and very tired of living at home, with her mother treating her as if Charmain were a tigress no one was sure was tame, and her father forbidding her to do things because they were not nice, or not safe, or not usual. This was a chance to leave home and do something - the one thing-Charmain had always wanted to do. (6) Without her mother's knowledge, Charmain secretly writes to the king and asks to help him organize his library; here she combines her passion for books with her longing to leave home and do something interesting (7). Thus, Charmain sets off on the first step of Pratt's archetypal pattern and leaves home to seek her adventure. Of course, for Charmain the goal of her adventure is to find a quiet room to read in, but she soon has to face many unexpected situations.

One of the preliminary acts of care Charmain performs involves the first being she meets after her Great-Uncle has gone to be healed by the elves. When sitting in the 
kitchen, Charmain looks under the table to see "an extremely small and ragged white dog, gazing up at her piteously and shaking all over" (25). Waif, as the disembodied magical voice of her Great-Uncle tells her, "came to me as a stray and he seems to be frightened of everything" (25). Most of all, Great-Uncle William tells Charmain "Be very kind to him" (25). Charmain doesn't really like dogs, but she still shares her only meal with Waif and "[i]n the end, they shared the pasty half and half" (26). Waif turns out to be more important than Charmain could have imagined, but she starts her journey of care with the small act of sharing a meal. Again, it is important that Charmain doesn't sacrifice her own meal at risk of herself; instead she takes care of both the dog and her own needs by sharing. Waif and Charmain have begun to develop an innermost circle of care. This is also part of Jones' nod to the fairy tale tradition, in that both Charmain and Sophie begin their journeys with a series of tasks to provide help to strangers. These tasks, performed out of kindness to others (in Charmain's case, very reluctantly), end up helping them by the end of the story. In both novels, Jones draws on fairy tale motifs (things happening in three, the problematic power of magical wishes or spells, Sophie being convinced that good things only happen to youngest siblings) while playing with metaphors of power. Many of Jones' novels deal with magic and fantasy but these two novels specifically play with the traditions and structures of fairy tales in interesting ways.

Charmain's second act of caring is a bit more difficult; she is supposed to take care of Great-Uncle William's house, which he has left in shambles. Charmain has no idea how to clean anything, much less deal with a household with magical chores. When she finally figures out what a wash house is she realizes, "I'm beginning to think I've led 
a much too sheltered life" (29). At first she tries to ignore the cleaning but as piles of magical dishes start to pile up on top of magically appearing laundry bags, Charmain realizes that she will have to learn to do a few things. She doesn't do well at first, putting a bar of soap into the fireplace so that the fire spell spews out bubbles, but she soon finds a solution (69). Just as Charmain is almost pushed out of the kitchen by the bubbles, she hears a knock at the door. She doesn't want to answer it but "[b]efore Charmain could do more than put both hands out to hold it shut, the door crashed open and a soaking wet boy surged inside" (70). This boy turns out to be Peter, a wizard's apprentice arriving to work with Charmain's Great-Uncle William. Peter and Charmain develop an interesting relationship; they remain at conflict throughout most of the book but Charmain does learn to care for him. Peter is annoyed that Charmain has no idea, and doesn't intend to learn, how to wash dishes, clothes, cook, or do anything around the house she is supposed to be taking care of. She tells him "I haven't the remotest idea how to wash dishes anyway.... My mother brought me up to be respectable.... She never let me near the scullery, or the kitchen either" (129). There are clearly some class issues at work here, with Charmain's mother trying to separate her daughter from the hard labor done around the house, but as Peter points out, "I should think you had enough pride to help me do it" (129). Peter's statement about pride shows that he thinks the labor done in the home is worthy and valuable work. He is at the house to learn magic but immediately starts pressuring Charmain to learn about washing dishes, cooking, and taking care of herself. The emphasis here is less on taking care of others than on taking care of the self. Charmain's journey is not just that of a young girl trying to find her place in the world (ideally in a library); it is also a journey of learning to care for herself. 
She and Peter have to try to survive on their own with no adults in the house, so their work at caring for themselves also becomes caring for each other. When Charmain gets a job helping the king sort through the library at the castle, she recognizes that the household work must still be done. She "could not help grudgingly thinking that it was much nicer having the kitchen clean and tidy. I suppose Peter has his uses, she thought" (148). It is notable that Charmain is the one to leave the home in search of a vocation while Peter stays home and figures out the household chores. Charmain even notes that "I feel like a proper grown-up working girl" on her way to the castle one day, following through on the promise of a bildungsroman journey (240). She even gets mad at Peter once, despite her resolution to be more kind to him, when he tidies up her room for her while she's away. He thinks she will be pleased, but in a scene that could easily be gender-reversed she get angry and shouts:

"But I'm not!" Charmain said. She was surprised to find herself almost in tears. "I was just beginning to learn that if I drop something on the floor it stays dropped unless I pick it up, and if I make a mess $I$ have to clean it away because it doesn't go by itself, and then you go and clear it up for me! You're as bad as my mother!"

"I've got to do something while I'm alone here all day," Peter protested. “Or do you expect me to just sit here?" (226)

However, both adolescents learn to compromise; Peter is learning magic by trying to take care of and explore a magical house, while Charmain learns to care for others and herself while sorting and reading books at her job. The emphasis here is that both adolescents have something to learn from each other, and Charmain especially doesn't need to learn 
to care for others in the home so much as she needs to learn to care for herself.

The house Great-Uncle William leaves in Charmain's temporary possession is almost as interesting as Howl's moving castle itself. While Great-Uncle William's house doesn't move about independently (nor does he have a fire demon), it does have mysterious doors leading to very different places. When Charmain first arrives at the house, she notices, “[a]11 Great-Uncle William's doors seemed to need the strength of ten men to open, she thought angrily. She could almost feel the weight of magic holding them shut" (22). Soon she starts to get the trick of the doors:

and turned briskly left into the door frame before she had time to think of it as impossible. She found herself in a passageway with an open window at the far end. The breeze coming in through the window was strongly full of the mountain smell of snow and flowers. Charmain had a startled glimpse of a sloping green meadow and faraway blue distances, while she was busy turning the handle and shoving her knee against the nearest door.

Eventually she and Peter find a map of the house, folded "back and forth to fit in the suitcase. It came out on the table in a huge zigzag" (206). The map is labeled with many different kinds of spaces, including "To unexplored North Section" or "To Ballroom: I doubt if we shall ever find a use for this" (207). It turns out that Great-Uncle William found the house and has spent his life exploring the way space (and time) has been folded within the house in different ways (209). The geographical implications are similar to those that Sophie experiences when she takes over and cleans Howl's castle. Charmain and Peter have taken over Great-Uncle William's home and are able to discover and use 
the magic of the space for their own goals. Even if Charmain were entrapped in this home, she would be able to spend a lifetime exploring, meeting new people, having adventures, and learning how to care. By the end of the novel, Great-Uncle William realizes that Charmain has magical powers of her own and tells her, "Then that settles it....You come and live with me as my apprentice from now on" (400). Charmain, still the same person despite all of her experiences and learning to care for herself, is still only interested in the books. Her interest in books is not just in wanting to be left alone to read, however; she has turned her desire into a job and desperately longs to go back to work with the king, sorting and cataloging the books. They all agree that Charmain can come and work with the king in the library two days a week, thus maintaining her own interests while also providing a space to explore her newfound powers. Just as with Sophie in Howl's Moving Castle, Charmain starts out on a traditional bildungsroman journey but through care of the self and of others, is able to assert her voice and become independent while maintaining relationships with those who are important to her. And of course both are tied to very important and deceptively domestic spaces (because they appear in one way but are actually much more than they appear), full of magic, twists, surprises, and unexpected doors to new worlds.

The moving castle and house bent through time and space are both fascinating features in Jones' work that encourage multiple spatial interpretations, including an invitation for the reader to think of the spaces of the magical homes in different ways. While I have argued that the spaces in Howl's castle and Charmain's uncle's house are open and encourage agency, they can also be seen as gothic spaces reflecting fears of entrapment. That Howl's Moving Castle is a fantasy, allowing metaphoric stories of 
power to be told through magic, keeps many possibilities open for Sophie. However, the moving castle itself has shades of the gothic amongst its hidden rooms, doorways to strange lands, and magical mysteries. Rose Lovell-Smith describes "the classic Gothic house" as "one that is difficult to get into" and "is also often difficult to get out of, containing within itself, or forming for its inhabitants, a prison" (101). On the other hand, Gilbert and Gubar challenge the usual description of the gloomy mansion of Thornfield in Jane Eyre as "just another gothic trapping introduced by Charlotte Brontë to make her novel saleable" (347). Instead, they argue that "not only is Thornfield more realistically drawn than, say, Otranto or Udolpho, it is more metaphorically radiant than most gothic mansions: it is the house of Jane's life, its floors and walls the architecture of her experience" (347). Sophie's experiences in the moving castle, owned by Howl but claimed by herself through domestic labor, can be seen as a reflection of her own mind, and her own experiences looking for agency and caring. Charmain as well is left to her own devices in her uncle's house and has to map out her own way through the home, driven by the need to care for herself through domestic labor and eventually care for others. While both spaces present challenges (Sophie has a hard time getting into the moving castle, while Charmain is stumped by the home's magical way of doing chores), the female protagonists are able to use their intellect and own power to claim the spaces for themselves. Once they do, the metaphoric nature of fantastic literature allows them to maintain their freedom and travel through many kinds of spaces while still being connected to the home and the ones they care for. 


\section{Conclusion}

Ethics of care, domestic labor, and gendered spaces all overlap in one important space: the cultural construction of what a female adolescent is or should be. The way the society views domestic labor and care is often tied to the people performing those activities and the spaces they are performed in. The examples I have provided from Diana Wynne Jones' texts Howl's Moving Castle and House of Many Ways show that although a female adolescent protagonist may end the novel in a home, her agency has been developed through use of voice, care for others, and care for the self. Thus, the pattern laid out for female heroes by Annis Pratt is not the depressing life sentence it seems; home does not mean oppression, especially when that home travels through time, space, and opens into many worlds.

In the end, I've realized that ethics of care is a perfect term for the work I'm doing in this project: I argue that the relationships between various theoretical areas are important and that by examining how spaces are gendered in adolescent literature, I am also making connections between postcolonial theory, theories of abjection and domestic labor, and ethics of care. As Noddings explains, "since caring is a relation, an ethic built on it is naturally other-regarding. Since I am defined in relation, I do not sacrifice myself when I move toward the other as one-caring. Caring is, thus, both self-serving and otherserving" (99). The balance between binaries, the acceptance and exploration of the liminal gray spaces between either/or should be the goal, especially of female adolescents, balanced on the edge of so many binaries. The relationships between all of these theories overlaps in the literature written for adolescents and the often didactic messages for the implied reader; in some ways, the spaces females inhabit are only 
temporarily safe and they must escape them to achieve agency. However, as ethics of care argues, the notion of true independence is a myth, and the process of growing up should not necessarily be seen as a construct of traveling (sometimes literally) from dependence to independence. Obviously, this is a Westernized patriarchal vision of growth. Instead, achieving agency through relationships of caring-for and cared-for is a feminist process of growth and the way spaces have been constructed through gender binaries is fundamentally flawed; the home is not a trap. Instead, living there is a choice, one among many.

Diana Wynne Jones' novels, particularly the fantasy novels I've selected to include in this chapter, do allow for an extraordinary amount of freedom and agency for the female protagonists, particularly through the moving and bending spaces of their new homes. This kind of metaphorical freedom to travel while still living in a close circle of care is a wonderful example of the balance between caring for other and caring for themselves. However, this kind of freedom is not available to all female protagonists, especially those in realistic novels without the kind of magical power Sophie and Charmain develop access to. As Moran has argued, Anne Shirley, Judy Bolton, and many of the female characters in Elizabeth Gaskell's Cranford, are examples of realistic characters that find the balance between care for other and care for the self. I would argue that this balance is perhaps harder to achieve in realistic fiction without the magic of moving castles, but some female characters do find a circle of care including themselves and others. Harriet in Fitzhugh's Harriet the Spy has to learn to care for others as much as for herself; Staggerlee in Woodson's The House You Pass on the Way has to find a balance between protecting herself by including only her family in her circle 
of care and becoming a part of society as a way of caring for herself; and Eleanor in Rowell's Eleanor \& Park deals with the many repercussions of trying to care for her family only and finally recognizes the need to care for herself. These female characters aren't given the opportunity to have a magical voice, or turn from one kingdom to another by opening a door, but they demonstrate a similar struggle with caring for the self and others as agency. While Jones' novels may demonstrate some of the most hopeful outcome for female adolescent protagonists, other novels with realistic settings also deal with these same issues and attempt to maintain a balance on a continuum that problematizes many binaries, including entrapment and/or escape, caring for the self and/or caring for others, and powerlessness and/or agency. 


\title{
CHAPTER V
}

\section{PEDAGOGY, SPACE, AND GENDER IN THE LITERATURE CLASSROOM}

\author{
Introduction
}

In my previous chapters I have set out the theoretical framework for my overall argument: female adolescent characters in YA literature are often tied to a domestic space. I have used several different approaches to exploring theses ideas through three specific authors, including Margaret Mahy, Cynthia Voigt, and Diana Wynne Jones. My last chapter will expand my argument beyond literature to a pedagogical examination of teaching adolescent and children's literature with a focus on gender and space issues. My overall goal for this chapter, and more generally, in my pedagogy, is to connect abstract concepts like discourse, feminism, and power with concrete discussion about particular moments in the text, including classroom dialogues about the construction of spaces in the text as a reflection of any author's culture and ideologies. My contention is that issues of space are particularly productive in getting students to engage with theoretical terms and ideas. What follows is an exploration of my own pedagogy and the experience I had implementing a pedagogy of gender and space in my teaching internship in the fall of 2011 .

First, I will review the three research questions that I raised in my internship proposal; then I will explore what I learned. Overall I will argue that discussing space 
and spatial theories leads students to a better understanding of the texts themselves while also helping students make connections to other theoretical perspectives. I will demonstrate examples from this experience with student writing, especially focusing on how students' introduction to spatial issues in literature has altered, enhanced, or changed their perspectives. This chapter concludes with my assessment of my future research goals and an overview of the dissertation's overall argument.

\section{Research Questions}

During the course of my teaching, I've discovered that the same issues I respond to (both positively and negatively) in literature are often issues in my students' lives as well. Moreover, the relationship between space and gender is not just limited to literature; the way we construct both influences almost all aspects of our lives. When writing my internship proposal, I proposed to focus on how looking at space in literature would affect students. I hoped that examining spaces in connection to gender through different theoretical approaches would help my students connect to literature in a different and more concrete way, as well as allowing them to connect to literature other than that which is written for teenagers. As I set out to teach my internship, I had a huge collection of primary texts, theoretical works on gender and space, and several big questions. Here, effectively, are the three research questions that informed my project:

- How does a connection between space and gender broaden students' understanding of literature? Of literary movements or genres? Of specific texts?

- How can students best discuss and develop an understanding of the spatial and gendered elements of literary texts? 
- Does discussion/analysis of the settings and gender roles in a text help students become better at close-reading and literary analysis?

The rest of this chapter is designed to describe the answers that I found - and did not find - to these questions.

At the beginning of my syllabi I always use the quotation I cited in Chapter One from Gaston Bachelard. I read to my students from the introduction to his book The Poetics of Space, in which Bachelard argues, “...there is ground for taking the house as a tool for analysis of the human soul.... Our soul is an abode. And by remembering 'houses' and 'rooms,' we learn to 'abide' within ourselves" (xxxvi-xxxvii). That quotation provides a rich series of metaphors that students respond to well in preliminary discussions.

\section{Pedagogical Influences}

Much of the theory underlying my discussion of adolescent literature deals with discourse, subjectivity, and ideology. One problem I have found with theoretical approaches to pedagogy is that many theorists use unspecific terminology to describe their potential outcomes, often without definition or clarification as to what their specific goals mean or will do for the students. I often hear that the classroom should be a safe environment and that students should be empowered, but no one has ever explained to me what that actually means. What, exactly, does an empowered student look like? How do we even assess that students are empowered? Amy Lee's work in Composing Critical Pedagogies: Teaching Writing as Revision provides a helpful gateway into some of this jargon, and her approach to breaking down pedagogical discourse has influenced my 
approach to the classroom. Lee defines some of the nebulous jargon often used in pedagogy:

[My] experience of being trained in a process-oriented writing program and on my reading in composition studies, suggests that specific teaching practices will necessarily result in "better" writing and "better writers." Here, "better" is understood an empowered writers, confident writing with a "voice," successful academic discourse that does not necessitate the total erasure of silencing of the individual author. ... "[B]etter" is understood as capable of critically reading dominant discourses of identity and socioeconomic relations, recognizing that we are shaped by these discourses and are capable of resisting and revising them, and working toward a radical democracy. (6-7)

Lee defines a "radical democracy" as "a set of aims that will result in radical, political effects" (7). While I do not share her goal of radical democracy, I do respect her insights on how problematic some discourses about teaching can be. Lee's very precise definitions about "voice" and becoming "better" work to provide specific goals for both the students and the teachers in classrooms, which is Lee's primary influence on my own pedagogy. As I have discussed in previous chapters, I argue that the spaces in texts for adolescents are constructed to reflect gender norms, and breaking down the discourse of the author, society, and our own lives can help us understand how these norms are constructed. While Lee's text focuses on the composition classroom, many of her ideas are equally relevant in a literature classroom. Lee says that "to understand language as a discourse is to see it as a social system, informed by and determining of power, 
knowledge, and identity," which has become one of my biggest goals in the classroom (159). Since much about the relationship between space and gender is based on power structures, I hope that bringing that discussion into the students' lives will help them "separate[e] the source of discourse from the writer," as Lee writes (160). I believe that students can learn to interrogate the relationship between a discursive product and its source, although I also believe that no one exists entirely separate from the culture in which they live. Students can, however, learn to recognize the influence of ideologies in literature and to think specifically about how gender is constructed in the context of adolescent literature. Lee herself cites Foucault in her discussion of discourse and power, noting:

Foucault brings language itself into the transaction. The language a writer chooses in order to tell a story, to construct a world, does not only reflect or describe, but also plays an active role in determining, in producing and not simply reproducing, that version of the story, that world. If we shift our focus from language to discourse, we can understand that writing, the act of using discourse, is not simply a means of conveying the world as we already know it to exist within ourselves; instead, discourse itself determines the world we construct, the world we come to know. $(161)^{16}$ In other words, while it is not be possible to separate the writer from the discourse that

${ }^{16}$ According to Foucault, while language is "the concrete link between representation and reflection," discourse is the entire system of "verbal signs" within which meaning-making occurs (Order 83). 
constructs them, we can still discuss the implications of the productions and reproductions of stories and how the world around an author affects his or her writing. In my internship, and indeed in all of my classes, I have found that talking with students not just about specific language in a text but also about how the author uses the entirety of discourse to construct a fictional world helps complicate the position of literature in students' lives. The discursive depiction of physical spaces in the text usually reflects the author's culture and ideology but also helps, in turn, to shape the reader's own sense of culture and ideology. Specifically looking at the physical geographies of a text provides a foundational for more abstract ideas about discourse and power in the ways that Foucault employs the concepts. ${ }^{17}$ In my pedagogy, I invite students to examine how their identities have been constructed and manipulated through discourse. The works we are reading are products of a culture full of ideologies about the world, and the author's work is an inseparable part of that discourse. Reading children's and adolescent literature allows us to talk about how society deals with children and adolescents and a framework for thinking about ideology. My goal for the students is not just to empower them (what kind of power, I always wonder?) but instead to join Lee in "envision[ing] our classes as serving not to empower individual writers, but as forums for recognizing and analyzing when we, as writers, readers, teachers, or students, exercise power, for making power (like language) a focus of study rather than simply a commodity to be produced and/or exchanged" (165). Power as a dynamic of the discourse we use everyday is also a part of

${ }^{17}$ According to Foucault, "power is everywhere; not because it embraces everything, but because it comes from everywhere" (History 93). 
the literature we read, especially children's and adolescent literature, so by analyzing power within the classroom, students can also explore their own sense of power, their own ideologies, and their own immersion in multiple discourses.

These concepts about power and discourse also tie into some of the feminist pedagogy I have cited in my teaching philosophy and enact in the classroom. I often use bell hooks as my source for feminist pedagogy because she points out some of the limitations of the older forms of feminist pedagogy. She specifically questions ideas about women, voice, and "safety." In Talking Back: Thinking Feminist, Thinking Black, hooks writes:

Unlike the stereotypical feminist model that suggests women best come to voice in an atmosphere of safety (one in which we are going to be kind and nurturing), I encourage students to work at coming to voice in an atmosphere where they may be afraid or see themselves at risk. The goal is to enable all students, not just as assertive few, to feel empowered in a rigorous, critical discussion. (53)

Although it's now a popular construct to claim that the classroom is a safe space, my classroom is not a safe space. I don't always feel safe as a teacher, nor can I assume or guarantee that my students feel safe. My goals while teaching are to challenge the students in my classroom to think critically about the way ideologies are constructed through language and to learn to operate and challenge that discourse. This involves a great deal of risk and discussion, for both the students and me. Developing a voice (not just the act of speaking, but also of writing and communicating in different forms) is an essential goal I have set for the students in the classroom. On the first day of class we 
discuss the importance of respecting everyone, and I emphasize throughout the semester that while we may discuss controversial topics our discussion needs to remain respectful to everyone; this is, however, very different from being "safe." Teaching to Transgress, also by hooks, further develops her ideas about the classroom as a space, especially the importance of "transgressing boundaries" of all kinds (9). Especially in my internship, my pedagogy involved thinking about "recognizing subjectivity and the limits of identity [to] disrupt that objectification that is so necessary in a culture of domination" (Teaching 139). In this class I was looking to analyze the subjectivity of the female characters in the text while simultaneously acknowledging the students' subjectivity my own views as being continually at risk in the classroom. Based on my internship work, I argue that close reading and analyzing literary spaces is one way to analyze how subjectivity works in novels and to challenge students to think outside of what is safe. By using the relatively neutral concept of spaces I was able to then bring feminist concepts of agency, power, voice, and subject construction into the class discussion. Because space surrounds everyone and most students find it to be a neutral concept, those who might be inclined to reject the term feminism found concepts of space to be a "safe" way to engage with feminist ideas about agency and power. (That "safeness," of course, is only an illusion, as bell hooks implies, since no classroom can ever be safe for all students.)

Description of the Class, Assignments, and Students

In the fall of 2011 I completed my teaching internship, using two different classes to gather data and explore issues of pedagogy relating to my dissertation. I taught ENG 125, Literary Narrative, and ENG 170, Foundations in Literature for Children, both with 
a focus on space and gender. While I used "space" as a theme for my ENG 170 class, I developed my entire curriculum around space, gender, and adolescent literature for ENG 125. The quotations in this chapter, however, are drawn entirely from my ENG 125 class, since the focus in that class was entirely shaped by my dissertation topic.

The students in ENG 125, Literary Narrative, were mostly new to thinking about literature critically, and especially children's and adolescent literature (genres often associated with pop culture and dismissively regarded by neophyte students as "easy" or "simple"). By using space to discuss gender, ideology, discourse, and theories about children's and adolescent literature, I encouraged the students to complicate the effects of literature on young readers and on themselves in new ways.

The class population included twenty-four female students and six male students. Fourteen of the students were education majors of some form. The vast majority of the class included juniors who had never taken a literature class before. Of the thirty total students, thirty signed an IRB permission form; when I use their writing as evidence below, all quotations and descriptions are cited anonymously, per the consent form that the students signed.

Little pedagogical work has been done connecting the physical spaces in text to the way students think about literature. I argue that the way students relate to and respond to the spaces in the text helps them understand how subjectivity, ideology, identity formation, and discourse are formed and challenged. Thus, during my internship, early in the semester we spent time discussing the setting of the course itself, because classroom space often provides a concrete framework for learners. This proved to be one of the most useful class discussions we had, since it helped frame the way that students 
thought about physical space in a very literal way. We then transitioned into thinking about how the literary construction of houses, rooms, and other spaces can provide a physical link to thinking about the ways literature is used to socialize, manipulate, and disseminate ideologies. For example, as I will discuss below, early in the semester we discussed the relationship between space, ownership, and power in The Secret Garden. In other words, looking first at our classroom space and then at the spaces in the texts we were reading helped the students new to literary criticism begin with a visual picture. I helped my students think about space by asking them to think about it with three specific foci: how literary space connects to characters by gender, by subjectivity, and by power relationships.

All of the activities and assignments during the semester in ENG 125, Literary Narrative, were designed to explore how authors (including the students as authors) use language and how their views about gender, race, culture, childhood, and other issues are depicted within the text. Through these assignments the students experimented with developing their own voices while critically thinking about literature. These assignments included weekly response journals (in which students were invited to write an unguided and totally personal response to the class), one short paper about space and identity (which invited students to make a connection between the class and their lives), one longer traditional literary analysis paper (at least 2,000 words on a specific argument about an adolescent literature book based on the topics we discussed all semester: space, identity, and gender), various class discussions, weekly quizzes, and a final essay exam, including essay prompts that specifically ask about the relationship between space and gender in three of the texts we read over the course of the semester. Most of the 
assignments I left as open as possible to allow the students to interpret and respond to their topics in different ways.

With some inevitable exceptions, most of the class meetings were structured with five minutes at the beginning of class for announcements or a reading quiz. We would then spend about ten minutes sharing our reactions to the previous class and new reading with a partner, small group, or as a class. The bulk of the class (about thirty minutes) was spent in discussion, usually including either a short lecture, guided questions, or both. Typical discussion questions included:

- Does this character have a special space that is significant to them?

- Is that space a space of power or of limitation?

- Do you think that space is connected to the character as a child or as an adolescent?

- What gender issues do you see in the text?

- How are those gender issues connected to the spaces and the characters?

One of the biggest changes I faced in our daily schedule was allowing five minutes at the end of class for the students to write. This time could be used for any kind of writing about the class, and most of the students used the time to jot down notes for their weekly response journals.

\section{Experiences in the Classroom}

The first question I asked in my internship proposal was probably the largest in scope. Thinking about how a connection between space and gender might broaden students' understanding of literature, literary movements or genres, and of specific texts 
is a complex task. Student response journals allowed students to express their personal voices. Every week, each student had to submit at least 300 words to a Blackboard post responding to some aspect of the class. As I said in the assignment sheet distributed to the students at the beginning of the semester, "[y]ou'll notice that a big part of the purpose of this assignment is geared towards your needs and thoughts in the class; the response should be personal and unique to you." I set a deadline and a word minimum (300 words) but then left the rest of the assignment up to the students; they could write about anything to do with the class (the texts, discussion, a connection to something outside of the class, paper pre-writing, anything) as long as they were responding to the class in some way. I also assigned a paper called "A Personal Look at Space and Identity." This assignment's guidelines was fairly unstructured, but I asked the students to answer the following question:

How has a space influenced your identity? This question is open to many interpretations: a space can be a room, a tree house, a park, a closet, a house, a town, an entire country, or even an imaginary space. Your identity can be influenced from birth to today and can include a wide range of time and circumstances. In your paper, please include a description of the space. What makes that space special to you? How has that space influenced who you are today?

Between the students' journal responses and their personal essay about a space in their lives, I could perceive students' ideas about literature, gender, space, and their own lives changing during the course of the semester.

One student, who became an active discussion participant over the semester, 
wrote in her first reading response, "[a]t first this idea seemed so obscure to me, being that I had never analyzed space in any kind of literature, I assumed I would struggle with this core concept. Having finished The Secret Garden I find it to be somewhat remarkable that the concept of space in relation to this story seems almost second nature to me." I received many variations on this type of comment: the students had no idea what to think when I first mentioned we would be studying space in literature on the first day of class; many of them later wondered why they hadn't thought about it before. I started the semester with Frances Hodgson Burnett's The Secret Garden; it is longer and more old-fashioned than most of the other novels we read, but the students responded well to the gender issues in the book and connected them to the spaces. One of the key aspects of our discussion of the book was to discuss why the word "Magic" is capitalized throughout the text. We split up into groups to think about each one of the main characters and their relationship to the word "Magic." I asked the groups to go back and look at how each character-Mary, Colin, and Dickon — use the word magic, and what they thought the word means to that character. We made a list on the board and wrote down words and associations for each character's connection to the word; through this process the students discovered that Mary uses the word Magic most often in connection with her experiences in India (which we have also discussed in terms of postcolonial theory), as well as in terms of her connection to the natural world. Colin's connection to magic is through science and experimentation, which I used as an opportunity to discuss Burnett's own beliefs about Christian Science and spiritualism. Finally, we discussed Dickon's belief in Magic as the most purely tied to the natural world. This led to a discussion about what kind of space is associated with each one of these characters and 
what relationship that space has to the character's association with Magic. By this time, the students started to realize that Colin represents patriarchal attitudes in the book, attitudes specifically connected to the manor house and the scientific realm. Mary's space, the garden, connects her ideas of Magic from her experiences in India to her newfound freedom in the secret, walled garden. Finally, we discussed how Dickon is connected to the moors and the wild untamed space outside of civilization. Once the students grew comfortable with discussing the spaces associated with certain characters, I asked them about the ownership of the secret garden. Usually several students immediately responded that the garden is Mary's given to her by Mr. Craven; I point out that the garden is still owned by Mr. Craven, and it is part of the estate which will be passed down to Colin.

When the students grew uncomfortable with the implications for Mary, I asked them to discuss one more question within their groups: Who is the main character of the novel? This final question inspired much debate in the internship class, with students arguing for both Mary and Colin (no one supported Dickon being the main character, although several times I have had students say that the garden is the main character). First I let the Mary supporters defend their choice, and then asked to hear from the Colin supporters. The students had different reasoning for their ideas about who the main character of the novel is, but when I pointed out that the last words of the novel are "Master Colin" and that Mary has virtually disappeared from the narrative by the last two chapters, many of the students become uncertain or switch to believing that Colin is the main character. I have held this discussion in subsequent semesters, and it is usually the best example I can give the students of how spaces are gendered. This discussion about 
space in The Secret Garden helps students trace the evolution of power in connection to the spaces clearly through the novel and so that most of them come to understand that while Mary has a space of empowerment, she has no ownership over the space and is ultimately silenced by the Colin's narrative. Whether or not students agree with me about Mary's diminished power in the novel, through this exercise they almost invariably come to recognize that literary space is often affected by gender.

Even writing about the first novel at the beginning of the semester, the students' showed that they were beginning to grapple with their own ideologies about gender. All of the following quotations also come from that first response journal. One student wrote, "I do not like how the book switched focalizers and then at the end of the book, Mary gets shoved aside like she should not have been there in the first place." Another student clearly struggled with her own (possibly sexist) ideas about gender constructions and the spaces we discussed in class when she wrote, "[o]ne thing I thought was weird was how feminine the boys were portrayed throughout the book. Colin was very fragile and always laying in bed, and Dickon (who was suppose[d] to be more manly) was always communicating with the animals and plants." Finally, a student who became very vocal about the gender constrictions character experience wrote, “...it upsets me that Frances Hodgson Burnett would even make this strong female character, in order to just have her be not important in the end of the book. As the book progresses this female character that was so strong ends up being submissive to the male that she only tried to help. It annoys me that this book could not just remain focusing on a strong female character." In our class discussions the transfer of the narrative focus from Mary to Colin became a big point of contention, and that controversy remained a touchstone for the rest 
of the semester. When the students were faced with issues of power and gender in connection to a specific space (the garden), their reactions showed that they were willing to think critically about the book and their own ideologies.

Much of what we did and talked about during the semester went far beyond the specific texts we were reading in any week. Looking back over the reading responses for the semester, I can see that several students started connecting the class to their lives and challenging their previous assumptions. One African American student wrote in his second response, "the discussion about the feminist movement and the class system involved, got me thinking from things from the perspective of how the African American experience would have been at the time...Any Black Woman would be destined for work and the lower class.... For the black woman to gain these freedoms and rise in status, it would mean that racism, sexism, and class oppression would all need to end at the same time." When we read Sweet Whispers, Brother Rush, we addressed this topic in class but this student was clearly applying our conversations about the feminist movement to his own perspective. One of the reasons I included Sweet Whispers, Brother Rush into our class reading list is because it adds additional dimensions of race and class onto the gendered spaces we had discussed with other novels. The students by this time had grown accustomed to seeking out a specific space for each character, but I highlighted in this novel that spaces can change and that having a space of empowerment can be a privilege not available to those with little money or access to power. The student's response above emphasizes the complex interactions between race, class, and gender that appear in Virginia Hamilton's novel. Moreover, when I asked about the possibility of Tree's space being a car during discussion, several students pointed out that while a car 
implies freedom, it can also tie a character down with payments and/or a job to pay for the vehicle. That this kind of space could be an economic privilege not available to many was something we continued to discuss throughout the semester; we also discussed the way Tree describes being uncomfortable in her own skin.

Another student wrote, "[a]fter reading the three novels for this class and discussing the idea of spaces, I have been thinking more about the different spaces in all the books I have read.... The idea of spaces shows up in almost every book that I have read, I just never really noticed how important they seemed to be while I was reading them." One student wrote about his background in history classes, and made the connection "[f]rom our discussion about the different types of criticism, I know that children's literature came about from women's literature and from women writers especially. One feminist writer-Virginia Woolf, I believe—wrote A Room of One's Own which posits that female writers absolutely need their own private space apart from their husband, children, and other domestic household duties." While Virginia Woolf's work is of course pivotal to my research I had not brought it up in class. As the semester progressed I could see the students making connections with the spaces we discussed in class and transferring that from the literature we discussed in class to other literary movements, genres, and texts. While it's possible that the students were writing about space in these ways because they wanted to please me, the fact that so many of them expressed amazement indicates to me that they were engaged critically and in terms of their own lives.

This trend of being surprised by what they learned when they thought about space was also mirrored in the first paper assignment. In the assignment sheet, I asked one 
simple question: "How has a space influenced your identity?" Almost all of the students cited this first assignment in their end of semester comments. For example, one student wrote that she "found the first paper to be fun to write," another that "I had fun with that paper I was happy to show to you what my spaces are," and one simply that "I enjoyed the first paper." While these comments do not necessarily explain why the students enjoyed writing the paper, the comments indicate that they enjoyed connecting what we were talking about in class with their lives. This assignment also helped me to learn more about my students. On the due date the students shared their writing with a partner, and we discussed as a class why those spaces were so important and what they had in common. We noticed that almost everyone's space was an area for them to retreat from the world, a metaphorical fortress from causes of stress and anxiety. As I theorized in my internship proposal, the spaces in our lives are often more influential than we know.

In addition to the response journals and the first paper, one of the spaces that proved most important in terms of the class experience was our community within the classroom. Specifically thinking about the importance of discussion within a community and how I as a teacher interact with the students during the discussion was a significant part of the pedagogical framework of my internship. As Elaine Showalter suggests, I worked on preparing questions that were "open-ended, diagnostic, information-seeking, challenging, action-seeking, predictions, hypotheticals, and generalizations" (53). Because most of our classroom time was dedicated to discussion, I spent a significant amount of time preparing for them and thinking about them. Having a group of students with a wide variety of backgrounds and opinions made for some interesting and vibrant discussions; the students seemed to learn from each other as much as I did. One 
very articulate student wrote at the end of the semester:

I found that the classroom discussions about the books were the best part of the semester. Reading a story is one thing, but everyone reads a page a different way from everyone else, and having a perspective discussion was truly exciting seeing if others were thinking like mindedly or the complete polar opposite. Picking apart the book around spaces narrowed the field of focus but also broadened the perspective of the reading. I found that most of the time I didn't agree with anyone's idea of spaces in the books, but neither were they invalid or false.

This student did present differing opinions throughout the semester and seemed to enjoy pointing out when someone else (including me) was making an assumption or generalizing. The student was certainly engaged in critical thinking. Another student wrote in response to me asking for a review of the course and our topic of space and gender, "[a]nother thing I really liked about this class was all the class discussions. When I read books it is hard for me to go into a deeper meaning, and this class has forced me to go beyond that. The students in class are also so creative in their different interpretations of the books. I like the fact that the class is very student centered." Class discussions were thus a valuable part of helping students complicate concepts of space, power, and ideology. Of course, there are always experiences in the classroom that I can't prepare for. I came to recognize that my second research question was flawed in that it involved what I could do rather than what the students could do. If I could go back in time, I would change the phrasing of this question to focus on how we could best discuss and utilize the texts. This problem became clear to me about half-way through 
the semester; one day in particular sticks out in my mind, perhaps because I hadn't expected or planned for it at all. On October 3, 2011, we were in the middle of discussing Sweet Whispers, Brother Rush by Virginia Hamilton (a book for which many of the students expressed dislike, but which I've continue to teach precisely because of the discursive challenges it presents) and one student said she didn't like the book because it wasn't "realistic." This is a comment I've heard many times while teaching literature, so I stopped the class to ask everyone else what they thought. The following is excerpted from what I wrote in my teaching journal about that day:

Wow. WOW. We just had one of the most amazing conversations I've ever led in a class...I think I was especially blown away because I in no way was prepared to talk about this but it just happened. I asked for reactions to $S W, B R$ which they finished reading for class today. One student raised her hand and said that she didn't really like it because it wasn’t "realistic." I really pushed her to define what "realistic" was and why it was important to her in literature.... This led to a really long conversation about realism in children's literature and why we look for characters and stories that are "realistic" or "relatable." Most of the class participated and one of the things I really liked is that they all had different opinions and different perspectives - nobody had the right or wrong answer. We talked about whether children should read books that reflect their own lives or books that show them how someone else lives, and what effect each kind of book might have on the reader. We also talked about subjectivity and the ability to put yourself in someone else's shoes, just 
like Harriet [in Louise Fitzhugh's Harriet the Spy] does.... I asked about fantasy books and whether they were okay to read or not, and if they were "relatable"... It was such a fascinating discussion because it crossed so many lines; it concerned genres of literature, children's literature, education, subjectivity, and why people read books at all. I really liked the way we were able to discuss the "so what" of literature - what we read and why what we read plays such a part in our discussions, but we don't get to talk about that as often. Why is adolescent literature important, and what does it matter to children if they read one type of book or another?

This conversation took the entire class and changed the way we all interacted the rest of the semester.

This discussion, and the many others we had throughout the semester, illustrate the biggest change my teaching underwent as a result of my internship experience. When I set out to design the class I was thinking about my own research, and the ways that the students could use space to think about literature critically. Instead what I came to realize is that talking about space, gender, identity, and adolescent literature inevitably leads outside the classroom to our lives and the way we think about the world. Now when a student writes, "this is the first class I have taken that has really made me think about what I'm reading," I know the student has learned something about reading with critical engagement. The ability to reach beyond the texts we were reading in class to connections in their own lives was one of my favorite parts of teaching the course, and continues to be one of my favorite things to read about in the students' reading responses. One female student wrote towards the end of the semester in a reading response: 
I relate to the issues many of the protagonists have had by being held down by their prescribed gender and adjusting [to] being more of a tom boy where it is uncalled for. I still think that the ending to What Katie Did is absolutely infuriating. I think that the author used Katie's illness/injury as a metaphor for the life of an adult woman. Once Katie grew up, despite how happy or how happy she was portrayed to take on this roll [sic], that came from a forced circumstance and not of her own free choice. ...

Women have been serving the role of caretaker and provider to men and other women with no repayment for far too long. Coming from a young woman who has grown up in a small town where women stayed at home and cooked and cleaned I am now very proud to say that I live on my own in my own apartment and go to school without the need to take care of anyone but myself. What Katie had to do is admirable in the sense that she was able to put past herself and do what was best for her family and in some ways, her but it is also so tragic to see a young girl full of potential lock herself away in a house, condemned to be used. I find it infuriating that books still portray the woman as a trapped servant in the house for her man and not someone to go experience and explore the world and be just as valued as any other man would be. I really do believe the author of What Katy Did, recognized this and showed her frustration with domesticity and how crippling it is to women through putting Katie's freedom to a halt. When I made this interpretation I grew extremely fond of this book when at the time, it was not a book I hated but not one I liked 
either. Since reading it in class, I have read it a second time on my own just to feel what Katie feels and to remind myself that for a young college student, I am actually very empowered. I am overjoyed that this class has taught me how to appreciate my lifestyle and shown a new light on a whole genre of literature that I at one point would have said I did not like.

I include this quotation in full because this student in particular put into words the effect I hoped would come out of the goals I had for my internship, and indeed my teaching in general. Not only did she learn something about the importance of the ethics of care needing to include self-care, she could recognize the literary potential of those concepts. For students such as this, analyzing how space and gender issues affect the characters in the text is just the beginning of her intellectual work; for me, investigating how gender issues are constructed today, especially during adolescence, is one of the most important parts of my job in the classroom. As one male student wrote, "typically, I would turn away from any book with a female character (I blame every cheesy cookie cutter romantic novel ever published), but I found many of the female driven books to be the more entertaining." I could see that talking about space and gender changed his perception of literature (and hopefully also some of his gendered assumptions). Our discussions and writing about space, gender, agency, and many other issues lead to his ability to reevaluate his assumptions about books with female characters; just as some may devaluate a book based on a female protagonist, so too is the theory written about feminist discourses devalued.

The last research question I asked in my internship proposal asked if discussion/analysis of the settings and gender roles in a text helped students become 
better at close-reading and literary analysis. This question especially deals with the academic trajectory of a general education literature class; learning to close read and analyze literature are skills useful in almost any future. As the student quotations above have demonstrated, the students were pleased with their newfound ability to "dig deeper into books" because "it seems as though authors always have hidden plots and ideas in books and it can be harder to learn them if you don't engage yourself in a class like English 125," as one student wrote. That this student used a spatial metaphor to describe the process of critically reading books reinforces my overall argument about the usefulness of focusing on the setting in books; the more we discussed the implications of the spaces in the text, the more some of the students began to view the act of reading in dimensions. Instead of just looking at the surface, we were able to talk about what was underneath, between, on top of, and missing from the texts we were reading. But for me one of the most satisfying exchanges of the semester was with one specific student. This interaction took place entirely electronically (the student did not talk much in class), and it is another reason I am so grateful for the response journal conversations. More than halfway through the semester, the student was using her response to brainstorm some ideas for her second paper. After talking through some ideas, she asked, "[i]s it right that these topics should be in children's literature, do children automatically start making judgements [sic] after reading these things? Another question I'm considering is that adults will understand these topics when reading them, but because children are young and innocent, do they even realize what it all means?" In the comment box I responded: [a]re children really innocent? What do you really mean by innocent? Do you mean that they don't lie or steal or hurt other people? Or do you mean 
that they aren't exposed to sex/violence/drugs/bad things? WHICH child are you talking about here? What I'm really cautious about is generalizing all children as being one way or one thing; there are SO MANY children in the world in so many different circumstances it is really hard to say ANYTHING is true of all children, just like with adults.

This conversation continued over the course of several additional responses until the end of the semester. During an extra assignment in the last week of classes, this same student wrote:

I always saw children as innocent and young too. Even when we first started reading children's literature, I kept referring to them as innocent and how society sees children, but I was wrong. All children are not innocent. Every child is different and the definition of innocent can be defined in many ways. Each main child character in the books we read have done something that is not innocent.

Here this student has progressed beyond her original ideology and started to think about children (and thus our cultural constructions about childhood) in more complex and multilayered ways. I believe that she is one example that demonstrates that through close-reading and discussions about gender and space in adolescent literature, students had the opportunity to learn to recognize their own ideologies and read literature critically. One of the assumptions some students make about children's and adolescent literature is that all children/adolescents are happy, innocent, and come from safe homes. By reading and discussing many examples of protagonists dealing with difficult 
situations, feeling conflicted about the home and their family, or seeking out a new life, these assumptions are challenged and the space of the home is similarly complicated.

Focusing on Literary Space in Adolescent Literature

Below are some specific guidelines for this internship course, based on using space and gender to discuss adolescent literature. I summarize these findings in case other college-level pedagogues might find the information useful. The description of the overall course was available for students on the first page of the syllabus:

In this class we will be looking at literature through a specific theme: space. We will explore how characters in a text interact with space, especially focusing on female protagonists. We will start with Victorian ideas about space, including the angel of the house and separate spheres for men and women. Then we will move on to looking at how children's literature interacts with space, both historically and in modern texts. We will be exploring both traditional gender roles and subversions of those gender roles in texts, as well as critical reactions to those elements. Contemporary adolescent literature, as a liminal space between child and adult literature, is also well suited to investigating these issues of space and gender.

\section{Goals}

The specific goals of the course include:

- Learning to think about gender in different ways 
- Thinking about how gender constructions affect everyone in ways large and small

- Connecting our discussions to the world outside the classroom

- Learning to write clearly, expressively, and creatively

- Learning to discuss and verbally defend academic ideas

- Learning to develop critical and analytical thinking

\section{Course Design}

Novels that have been particularly effective in this type of course include:

- Elske, Cynthia Voigt

- Ender's Game, Orson Scott Card

- Harriet the Spy, Louise Fitzhugh

- Marcelo in the Real World, Francisco X. Stork

- Sweet Whispers, Brother Rush, Virginia Hamilton

- The House You Pass on the Way, Jacqueline Woodson

- The Hunger Games, Suzanne Collins

- The Parable of the Sower, Octavia Butler

- $\quad$ The Secret Garden, Frances Hodgson Burnett

- What Katy Did, Susan Coolidge

\section{Assignments}

The assignments for this course are listed below; descriptions are from the course syllabus: 
- Weekly quizzes: These quizzes will vary times and dates throughout the semester but will be administered during each week at some point. If you consistently attend class and do the reading, the quizzes should be easy; my goal is to not trip you up, but to provide incentive to do the reading and come to class. The quizzes will usually be 5 questions about the reading for the day or literary terms covered in class. As discussed in the attendance policy above, if you miss a quiz you will not be able to make it up. However, the lowest quiz grade will be dropped.

- Reading journal: The last five minutes of class will be devoted to free writing a response journal. You can use this time to collect your thoughts about the reading and theory covered during class, as well as to brainstorm other questions and ideas. Once a week, you will submit an electronic response journal to the Blackboard Dropbox. This response is meant to be an informal reaction to the material covered in the class as well as a place for you to develop your thoughts throughout the semester.

- First paper: The first paper in this class will be a chance for us to get to know each other. I will learn about your writing style and you will learn about my grading style. In this paper (3-4 pages) you will explore an important space in your life and how it influenced your identity.

- Second Paper: The second paper in this class will be a critical analysis of a work with outside research to back up a specific argument. This paper will specifically look at the use of space in an adolescent text with a focus on the interaction between space, gender, and identity. 
- Final Exam: The final exam will include objective and short identification as well as essay questions that focus on issues of space. You will need to purchase a blue book (available at the University bookstore and Alamo II). I will hand out a study guide for the final exam and we will discuss it during class.

It is my hope that other teacher-scholars who are interested in utilizing concepts of space to guide general education students into critical reading and thinking skills will find these practical details useful to their own course design.

Future Research and Conclusions

When I look back at my internship experience I am incredibly grateful for the opportunity to learn so much. Having a semester dedicated to exploring my own pedagogy in connection with my area of research was a pleasure (and hard work). I've come to several conclusions over the course of the semester, including that talking about space and gender in a literature classroom works successfully as one entrance to discussions about subjectivity and ideology. During my internship, students were learning about the complicated relationship between space and gender, just as the characters in the texts we were reading often come to terms with their own places in the world.

Reading, writing, and thinking critically about literature are skills that go beyond an academic setting; learning to think critically about spaces is one clear way to connect students' lives after graduation to what they've learned in academia. For example, the issues presented in this project have connections to students' lives outside the classroom. Race provides one example: while I argue that Mahy's novels do not consider the 
difference in privilege between the Maori people and white female adolescents, one of my students was dealing with the racial issues sometimes left out of the feminist movement. In terms of gender and ethics of care, another student left home to discover a new world of ideas and began to challenge gender stereotypes in her own life, while we learned in class about protagonists learning to take care of themselves and others.

The overall argument of my dissertation is that the way space and gender are constructed in adolescent literature reflects the way our culture has constructed adolescents, especially female adolescents. Sometimes this construction is problematic, as I argue in Chapter Two. Margaret Mahy demonstrates this when she conflates the adolescent female body with the colonized land of the Maori people in New Zealand. Herein, I have particularly chosen to use Mahy's novels to demonstrate this problematic relationship between female adolescents characters and colonization because of Mahy's conscious effort to highlight some of the colonization issues within her home country, and the country where most of her novels are set, New Zealand. However, some authors such as Cynthia Voigt, work to create methods of empowerment through the patriarchal connection between domestic spaces and women. In Chapter Three I argue that Voigt's novels often feature adolescent female protagonists who assert agency through domestic labor. Cynthia Voigt's novels, especially Dicey Tillerman's adolescent experiences and the Kingdom series, show that some adolescent female protagonists specifically seek agency and want to escape the home they view as a limited but are also able to subvert that limitation while still remaining inside the domestic realm. The traditions associated with the home and domesticity are also not always limiting, as ethics of care theorists argue that caring for others is entwined with a moral way of living and caring for the self. 
But that care has been devalued by our patriarchal society, which is the problematic element here, and so in Chapter Four I argue that adolescent female characters in Diana Wynne Jones' novels display an ethical way of caring for themselves and others. Ethics of care tries to revalue the activities that have taken place within patriarchal cultures. This way of thinking allows me to argue that the connection between women and the home does not always have to be a limitation, and instead some adolescent protagonists can learn to balance between caring for the self and caring for others. Diana Wynne Jones' novels are particularly pertinent to this chapter's argument because of the unique, fantastic spaces in the novels. It would appear that it is harder for female adolescents in realistic fiction to achieve similar agency within the home since their homes are not magically expandable. While each one of these theoretical approaches could have been applied to other books (the similarities between looking at domestic labor and ethics of care makes analyzing Voigt's novels in terms of care particularly interesting), I contend that each author's work provides examples of the argument I am illustrating. Finally, Chapter Five provides a pedagogical basis for methods of approaching space and gender in the classroom, and I argue that focusing on the spaces in the text provides a concrete method for students to approach abstract topics like discourse, ideology, and gender norms. In each chapter the theory uniting all of the disparate approaches I use is the underlying foundation of feminist geography; that just as people are culturally constructed into gendered norms, so too are spaces, and so spaces become associated with those gendered norms. While feminist geography uses data and examples from the real world, I argue that gendered spaces occur in adolescent literature and that the way adolescent characters deal with the spaces they inhabit reflects their relationship with 
power, agency, their choices for the future, and their ability to establish a circle of care which includes themselves.

I particularly focus on adolescent female protagonists because of the historical association between women, the home, and the work done in the home. Ultimately, I argue that there cannot be a binary setting up the home as only a space of limitation but that the character's decisions and ability to make choices creates a continuum of power. Whether the character has to rescue her brother from a magic spell by becoming a witch, set out on a quest to escape slavery while building a romantic relationship, or clean out a magical castle in order to take care of herself and those around her, each protagonist faces a different situation but similar challenges. Not all of these books end happily, and most do not end with either the female adolescent trapped in the home or totally free from the home; instead, these protagonists inhabit spaces full of cultural associations and seek to make the best choices they can. 


\section{REFERENCES}

Alaimo, Stacy. Undomesticated Ground: Recasting Nature as Feminist Space. Ithaca, NY: Cornell UP, 2000. Print.

Bachelard, Gaston. The Poetics of Space: The Classic Look at How We Experience Intimate Places. Boston: Beacon, 1958. Print.

Belsey, Catherine. Critical Practice. London: Routledge, 1980. Print.

Bhabha, Homi L. The Location of Culture. London: Routledge, 1994. Print.

Blackford, Holly Virginia. The Myth of Persephone in Girl's Fantasy Literature. New York: Routledge, 2012. Print.

Bradford, Clare. Unsettling Narratives: Postcolonial Readings of Children's Literature. Waterloo, Canada: Wilfrid Laurier UP, 2007. Print.

---. Unsettling Narratives: Postcolonial Readings of Children's Literature. Waterloo, Canada: Wilfrid Laurier UP, 2007. Print.

Burnett, Frances Hodgson. The Secret Garden. New York: Norton, 2006. Print.

Butler, Judith. Gender Trouble: Feminism and the Subversion of Identity. New York: Routledge, 1999. Print.

---. "Subjects of Sex/Gender/Desire." Feminist Theory: A Philosophical Anthology. Ed. Ann E. Cudd and Robin O. Andreasen. Malden, MA: Blackwell, 2005. 145-153. Print.

Clark, Dorothy G. "Edging Toward Bethlehem: Rewriting the Myth of Childhood in Voigt's Homecoming." Children's Literature Association Quarterly 25.4 (2000): 191-202. Print.

Clausen, Christopher. "Home and Away in Children's Fiction." Children's Literature 10 (1982): 141-152. Print.

Coats, Karen. Looking Glasses and Neverlands: Lacan, Desire, and Subjectivity in Children's Literature. Iowa City: U of Iowa P, 2004. Print. 
---. Message to the author. 12 June 2014. Email.

Chodorow, Nancy J. The Reproduction of Mothering. Berkeley: U of California P, 1978. Print.

de Beauvoir, Simone. The Second Sex. Trans. and ed. H. M. Parshley. New York: Knopf, 1952. Print.

DePauw, Karen P. “'Space: The Final Frontier': The Invisibility of Disability on the Landscape of Women Studies." Frontiers: A Journal of Women Studies 17.3 (1996): 19-23. Print.

Dewan, Pauline. The House as Setting, Symbol, and Structural Motif in Children's Literature. Lewiston, NY: Mellen, 2004. Print.

Fitzhugh, Louise. Harriet the Spy. New York: Yearling, 1964. Print.

Foucault, Michel. The History of Sexuality. Volume 1: An Introduction. 1976. New York: Random, 1978. Print.

---. The Order of Things: An Archaeology of Human Sciences. 1966. New York: Random House, 1970. Print.

Gavin, Adrienne E. “The Clew of Her Story: Female Myth-Making in Margaret Mahy's The Tricksters." Re-Embroidering the Robe: Faith, Myth and Literary Creation Since 1850. Ed. Suzanne Bray, Adrienne E. Gavin, and Peter Merchant. Newcastle, England: Cambridge Scholars, 2008. 48-62. Print.

---. "Apparition and Apprehension: Supernatural Mystery and Emergent Womanhood in Jane Eyre, Wuthering Heights, and Novels by Margaret Mahy." Mystery in Children's Literature: From the Rational to the Supernatural. 131-148. Basingstoke, England: Palgrave, 2001. Print.

Gilbert, Sandra M., and Susan Gubar. The Madwoman in the Attic: The Woman Writer and the Nineteenth-Century Literary Imagination, $2^{\text {nd }}$ ed. New Haven: Yale UP, 1979. Print.

Gilligan, Carol. In a Different Voice: Psychological Theory and Women's Development. Cambridge, MA: Harvard UP, 1982. Print.

Gubar, Susan. Introduction. A Room of One's Own. By Virginia Woolf. Orlando, Harvest, 1929. xxv-lxi. Print. 
Held, Virginia. The Ethics of Care: Personal, Political, and Global. Oxford: Oxford UP, 2006. Print.

hooks, bell. Talking Back: Thinking Feminism, Thinking Black. Boston: South End P, 1989. Print.

---. Teaching to Transgress: Education as the Practice of Freedom. New York: Routledge, 1994. Print.

James, Kathryn. Death, Gender and Sexuality in Contemporary Adolescent Literature. New York: Routledge, 2009. Print.

Johnson, Barbara. A World of Difference. Baltimore: Johns Hopkins UP, 1987. Print.

Johnston, Lynda and Robyn Longhurst. Space, Place, and Sex: Geographies of Sexualities. Lanham, MD: Rowman \& Littlefield, 2010. Print.

Jones, Diana Wynne. House of Many Ways. New York: HarperCollins, 2008. Print.

---. Howl's Moving Castle. New York: HarperCollins, 1986. Print.

Jong, Rosemarie. Feminine and Feminist Ethics. Belmont, CA: Wadsworth, 1993. Print.

Lawrence-Pietroni, Anna. "The Trickster, The Changeover, and the Fluidity of Adolescent Literature." Children's Literature Association Quarterly 21.1 (1996): 34-39. Print.

Lee, Amy. Composing Critical Pedagogies: Teaching Writing as Revision. Urbana, IL: NCTE, 2000. Print.

Leger, Gretchen T. "Ecofeminist Literary Criticism." Ecofeminism: Women, Culture, Nature. Ed. Karen J. Warren. Bloomington, IN: Indiana UP, 1997. 227-238. Print.

Longhurst, Robyn. Bodies: Exploring Fluid Boundaries. London: Routledge, 2001. Print.

Lovell-Smith, Rose. "On the Gothic Beach: a New Zealand Reading of House and Landscape in Margaret Mahy's The Tricksters." The Gothic in Children's Literature: Haunting the Borders. Eds. Anna Jackson, Karen Coats, and Roderick McGillis. New York: Routledge, 2008. 93-115. Print.

Mahy, Margaret. The Catalogue of the Universe. New York: Simon, 1985. Print. 
---. The Changeover. London: Collins, 1984. Print.

---. Kaitangata Twitch. Crows Nest, Australia: Allen \& Unwin, 2005. Print.

---. Memory. London: HarperCollins, 1987. Print.

---. "On Building Houses That Face Towards the Sun." A Track to Unknown Water. Ed. Stella Lees. Metuchen, NJ: Scarecrow, 1987. 104-118. Print.

---. The Other Side of Silence. London: Puffin, 1995. Print.

---. The Tricksters. New York: Aladdin, 1986. Print.

Massey, Doreen. For Space. Los Angeles: Sage, 2005. Print.

---. Space, Place, and Gender. Minneapolis: U of Minnesota P, 1994. Print.

McCallum, Robyn. Ideologies of Identity in Adolescent Fiction: The Dialogic Construction of Subjectivity. New York: Garland, 1999. Print.

McDowell, Linda. Gender, Identity and Place: Understanding Feminist Geographies. Minneapolis: U of Minnesota P, 1999. Print.

Meldrum, Tim. Domestic Service and Gender: 1660-1750. Harlow, U.K.: Pearson, 2000. Print.

Mohanty, Chandra Talpade. Introduction. Third World Women and the Politics of Feminism. Ed. Mohanty, Ann Russo, and Lourdes Torres. Bloomington, IN: Indiana UP, 1991. 1-47. Print.

Moran, Mary Jeanette. “'I'll Never Be Angelically Good': Feminist Narrative Ethics in Anne of Green Gables." Anne's World: A New Century of Anne of Green Gables. Eds. Irene Gammel and Benjamin Lefebvre. Toronto: U of Toronto P, 2010. Print.

---. "Use Your Head, Judy Girl': Relationships, Writing, and an Ethic of Care in the Judy Bolton Mysteries." Clues: A Journal of Detection 27.1 (2009): 22-32. Print.

---. "A Word or Two Here About Myself: Narrating Subjectivity and Feminist Ethics in Cranford." The Gaskell Society Journal 22 (2008): 10-21. Print.

Nikolajeva, Maria. From Mythic to Linear: Time in Children's Literature. Lanham, MD: Scarecrow, 2000. Print. 
---. Power, Voice and Subjectivity in Literature for Young Readers. New York: Routledge, 2010. Print.

Noddings, Nel. Caring: A Feminine Approach to Ethics and Moral Education. 2nd ed. Berkeley: U of California P, 1984. Print.

Nodelman, Perry, and Mavis Reimer. The Pleasures of Children's Literature, $3^{\text {rd }}$ ed. Boston: Allyn, 2003. Print.

Nodelman, Perry. "The Other: Orientalism, Colonialism, and Children's Literature." Children's Literature Association Quarterly 17.1 (1992): 29-35. Print.

---. The Hidden Adult: Defining Children's Literature. Baltimore: Johns Hopkins UP, 2008. Print.

Palmer, Phyllis. Domesticity and Dirt: Housewives and Domestic Servants in the United States, 1920-1945. Philadelphia: Temple UP, 1989. Print.

Paul, Lissa. "Enigma Variations: What Feminist Theory Knows About Children's Literature.” Signal 54 (1987): 186-202. Print.

---. Reading Otherways. Stroud, U.K.: Thimble, 1998. Print.

Pratt, Annis. Archetypal Patterns in Women's Fiction. Bloomington: Indiana UP, 1981. Print.

Reid, Suzanne Elizabeth. Presenting Cynthia Voigt. New York: Twayne, 1995. Print.

Rose, Jacqueline. The Case of Peter Pan: or the Impossibility of Children's Fiction. London: Macmillian, 1984. Print.

Rowell, Rainbow. Eleanor \& Park. New York: St. Martin's Griffin, 2013. Print.

Rudd, David. "Building Castles in the Air: (De)Construction in Howl's Moving Castle." Journal of the Fantastic in the Arts 21.2 (2010): 257-270. Print.

Ruddick, Sara. Maternal Thinking: Toward a Politics of Peace. Boston: Beacon P, 1989. Print.

Scutter, Heather. "Choose Your Own Agenda: Margaret Mahy's Memory." Children's Literature Association Quarterly 20.1 (1995): 9-14. Print.

Showalter, Elaine. Teaching Literature. Malden, MA: Blackwell, 2003. Print.

Slote, Michael. The Ethics of Care and Empathy. London: Routledge, 2007. Print. 
Spain, Daphne. Gendered Spaces. Chapel Hill, NC: U of North Carolina P, 1992. Print.

Spivak, Gayatri Chakravorty. "Can the Subaltern Speak?” The Post-Colonial Studies Reader. Ed. Bill Ashcroft, Gareth Griffiths, and Helen Tiffin. London: Routledge, 1995. 28-37. Print.

Stephens, John. Language and Ideology in Children's Fiction. New York: Longman, 1992. Print.

Tong, Rosemarie. Feminine and Feminist Ethics. Belmont, CA: Wadsworth, 1993. Print.

Trites, Roberta Seelinger. Disturbing the Universe: Power and Repression in Adolescent Literature. Iowa City: U of Iowa P, 2000. Print.

---. Waking Sleeping Beauty: Feminist Voices in Children's Novels. Iowa City: U of Iowa P, 1997. Print.

Tronto, Joan C. Moral Boundaries: A Political Argument for an Ethic of Care. New York: Routledge, 1993. Print.

Tuan, Yi-Fu. Space and Place: The Perspective of Experience. Minneapolis: U of Minnesota P, 1977. Print.

Voigt, Cynthia. Dicey’s Song. New York: Fawcett Juniper, 1982. Print.

---. Elske. New York: Simon, 1999. Print.

---. Homecoming. New York: Simon, 1981. Print.

---. Jackaroo. New York: Simon, 1985. Print.

---. On Fortune's Wheel. New York: Simon, 1990. Print.

---. The Wings of a Falcon. New York: Scholastic, 1993. Print.

Walker, Michelle Boulous. Philosophy and the Maternal Body: Reading Silence. London: Routledge, 1998. Print.

Waller, Alison. Constructing Adolescence in Fantastic Realism. New York: Routledge, 2011. Print.

---. “'Solid All the Way Through': Margaret Mahy's Ordinary Witches." Children's Literature in Education 35.1 (2004): 77-86. Print. 
Warren, Karen J. Introduction. Ecofeminism: Women, Culture, Nature. Ed. Warren. Bloomington, IN: Indiana UP, 1997. xi-xvi. Print.

Watson, Victor. “The Tillerman Series.” Coming of Age in Children's Literature. By Margaret Meek and Watson. London: Continuum, 2002. 85-124. Print.

Wilcox, Carolynn E. "Everyday Magic: Howl's Moving Castle and Fantasy as Sociopolitical Commentary." Welsh Mythology and Folklore in Popular Culture: Essays on Adaptations in Literature, Film, Television and Digital Media. Eds. Audrey L. Becker and Kristin Noone. Jefferson, NC: McFarland, 2011. 160-170. Print.

Wilkie-Stibbs, Christine. “'Body Language': Speaking the féminine in Young Adult Fiction." Children's Literature Association Quarterly 25.2 (2000): 76-87. Print.

Winters, Sarah Fiona. "Aliens in the Landscape: Maori Space and European Time in Margaret Mahy's Fiction." Children's Literature Association Quarterly 33.4 (2008): 408-25. Print.

Woodson, Jacqueline. The House You Pass on the Way. New York: Puffin, 1997. Print. Woolf, Virginia. A Room of One's Own. Orlando: Harvest, 1929. Print. 